Aus dem Institut für Pathologie

(Univ. Prof. Dr. med. P. Ströbel)

der Medizinischen Fakultät der Universität Göttingen

\title{
FGFR-Alterationen in primären und oligometastasierten kolorektalen Karzinomen
}

\author{
INAUGURAL-DISSERTATION \\ zur Erlangung des Doktorgrades \\ der Medizinischen Fakultät der \\ Georg-August-Universität zu Göttingen
}

vorgelegt von

Julia Elisabeth Fromme

aus

Köln 
Dekan:

Referent/in:

Ko-Referent/in:
Prof. Dr. rer. nat. H. K. Kroemer

Prof. Dr. med. H.-U. Schildhaus

Prof. Dr. med. A. Bleckmann

Datum der mündlichen Prüfung: 17.11.2020 
Hiermit erkläre ich, die Dissertation mit dem Titel "FGFRAlterationen in primären und oligometastasierten kolorektalen Karzinomen" eigenständig angefertigt und keine anderen als die von mir angegebenen Quellen und Hilfsmittel verwendet zu haben.

Göttingen, den 17.11.2020

(Unterschrift) 


\section{Inhaltsverzeichnis}

Abbildungsverzeichnis ..................................................................................... III

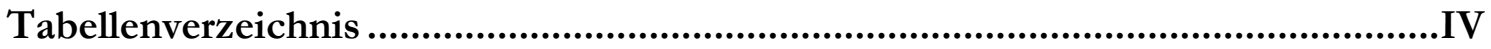

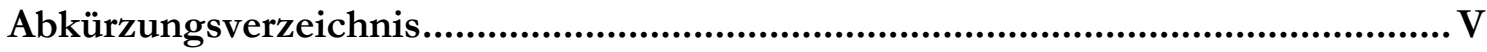

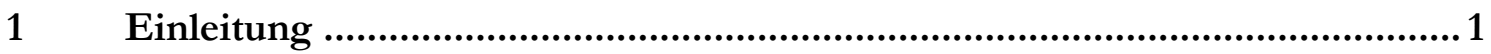

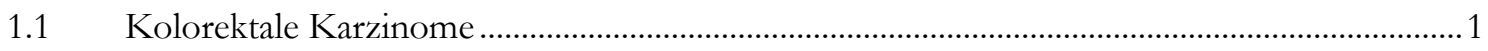

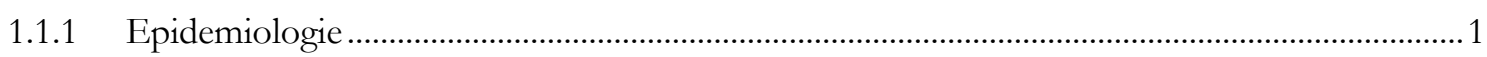

1.1.2 Therapie des kolorektalen Karzinoms - aktuell und in Zukunft..............................................

1.1.3 Therapieoptionen beim oligometastasierten kolorektalen Karzinom.......................................... 2

1.2 Fibroblast growth factor-Rezeptoren (FGFR) und - Liganden..................................................... 4

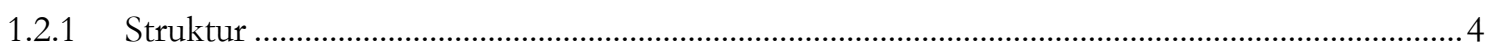

1.2.2 Physiologie des FGF-/FGFR-Signalwegs .........................................................................

1.2.3 FGF-FGFR-Signalweg in malignen Tumoren...................................................................

1.2.4 FGFR-Tyrosinkinase-Inhibitoren in der Krebstherapie ............................................................

1.2.5 Prädiktive Biomarker für eine anti-FGFR-Therapie..................................................................

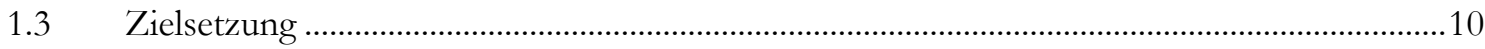

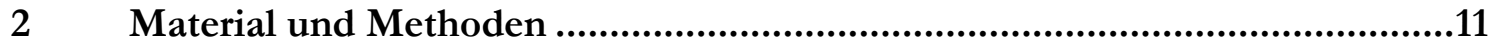

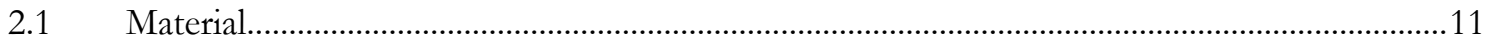

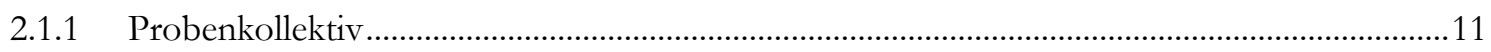

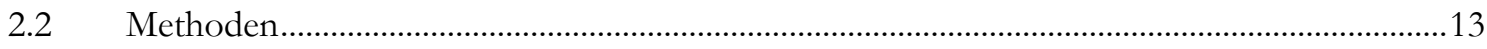

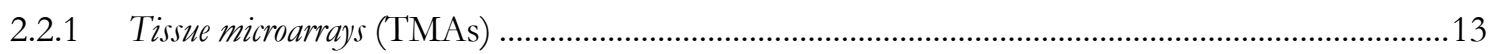

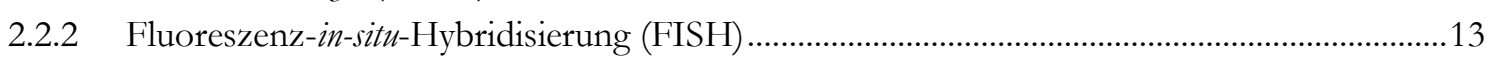

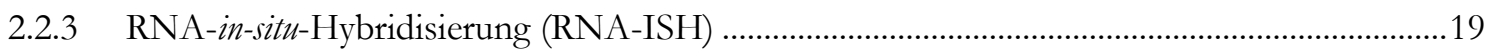

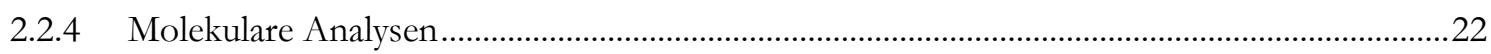

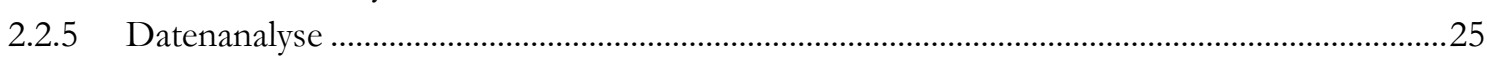

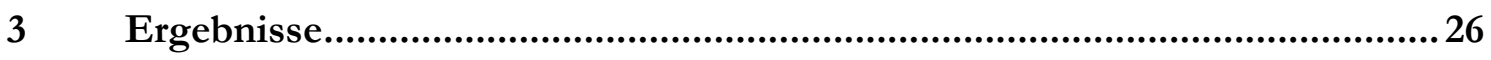

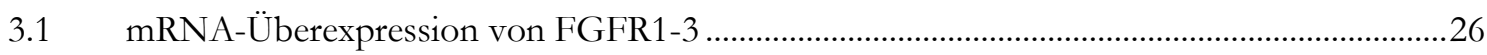

3.2 Genamplifikation von FGF-Rezeptoren und -Liganden ............................................................

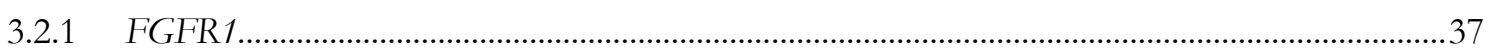

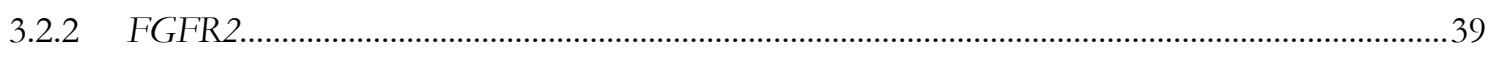

3.2.3 FGFR3

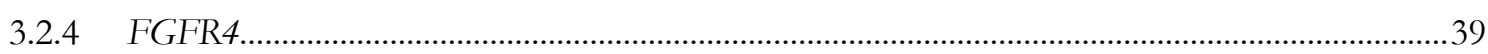

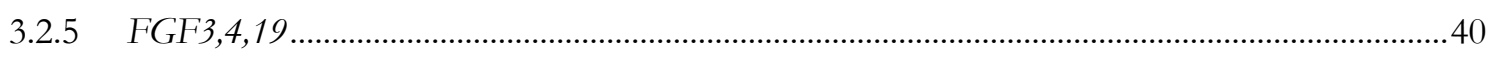

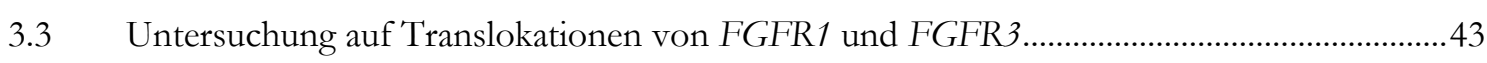

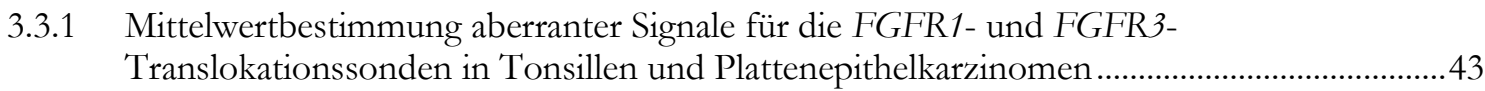

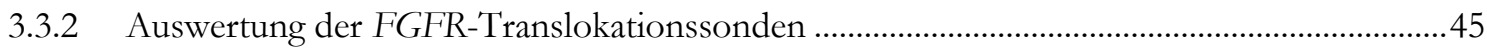

3.4 Zusammenschau der verschiedenen FGFR-Signalweg-Alterationen ........................................48

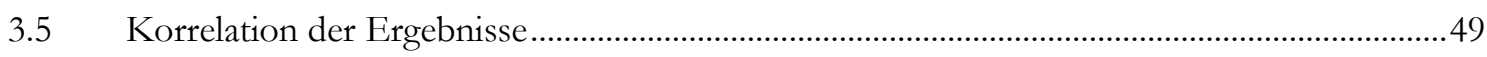


3.5.1 Korrelation von FGF(R)-Genamplifikation und mRNA-Überexpression mit klinischpathologischen Daten.

3.5.2 Korrelation von FGFR-Genamplifikation und mRNA-Überexpression mit molekularen Subtypen ......

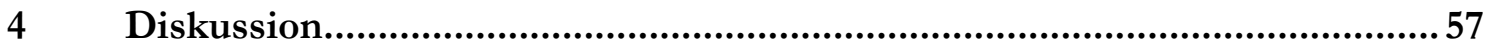

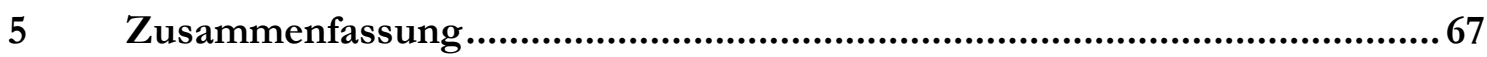

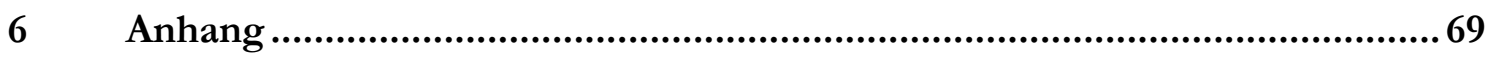

6.1 Auswahl aktueller klinischer Studien zu FGFR-Inhibitoren ..................................................69

6.1.1 Nicht-selektive FGFR-Inhibitoren (ClinicalTrials.gov) ………………………………...........69

6.1.2 Selektive FGFR-Inhibitoren (ClinicalTrials.gov) ……………....................................................69

6.2 Ergebnisse ausgewählter klinischer Studien zu FGFR-Inhibitoren ............................................72

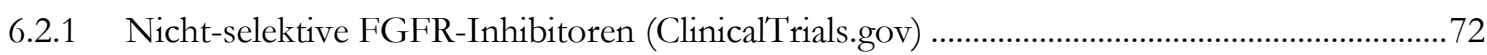

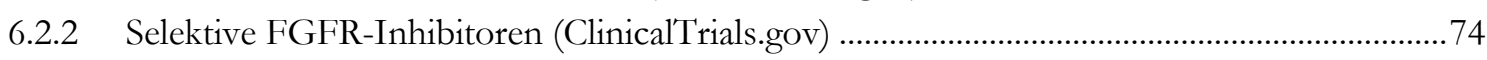

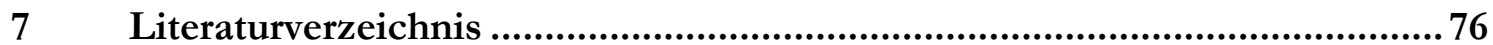




\section{Abbildungsverzeichnis}

Abbildung 1: FGF-Rezeptor

Abbildung 2: RNAScope-Verfahren, modifiziert nach Wang et al. (2012)

Abbildung 3: RNA-Überexpression in Primärtumoren und Lebermetastasen ........................28

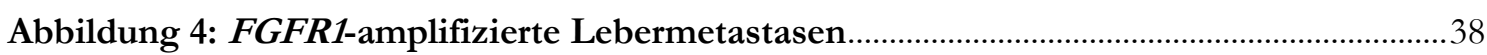

Abbildung 5: FGF3,4,19-Amplifikation in den Primärtumoren................................................40

Abbildung 6: FGFR1-break apart-Sonde, Fälle mit vermehrt extra 5'-Signalen .....................46

Abbildung 7: Fluoreszenz-in-situ-Hybridisierung mit FGFR3-Translokationssonde...........48

Abbildung 8: Alterationen von FGF-Rezeptoren und -Liganden in Primärtumoren .............49

Abbildung 9: Prognostische Relevanz einer FGFR3-Überexpression .....................................50

Abbildung 10: Prognostische Relevanz einer FGFR1-Amplifikation ........................................50 


\section{Tabellenverzeichnis}

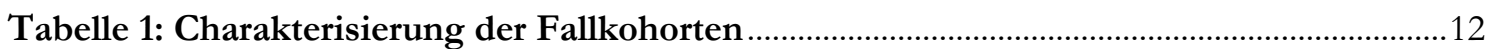

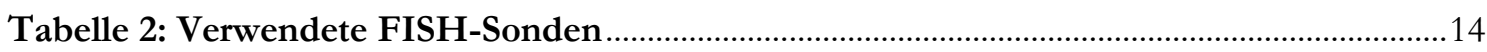

Tabelle 3: Charakterisierung der Amplifikationssonden..............................................................15

Tabelle 4: Charakterisierung der Translokationssonden ……………………..............................

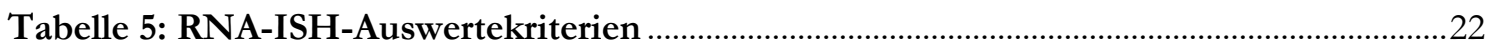

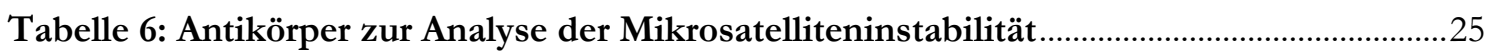

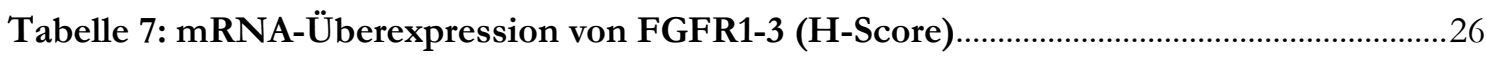

Tabelle 8: Fälle mit FGFR-Überexpression und Korrelation zur FISH .....................................29

Tabelle 9: mRNA-Überexpression von FGFR1-3 (prädominanter Score) ....................................36

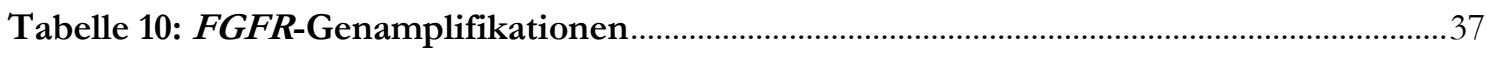

Tabelle 11: FGFR-Amplifikation in Primarien und Lebermetastasen.......................................... 41

Tabelle 12: Mittelwertbestimmung FGFR1- und FGFR3-Translokationssonde .......................44

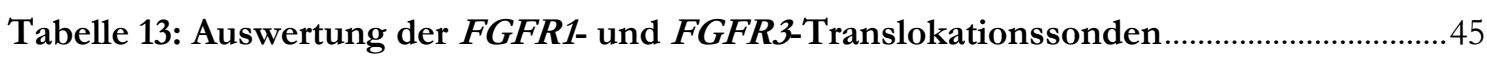

Tabelle 14: Hybridisierung mit der Quadruple-Sonde bezüglich FGFR3 ..................................47

Tabelle 15: Prognoserelevanz einer FGFR-Amplifikation/FGFR-Überexpression...................52

Tabelle 16: Patienten mit multiplen synchronen oder metachronen Metastasen.......................54 


\section{Abkürzungsverzeichnis}

\begin{tabular}{|c|c|}
\hline (B)-RAF & rapidly accelerated fibrosarcoma \\
\hline DAPI & 4',6-Diamidin-2-phenylindol \\
\hline DNA & Desoxyribonukleinsäure \\
\hline EGFR & epidermal growth factor receptor \\
\hline et al. & et alii. \\
\hline FFPE & formalin fixed and paraffin embedded \\
\hline FGF & fibroblast growth factor \\
\hline FGFR & fibroblast growth factor receptor \\
\hline FISH & Fluoreszenz-in-situ-Hybridisierung \\
\hline $\mathrm{HCl}$ & Hydrogenchlorid gelöst (Salzsäure) \\
\hline $\mathrm{HE}$ & Hämatoxylin-Eosin \\
\hline HER2 & buman epidermal growth factor receptor 2 \\
\hline HNSCC & bead and neck squamous cell carcinoma \\
\hline HPSGs & Heparansulfatproteoglykane \\
\hline (c)-KIT & (c)-kitten \\
\hline KRAS & kirsten rat sarcoma \\
\hline KRK & kolorektales Karzinom \\
\hline MAPK & mitogen-activated protein kinase \\
\hline MET & mesenchymal-epithelial transition factor \\
\hline mRNA & messenger ribonucleic acid \\
\hline MSI & Mikrosatelliteninstabilität \\
\hline N-RAS & neuroblastoma rat sarcoma \\
\hline NW & Nebenwirkung \\
\hline PDGFR & platelet-derived growth factor receptor \\
\hline PFS & progression-free survival \\
\hline PIK3CA & $\begin{array}{l}\text { Phosphatidylinositol-4,5-Bisphosphat-3-Kinase katalytische Untereinheit } \\
\text { Alpha }\end{array}$ \\
\hline RAS & rat sarcoma \\
\hline RECIST & response evaluation criteria in solid tumours \\
\hline RNA ISH & RNA-in-situ-Hybridisierung \\
\hline SqCLC & squamous cell lung cancer \\
\hline SqNSCLC & squamous non small cell lung cancer \\
\hline SSC & standard sodium citrate \\
\hline TMAs & tissue microarrays \\
\hline TKI & Tyrosinkinase-Inhibitoren \\
\hline UICC & Union internationale contre le cancer \\
\hline VEGF & vascular endothelial growth factor \\
\hline
\end{tabular}




\section{Einleitung}

\subsection{Kolorektale Karzinome}

\subsubsection{Epidemiologie}

Das kolorektale Karzinom (KRK) zählt zu den häufigsten Krebserkrankungen weltweit, in den USA ist es die vierthäufigste Krebsentität hinter Mamma-, Bronchial- und Prostatakarzinomen und die zweithäufigste krebsbedingte Todesursache (SEER). Die Surveillance, Epidemiology and End Results DataBase (SEER) geht von einer Inzidenz des kolorektalen Karzinoms von 140.250 Personen im Jahr 2018 aus, wobei die Mortalität auf 50.630 Individuen geschätzt wird (SEER). Für Deutschland registrierte das Robert Koch-Institut im Jahre 2014 rund 33.120 Neuerkrankungen bei Männern und rund 27.890 bei Frauen. Insgesamt verstarben 11.932 Frauen und 13.580 Männer 2014 in Deutschland an Darmkrebs (Krebsdaten 2018a; Robert Koch-Institut 2018a).

\subsubsection{Therapie des kolorektalen Karzinoms - aktuell und in Zukunft}

Die aktuelle leitliniengerechte Therapie des kolorektalen Karzinoms umfasst mehrere Säulen, darunter die operative Therapie, die systemische Chemotherapie, verschiedene lokale Interventionsverfahren zur Behandlung von Fernmetastasen sowie molekulare Therapieansätze mit monoklonalen Antikörpern (epidermal growth factor receptor (EGFR)-Antikörper, vascular endothelial growth factor (VEGF)-Antikörper) und Immuncheckpoint-Inhibitoren bei mikrosatelliteninstabilen kolorektalen Karzinomen (Leitlinienprogramm-Onkologie 2017). Initial nimmt die chirurgische Resektion den höchsten Stellenwert ein. Bei primär nicht gegebener Resektabilität wird insbesondere beim Rektumkarzinom eine neoadjuvante Therapie aus Radio- und Chemotherapie durchgeführt. Im metastasierten Stadium erfolgt eine molekulare Subtypisierung des KRK, um die molekularen Therapieoptionen zielgerichtet einsetzen zu können. Bislang beschränken sich die molekularen Analysen in der Klinik routinemäßig auf Mutationen in den Genen KRAS (rat sarcoma)/NRAS und BRAF (rapidly accelerated fibrosarcoma) sowie auf die Analyse der Mikrosatelliteninstabilität (MSI) (Van Cutsem et al. 2016). Bei einer vorliegenden $\mathrm{R} A S$-Mutation ist eine EGFR-Antikörpertherapie unwirksam (Amado et al. 2008; Karapetis et al. 2008; Lievre et al. 2006).

Bezüglich der personalisierten Therapieoptionen haben sich für die Therapie des kolorektalen Karzinoms seit der Etablierung von EGFR- und VEGF-Antikörpern in den letzten Jahren 
wenige Neuerungen ergeben. Hingegen ist vor allem die in vielen Fällen zu beobachtende Resistenzentwicklung (de-novo-Resistenz) gegenüber einer EGFR-Antikörpertherapie Gegenstand intensiver Forschung. In diesem Zusammenhang scheinen Mutationen in den Genen $K R A S$, NRAS, BRAF sowie Amplifikationen von MET (mesenchymal-epithelial transition factor) und HER2 (buman epidermal growth factor receptor 2) von Bedeutung zu sein (Bertotti et al. 2011; Kavuri et al. 2015; Misale et al. 2014). Auch eine PIK3CA (phosphatidylinositol-4,5-bisphosphate 3kinase catalytic subunit alpha)-Exon-20-Mutation könnte möglicherweise für eine EGFRResistenzentwicklung verantwortlich sein (Karapetis et al. 2014; Tian et al. 2013). Ferner könnten aktivierende HER2-Mutationen sowie HER2-Amplifikationen neben ihrer Bedeutung für die Resistenzentwicklung (Bertotti et al. 2011; Kavuri et al. 2015) auch einen therapeutischen Ansatzpunkt darstellen. In einer Phase-II-Studie zeigte sich ein Ansprechen der HER2-aberranten Tumoren unter Inhibition des Rezeptors (Sartore-Bianchi et al. 2016). Zur Integration dieser Beobachtungen in den klinischen Alltag bedarf es weiterer Studien, um die personalisierten Therapieoptionen weiter zu verbessern.

\subsubsection{Therapieoptionen beim oligometastasierten kolorektalen Karzinom}

Kolorektale Karzinome, die in einem frühen und lokal begrenzten Stadium diagnostiziert werden, sind durch eine operative Therapie des Primärtumors gut zu behandeln und haben exzellente Heilungschancen. Mit zunehmender Tumorausdehnung und Infiltration der umgebenden Strukturen verschlechtert sich die Prognose hingegen kontinuierlich. Daher sollte die relative 5-Jahres-Überlebensrate nicht für die Entität des kolorektalen Karzinoms als solches, sondern für die verschiedenen Tumorstadien getrennt betrachtet werden. Für die USA wurden diese Daten vom National Cancer Institute (NCI) in der SEER Database veröffentlicht. Entscheidend sind in diesem Zusammenhang die relativen Überlebens-/Sterberaten. Im Vergleich zu absoluten Überlebens-/Sterberaten gehen in die relativen Raten nur die Patienten ein, welche allein bedingt durch die Krebserkrankung verstorben sind (Krebsdaten 2018b; Robert KochInstitut 2018b). Rund 39\% der kolorektalen Karzinome werden im lokal begrenzten Stadium (Ia-II nach UICC (Union internationale contre le cancer)-Klassifikation) diagnostiziert und die relative 5-Jahres-Überlebensrate liegt bei 89,8\%. Bei einer bestehenden Lymphknotenmetastasierung (Stadium III nach UICC) erreicht die relative 5-Jahres-Überlebensrate bei leitliniengerechter Therapie immer noch 71,1\%. Das entscheidende Ereignis hingegen, welches die Prognose der Patienten gravierend verschlechtert, ist die hämatogene Fernmetastasierung (Stadium IV nach UICC). In diesem Stadium fällt die relative 5-Jahres-Überlebensrate auf 13,8\% (SEER). Einige Patienten weisen im Stadium IV bereits eine multiple Fernmetastasierung in mehrere Organe auf, bei anderen besteht eine oligometastatische Erkrankung. Mit dem Begriff 
„oligometastatisch“ werden im Lexikon des National Cancer Institutes Tumoren dann bezeichnet, wenn sie eine geringe Anzahl von metastatischen Absiedlungen in einem oder zwei anderen Organen aufweisen (Cancer.gov). Die European Society for Medical Oncology (ESMO)Konsensus-Leitlinie definiert den Begriff wenig präzise und spricht von einer begrenzten Anzahl von Metastasen (bis zu fünf, selten mehr) in meist bis zu zwei Organen (Van Cutsem et al. 2016).

Für diese Arbeit sollen nun die Patienten mit oligometastatischem kolorektalen Karzinom und Metastasenlokalisation in der Leber betrachtet werden, welches eine häufige klinische Konstellation darstellt. Zur Planung einer multimodalen Therapie werden die Patienten zunächst anhand ihres Allgemeinzustandes und ihres dementsprechenden Eignungsgrades für eine Chemotherapie in drei Gruppen aufgeteilt: Patienten, welche für eine intensive Chemotherapie geeignet erscheinen; Patienten, die für eine moderate Chemotherapie in Frage kommen; Patienten, denen keine Chemotherapie zugemutet werden kann (Leitlinienprogramm-Onkologie 2017). Bei einer bestehenden Oligometastasierung kommt der Metastasenchirurgie eine tragende Rolle zu. Ob zusätzlich zur Metastasenresektion eine neoadjuvante Chemotherapie erfolgen sollte, hängt nicht nur davon ab, ob die Metastasen primär operabel sind, sondern auch von prognostisch relevanten Faktoren des einzelnen Patienten. Letztere umfassen klinische Parameter wie sie im FONG-Score zusammengefasst werden (bestehende Lymphknoteninfiltration des Primärtumors, Zeitspanne zwischen Primärtumor und Manifestation der Metastasen $<1$ Jahr, Tumoranzahl $>1$, präoperativer CEA (Carcinoembryonales Antigen)-Wert $>200$ ng/ml, größter Tumor $>5 \mathrm{~cm}$ messend) sowie eine bestehende extrahepatische Manifestation (Fong et al. 1999; Van Cutsem et al. 2016). Die synchrone Metastasierung ist mit einem ungünstigeren Verlauf und einer schlechteren Prognose assoziiert als die metachrone Metastasierung (Mekenkamp et al. 2010; van der Pool et al. 2010). Bei Vorliegen von zwar primär resektablen Metastasen, jedoch prognostisch ungünstigen Kriterien empfiehlt die Leitlinie zunächst eine systemische Therapie zum Erreichen einer Stabilisierung der Erkrankung. Innerhalb der nächsten Monate sollte dann in einem zweiten Schritt die Resektion erfolgen (Van Loon und Venook 2014). Bei primär resektablen Metastasen und prognostisch günstigen Kriterien soll die primäre Resektion der Metastasen durchgeführt werden (Leitlinienprogramm-Onkologie 2017). Ob eine adjuvante Chemotherapie nach Metastasenresektion sinnvoll ist, bleibt bislang unklar (Leitlinienprogramm-Onkologie 2017). Sollte eine Reduktion der Tumorlast nicht in hinreichendem Maße durch die Metastasenchirurgie erzielt werden können, stehen weitere lokale Interventionsverfahren zur Verfügung, wie z. B. die Radiofrequenzablation, die Brachytherapie, die intraarterielle Chemotherapie der Leber oder die hypertherme Chemotherapie. 
Die Auswahl des Chemotherapieregimes orientiert sich an der molekularen Subtypisierung des Tumors sowie am Allgemeinzustand des Patienten.

Trotz der aufgeführten multimodalen Therapie haben viele Patienten mit oligometastasiertem kolorektalen Karzinom immer noch ein sehr schlechtes klinisches Outcome. Patienten mit wenigen Metastasen, die auf die Leber und eventuell zusätzlich auf die Lunge beschränkt sind, erreichen bei mikroskopischer R0-Resektion der Metastasen ein Langzeitüberleben in 20-50\% der Fälle (Weiser et al. 2013). Die Lungenbeteiligung scheint insgesamt mit einer besseren Prognose einherzugehen als die Lebermetastasierung. Das mediane Gesamtüberleben von Patienten, welche einzig Lungenmetastasen aufwiesen, betrug 41,1 Monate im Vergleich zu 22,8 Monaten bei den Patienten mit auf die Leber beschränkten Metastasen (Khattak et al. 2012). In retrospektiven Studien konnten Giacchetti et al. bei Patienten, welche eine neoadjuvante Chemotherapie und sekundäre Metastasenresektion erhielten, ein 5-Jahres-Überleben in knapp 50\% der Fälle zeigen (Giacchetti et al. 1999). Somit verbleiben rund 50\% der Patienten, welche in den auf die Metastasenchirurgie folgenden Jahren multiple Organmetastasen entwickeln (Kanas et al. 2012). Van Cutsem et al. berichten sogar von einer Rezidivrate von bis zu 75\% (Van Cutsem et al. 2014). Dem gegenüber steht eine Gruppe von Patienten, bei denen unter adäquater Therapie ein längerfristiges Überleben und manchmal sogar eine Heilung möglich sind. Bislang ist unklar, welche Faktoren dazu führen, dass das klinische Outcome der Patienten mit oligometastasiertem KRK so heterogen ist und prognostische Marker fehlen weitgehend. Für die Gruppe von Patienten, die unter einem sehr raschen Tumorprogress leiden, sind neue effektive Therapieoptionen dringend erforderlich. Hier bedarf es der Identifizierung von prädiktiven Biomarkern und molekularen Targets, welche die Patienten mit einer ungünstigen Prognose identifizieren und einen potentiellen therapeutischen Ansatzpunkt darstellen können.

\subsection{Fibroblast growth factor-Rezeptoren (FGFR) und - Liganden}

\subsubsection{Struktur}

Die fibroblast growth factor-Rezeptoren (FGFRs) werden auf der Oberfläche vieler verschiedener Zellen exprimiert und steuern zentrale Vorgänge in der Embryonalentwicklung sowie bei der Zellproliferation, Differenzierung und Angiogenese im erwachsenen Organismus (Turner und Grose 2010). Zur FGFR-Familie gehören vier Rezeptortyrosinkinasen (FGFR1-4), welche aus einer extrazellulären Bindungsdomäne, die drei Bindungsstellen für Immunglobuline enthält (Ig I, Ig II und Ig III), einer transmembranären Helix sowie einer in das Zytoplasma ragenden Tyrosinkinase aufgebaut sind. Ig II und Ig III bilden zusammen die Bindungsstelle für den 
FGFR-Liganden (Turner und Grose 2010). Insgesamt gibt es 18 fibroblast growth factors (FGFs): FGF1-FGF10 und FGF16-FGF23. Dies sind Glykoproteine, welche die FGFRs spezifisch aktivieren. FGF11-FGF14 werden hier nicht mit eingeschlossen. Obwohl sie den FGFs strukturell sehr ähnlich sind, sind sie nicht in der Lage, FGFRs zu aktivieren. FGF15 hat keine Bedeutung im menschlichen Organismus, sondern stellt das Korrelat zu FGF19 in der Maus dar (Beenken und Mohammadi 2009). Funktionell können die FGFs in zwei Gruppen unterteilt werden, wovon die eine Gruppe, welcher der Großteil der FGFs angehört, eine parakrine Stimulation auf die Zielzellen ausübt und die zweite Gruppe, bestehend aus FGF19, FGF21 und FGF23, als Hormone eine endokrine Wirkung entfaltet (Beenken und Mohammadi 2009). Letztere benötigen im Rahmen der endokrinen Stimulierung bestimmte Klotho-Proteine als Co-Faktoren, die die Interaktion von Ligand und Rezeptor erleichtern (Grose und Dickson 2005; Kurosu et al. 2006).

\subsubsection{Physiologie des FGF-/FGFR-Signalwegs}

Um die FGFRs zu aktivieren, binden FGFs an Ketten aus Heparansulfatproteoglykanen (HPSGs) auf der Zelloberfläche (Ori et al. 2008). Die HPSGs stabilisieren hierbei die Bindung zwischen Ligand und Rezeptor und schützen die FGFs vor Denaturierung (Mohammadi et al. 2005; Ornitz und Itoh 2001). Eine spezifische Liganden-Rezeptor-Bindung wird durch verschiedene Mechanismen ermöglicht: Alternatives Spleißen der FGFR-mRNA sorgt für eine gewebsspezifische Expression der FGFRs (Orr-Urtreger et al. 1993); eine Liganden-RezeptorSpezifität wird durch Unterschiede in der Basensequenz der verschiedenen FGFs und FGFRs erreicht (Beenken und Mohammadi 2009; Mohammadi et al. 2005; Zhang et al. 2006).

Nach Dimerisierung des Rezeptors und Autophosphorylierung der zytoplasmatischen Domäne interagiert die FGFR-Tyrosinkinase mit verschiedenen Proteinen, die im Verlauf Signalwege wie RAS-RAF-MAPK (mitogen-activated protein kinase), STAT (signal transducers and activators of transcirption) und PI3K (Phosphoinositid-3-Kinasen)-AKT (Proteinkinase B) aktivieren (Abbildung 1) (Eswarakumar et al. 2005; Turner und Grose 2010). Auch eine Inhibierung dieser Signalwege ist über eine Internalisierung der Rezeptoren sowie über eine die Signalkaskade abschwächende oder hemmende Wirkung verschiedener Mediatoren möglich, darunter CBL (casitas B-lineage lymphoma), ERK1 (extracellular signal-regulated kinases) und ERK2, MKP3 (MAPK-Phosphatase), SEF (similar expression to FGF genes) und Sprouty (SPRY)-Proteine. 


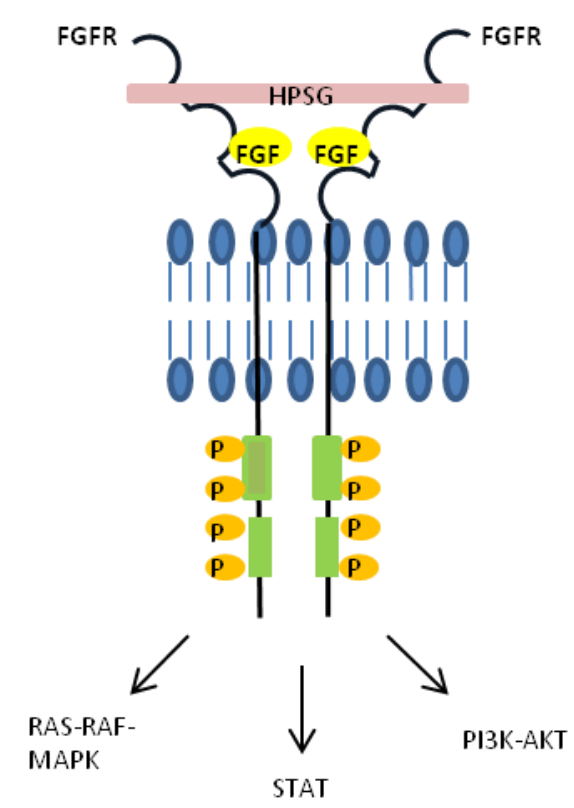

\begin{abstract}
Abbildung 1: FGF-Rezeptor
Abbildung 1: HPSG, Heparansulfatproteoglykane; RAS, rat sarcoma; RAF, rat fibrosarcoma; MAPK, mitogen-activated protein kinases; STATs, signal transducer and activator of transcription proteins; PI3K, Phosphoinositid-3-Kinasen; AKT, entspricht PKB, Proteinkinase B; P, Phosphorylierung; modifiziert nach Chae et al. (2017); Turner und Grose (2010).
\end{abstract}

\title{
1.2.3 FGF-FGFR-Signalweg in malignen Tumoren
}

In vielen verschiedenen malignen Tumoren sind Aberrationen im FGFR-Signalweg beschrieben worden. Die Folgen sind übermäßige Zellproliferation, -migration und Neovaskularisation, welche die Tumorentstehung fördern und den Tumorprogress beschleunigen (Grose und Dickson 2005; Turner und Grose 2010). Der FGFR-Signalweg kann sowohl durch genetische Alterationen wie Amplifikationen, Translokationen oder gain-of-function-Mutationen aktiviert werden als auch durch Aberrationen auf der RNA-Expressionsebene. Genamplifikationen können in einer Überexpression des Rezeptors oder Liganden resultieren; Translokationen lassen ein Fusionsprotein entstehen, welches, ebenso wie gain-of-function-Mutationen, eine Liganden-unabhängige Rezeptoraktivierung ermöglicht. Funktionelle Alterationen führen zu einer Rezeptor- oder Liganden-Überexpression. Ferner kann durch alternatives Spleißen der FGFRs die Zahl passender Liganden vergrößert werden (Eswarakumar et al. 2005; Grose und Dickson 2005). Eine Vielzahl solider Tumoren sowohl epithelialen als auch mesenchymalen Ursprungs ist mit spezifischen FGFR-Alterationen assoziiert (Taylor et al. 2009; Turner und Grose 2010). FGFR1-Amplifikationen finden sich in 20\% der Plattenepithelkarzinome der Lunge (Weiss et al. 2010), in 5\% der kleinzelligen Lungenkarzinome (Schultheis et al. 2014) sowie in 10\% der Mammakarzinome (Courjal et al. 1997; Reis-Filho et al. 2006). FGFR2- 
Amplifikationen und -Mutationen lassen sich in ca. 5\% der Magenkarzinome nachweisen (Jung et al. 2012). FGFR3-Mutationen zeigen sich häufig in Harnblasenkarzinomen, wobei 50$60 \%$ der nicht-muskelinvasiven und 10-15\% der muskelinvasiven Karzinome davon betroffen sind (Al-Ahmadie et al. 2011; Touat et al. 2015). FGFR3-Translokationen findet man in 3-7\% der Glioblastome (Parker et al. 2013; Singh et al. 2012) und in 15-20\% der Myelome (Chesi et al. 1997; Dieci et al. 2013).

Selten können FGFR-Alterationen auch eine hemmende Wirkung auf die Karzinogenese entfalten wie es z. B. für die FGFR2-Expression in Harnblasenkarzinomen beschrieben wurde (Ricol et al. 1999). In den allermeisten Fällen fördern sie jedoch das Tumorwachstum und verschlechtern die Prognose (Turner und Grose 2010). Eine Assoziation von FGFRAlterationen und einer rascheren Tumorprogression zeigte sich z. B. in Mammakarzinomen mit einer FGFR1-Expression (Courjal et al. 1997; Shi et al. 2016), in Magenkarzinomen mit einer FGFR2-Amplifikation (Jung et al. 2012), in Endometrium-Karzinomen mit einer FGFR2-Mutation (Jeske et al. 2017), in HPV (humanes Papilloma Virus)-negativen HNSCC (head and neck squamous cell carcinoma) mit einer FGFR1-Protein-Überexpression (Koole et al. 2016) und in Plattenepithelkarzinomen der Lunge mit einer FGFR1-Amplifikation (Seo et al. 2014).

Eine übermäßige Stimulation des FGFR-Signalwegs kann auch durch Alterationen der FGFLiganden entstehen. So können FGF-Amplifikationen in einer FGF-Überexpression resultieren, wodurch eine autokrine oder parakrine Schleife entsteht, welche den Rezeptor permanent stimuliert (Dienstmann et al. 2014). In diesem Zusammenhang sind vor allem die FGFLiganden 3,4, und 19 zu nennen. Eine FGF3,4,19-Co-Amplifikation wurde von Parish et al. in 5,6\% fortgeschrittener Karzinome beschrieben (Parish et al. 2015). Da die drei Liganden in einem Cluster auf dem langen Arm von Chromosom 11 (11q13) zusammen liegen, findet sich hier oft eine Co-Amplifikation. Eine FGF3-Amplifikation zeigte sich darüber hinaus in 1520\% der Mammakarzinome und war mit einem rascheren Tumorfortschritt verbunden (Parish et al. 2015). FGF19 stellt, unter anderen, für FGFR1 und für FGFR4 einen wichtigen Liganden dar (Yang et al. 2012).

\subsubsection{FGFR-Tyrosinkinase-Inhibitoren in der Krebstherapie}

Angesichts des häufigen Vorkommens von FGFR-Alterationen in verschiedenen Tumorentitäten werden aktuell eine Vielzahl von selektiven und nicht-selektiven TyrosinkinaseInhibitoren in klinischen Studien der Phasen I und II getestet. Erstere hemmen selektiv die 
FGFR-Tyrosinkinase, letztere inhibieren neben den FGFRs noch weitere Tyrosinkinasen wie PDGFRs (platelet-derived growth factor receptor) und VEGFRs. Multi-Tyrosinkinase-Inhibitoren erscheinen aufgrund des breiteren Spektrums an molekularen Zielstrukturen effektiver, bringen dadurch jedoch auch mehr Nebenwirkungen mit sich (Turner und Grose 2010). Hier sind vor allem Bluthochdruck, kardiale sowie gastrointestinale Nebenwirkungen, Proteinurie sowie Nebenwirkungen an Haut und Auge zu nennen. Die FGFR-selektiven TyrosinkinaseInhibitoren hingegen verursachen typischerweise eine Hyperphosphatämie, welche eine Gewebskalzifizierung verursacht (Chae et al. 2017; Dienstmann et al. 2014).

Aktuelle klinische Studien der Phase I und II zeigen vielversprechende Ergebnisse. In einer Phase-II-Studie in metastasierten kolorektalen Karzinomen war Nintedanib, ein VEGFR- und PDGFR-Inhibitor mit hemmender Wirkung auf FGFRs, in Kombination mit systemischer Chemotherapie der Standardtherapie zuzüglich Bevacizumab nicht unterlegen. Bei intensiv vorbehandelten Patienten war Nintedanib hinsichtlich des progressionsfreien Überlebens sowie der Lebensqualität der Standardtherapie sogar überlegen (Rossi et al. 2017). Für Lucitanib, ein VEGFR1-3, PDGFR $\alpha / \beta$ und FGFR1-3 Inhibitor, konnte in einer klinischen Studie der Phase I/II (FINESSE, NCT02053636) ein an RECIST (response evaluation criteria in solid tumours) gemessenes Ansprechen bei sechs von zwölf metastasierten, Östrogen-Rezeptor-positiven Mammakarzinomen mit einer FGFR1- oder FGF 3,4,19-Amplifikation erreicht werden (Soria et al. 2014). In metastasierten Nierenzellkarzinomen, welche zuvor mit VEGFR- und mTOR (mechanistic target of rapamycin)-Inhibitoren behandelt worden waren, zeigte sich Dovitinib (Novartis), ein FGFR, VEGFR, PDGFR, CSF (colony-stimulating factor)-1 und c-Kit Inhibitor, über eine Blockade von FGFR1 wirksam (Chae et al. 2017; Escudier et al. 2014). In einer klinischen Studie der Phase I zeigte Lenvatinib (E7080, Eisai), ein Inhibitor von FGFR, VEGFR, PDGFR, RET (rearranged during transfection) und KIT, eine Ansprechrate von 15,6\% und eine stable disease (SD) für mindestens 23 Wochen in 24,7\% fortgeschrittener Tumore (Hong et al. 2015).

Die Gruppe der selektiven FGFR-Tyrosinkinase-Inhibitoren zeigte ebenfalls eine gute Wirksamkeit bei einer Vielzahl von Tumoren. BGJ398, ein selektiver FGFR1-3-TyrosinkinaseInhibitor, zeigte bei FGFR3-mutierten Harnblasen- und Urothelkarzinomen sowie FGFR1amplifizierten Plattenepithelkarzinomen der Lunge ein partielles Ansprechen bei guter Verträglichkeit (Nogova et al. 2017). Auch bei Cholangiokarzinomen mit einer FGFR2-Fusion sowie in FGFR1-amplifizierten Mammakarzinomen zeigte sich ein Ansprechen der Tumoren (Sequist et al. 2014). Der Pan-FGFR-Inhibitor BAY1163877 erreichte in einer Phase-I-Studie eine Tumorverkleinerung bei sieben von acht Patienten (87,5\%) mit Urothelkarzinomen, welche eine FGFR3-mRNA-Überexpression aufwiesen (Joerger et al. 2017). Auch der Pan- 
FGFR-Inhibitor JNJ-42756493 hat sich in einer klinischen Studie der Phase I bei therapierefraktären Tumoren sowie Lymphomen bewährt (NCT01703481). Die partielle Ansprechrate lag bei $22 \%$ in diesen Tumoren (5/23), wobei alle fünf eine FGFR2- oder FGFR3Translokation aufwiesen (Tabernero et al. 2015). Schließlich ist noch der selektive FGFRInhibitor AZD4547 zu nennen, welcher vielversprechende Ergebnisse in einer klinischen Phase-II-Studie bei Patienten mit fortgeschrittenen Magen-, Bronchial-, und Mammakarzinomen mit einer FGFR1- oder FGFR2-Amplifikation zeigte. Bei den FGFR1-amplifizierten Mammakarzinomen lag die Ansprechrate bei 12,5\%; bei den FGFR2-amplifizierten gastroösophagealen Karzinomen lag sie sogar bei 33\% (Smyth et al. 2015).

\subsubsection{Prädiktive Biomarker für eine anti-FGFR-Therapie}

Angesichts der teils vielversprechenden Erfolge der anti-FGFR-Therapie, stellt sich die Frage nach geeigneten prädiktiven Biomarkern, welche die Patienten identifizieren, welche von FGFR-Inhibitoren profitieren könnten. Bislang wurden meist genetische Alterationen der FGFRs und FGFs, darunter Amplifikationen, Genfusionen oder Mutationen als Einschlusskriterium für klinische Studien verwendet (Guagnano et al. 2012; Guffanti et al. 2016; Kaibori et al. 2016; Nogova et al. 2017). Einige konnten auch eine positive Korrelation zwischen dem Vorhandensein von genetischen FGFR-Alterationen und dem Therapieansprechen zeigen. Die Autoren einer aktuellen Phase-I-Studie mit dem Pan-FGFR-Inhibitor BAY1163877 favorisieren jedoch ein erhöhtes mRNA-Expressionsniveau anstelle von genetischen Alterationen zur Auswahl von Patienten für eine anti-FGFR-Therapie. In der genannten Studie zeigte die Mehrzahl der Tumoren, welche auf die Therapie ansprachen, erhöhte mRNAExpressionsniveaus von FGFR1-3, jedoch keine genetischen FGFR-Alterationen. Das mRNA-Expressionsniveau wurde dabei mittels RNA-in-situ-Hybridisierung (RNAScope) und Nanostring bestimmt; genetische Alterationen wurden mittels Fluoreszenz-in-situHybridisierung (FISH) ermittelt (Joerger et al. 2017). Auch Wynes et al. und Göke et al. sehen eine erhöhte FGFR-mRNA- und Proteinexpression als verlässlicheren Parameter gegenüber der Genkopienzahl zur Vorhersage eines Therapieansprechens bei Patienten mit Bronchialkarzinomen und HNSCC (Goke et al. 2015; Wynes et al. 2014). 


\section{$1.3 \quad$ Zielsetzung}

Trotz der bestehenden multimodalen Therapieoptionen ist das Outcome der Patienten mit oligometastasiertem kolorektalen Karzinom bislang immer noch unbefriedigend. Es fehlt an prognostischen Markern, welche die Patientengruppe mit einem ungünstigen Krankheitsverlauf identifizieren, und an Therapieoptionen, um diese effektiv zu behandeln. FGFRAlterationen haben sich als potentielle molekulare Zielstrukturen in verschiedenen Tumorentitäten erwiesen und FGFR-Inhibitoren vielversprechende therapeutische Erfolge gezeigt. Im kolorektalen Karzinom sind sie bislang wenig erforscht und ihre Bedeutung ist weitgehend unklar.

Ziel dieser Arbeit ist es nun, Antworten auf die folgenden Fragen zu finden:

Wie ist die Prävalenz von FGFR- und FGF-Alterationen in primären kolorektalen Karzinomen?

Wie ist die Prävalenz derselben in Lebermetastasen oligometastasierter kolorektaler Karzinome?

Haben FGFR- und FGF-Alterationen eine prognostische Bedeutung in kolorektalen Karzinomen?

Besteht eine Korrelation der FGFR- und FGF-Alterationen mit den molekularen Subtypen des kolorektalen Karzinoms? 


\section{Material und Methoden}

\subsection{Material}

\subsubsection{Probenkollektiv}

Im Rahmen dieser Arbeit wurden zwei getrennte Kohorten von 140 Primärtumoren kolorektaler Karzinome, davon 70 Kolon- und 70 Rektumkarzinome sowie 63 Lebermetastasen kolorektaler Karzinome untersucht. Primärtumoren und Lebermetastasen stammten dabei von verschiedenen Patienten. Es wurden Lebermetastasen von insgesamt 55 Patienten analysiert, wobei von drei Patienten jeweils mehrere Metastasen untersucht wurden. Ferner wurde in einem Fall nicht nur die Lebermetastase, sondern auch der dazugehörige Primärtumor sowie dessen Lymphknotenmetastase untersucht.

Bei den Präparaten handelte es sich um Resektate von Primärtumoren und um Resektate von Lebermetastasen oligometastasierter Patienten, welche von erfahrenen Pathologen begutachtet wurden. Die Metastasen wurden zwischen 2011 und 2014 im Rahmen der Leberchirurgie oligometastasierter Patienten zusammengetragen. Eine Charakterisierung der Patientenkohorte bezüglich klinischer und histopathologischer Parameter sowie Informationen zum durchgeführten Therapieregime finden sich in Tabelle 1. Follow-up-Daten wurden aus dem lokalen Krebsregister der Klinik oder vom behandelnden Arzt bezogen. Das Gesamtüberleben wurde definiert als die Zeit zwischen der chirurgischen Resektion des Primärtumors und dem krebsbedingten Tod des Patienten. 
Tabelle 1: Charakterisierung der Fallkohorten

\begin{tabular}{|c|c|c|c|}
\hline & & $\begin{array}{l}\text { Primärtumoren } \\
(n=140)\end{array}$ & $\begin{array}{l}\text { Metastasen } \\
(n=55)\end{array}$ \\
\hline Geschlecht $(\%)$ & $\begin{array}{l}\text { Männlich } \\
\text { Weiblich } \\
\text { Angaben nicht verfügbar }\end{array}$ & $\begin{array}{l}81(57,9) \\
56(40) \\
3(2,1)\end{array}$ & $\begin{array}{l}36(65,5) \\
19(34,5) \\
--\end{array}$ \\
\hline Alter (Jahren) & $\begin{array}{l}\text { Median } \\
\text { Spanne } \\
\text { Angaben nicht verfügbar }\end{array}$ & $\begin{array}{l}74 \\
43-98 \\
3\end{array}$ & $\begin{array}{l}64 \\
32-84 \\
--\end{array}$ \\
\hline $\begin{array}{l}\text { Lokalisation/ Her- } \\
\text { kunft des Primär- } \\
\text { tumors }(\%)\end{array}$ & $\begin{array}{l}\text { Kolon } \\
\text { linksseitig } \\
\text { rechtsseitig } \\
\text { Transversum } \\
\text { Angaben nicht verfügbar } \\
\text { Rektum }\end{array}$ & $\begin{array}{ll}70 & (100) \\
33 & (47,1) \\
31 & (44,3) \\
5 & (7,1) \\
1 & (1,4) \\
70 & (100)\end{array}$ & $\begin{array}{ll}30 * & (100) \\
10 & (33,3) \\
10 & (33,3) \\
-- & \\
10 & (33,3) \\
24 * & (100)\end{array}$ \\
\hline T-Stadium (\%) & $\begin{array}{l}1 \\
2 \\
3 \\
4 \\
\text { Nicht verfügbar }\end{array}$ & $\begin{array}{ll}6 & (4,3) \\
29 & (20,7) \\
87 & (62,1) \\
15 & (10,7) \\
3 & (2,1)\end{array}$ & \\
\hline N-Stadium (\%) & $\begin{array}{l}0 \\
\geq 1 \\
\text { Nicht verfügbar }\end{array}$ & $\begin{array}{l}75(53,6) \\
62(44,3) \\
3 \quad(2,1)\end{array}$ & \\
\hline M-Stadium (\%) & $\begin{array}{l}0 \\
1 \\
\text { Nicht verfügbar }\end{array}$ & $\begin{array}{ll}104 & (74,3) \\
33 & (23,6) \\
3 & (2,1)\end{array}$ & $55(100)$ \\
\hline $\begin{array}{l}\text { Therapie } \leq 6 \text { Mona- } \\
\text { te vor Metastasen- } \\
\text { resektion }(\%)\end{array}$ & $\begin{array}{l}\text { Chemotherapie } \\
\text { Chemotherapie + anti-EGFR } \\
\text { Chemotherapie + anti-VEGF } \\
\text { Chemotherapie + anti-EGFR } \\
\quad+\text { anti-VEGF } \\
\text { Nicht verfügbar }\end{array}$ & $\begin{array}{l}-- \\
-- \\
-- \\
-- \\
- \\
--\end{array}$ & $\begin{array}{ll}6 & (10,9) \\
12 & (21,8) \\
9 & (16,4) \\
1 & (1,8) \\
27 & (49,1)\end{array}$ \\
\hline
\end{tabular}

Tabelle 1: * Ein Patient hatte gleichzeitig ein Kolon (Zökum)- sowie ein Rektumkarzinom, sodass unklar war, welches Karzinom die Metastasen verursachte; T, Größe des Primärtumors; N, regionaler Lymphknotenstatus; M, Fernmetastasen; anti-EGFR, Antikörper gegen den epidermal growth factor receptor; anti-VEGF, Antikörper gegen den vascular endothelial growth factor. Tabelle modifiziert nach Fromme et al. (2018).

Das Projekt wurde von der lokalen Ethik-Kommission genehmigt (EK-Nr. 21/3/11). 


\subsection{Methoden}

\subsubsection{Tissue microarrays (TMAs)}

Die vorliegenden Primärtumoren sowie die Lebermetastasen wurden anhand von tissue microarrays (TMAs) untersucht. Hierzu wurde das Gewebe zunächst in Formalin fixiert und in Paraffin eingebettet (FFPE). Dann wurden aus den Paraffinblöcken der einzelnen Primärtumoren, die als Donorblöcke dienten, je zwei Stanzzylinder mit einem Durchmesser von $1 \mathrm{~mm}$ von Tumor- sowie angrenzendem Normalgewebe entnommen. Aus den Paraffinblöcken der Metastasen wurden je zwei Stanzzylinder mit einem Durchmesser von $1 \mathrm{~mm}$ entnommen, die beide Tumorgewebe enthielten. Diese einzelnen Stanzen wurden daraufhin in einen weiteren Paraffinblock, den Empfängerblock, hineingesetzt, sodass der Tumor und bei den Primärtumoren das dazugehörige Normalgewebe, bei den Metastasen die beiden Gewebszylinder derselben Metastase, immer nebeneinander zu liegen kamen. Für die Fluoreszenz-in-situHybridisierung (FISH) wurden nun $4 \mu \mathrm{m}$ dicke Schnitte vom Empfängerblock angefertigt und auf einen Objektträger gezogen. Insgesamt konnten auf den TMAs der Metastasen bis zu 32 Metastasen auf einem Objektträger untersucht werden, bei den Primärtumoren waren es jeweils 70 Tumoren je TMA. Die TMA-Blöcke lagen vor.

\subsubsection{Fluoreszenz-in-situ-Hybridisierung (FISH)}

Die Fluoreszenz-in-situ-Hybridisierung ist ein Verfahren, mit dem isolierte DNA und RNA mithilfe von komplementär bindenden und mit Fluoreszenz-Farbstoffen markierten Sonden in situ, d. h. im Zellkern einer einzelnen Zelle dargestellt werden kann (Langer-Safer et al. 1982; Levsky und Singer 2003). Sie eignet sich sowohl zur Identifizierung von numerischen chromosomalen Anomalien als auch wie in unserem Falle zum Nachweis von strukturellen chromosomalen Aberrationen (z. B. Translokationen) und Genvervielfachungen (Amplifikationen). Hierfür muss die DNA zunächst denaturiert werden, damit sie als Einzelstrang vorliegt. Dann wird die Sonde hinzugegeben, ebenfalls bestehend aus einem DNA-Einzelstrang, dessen Basenabfolge so beschaffen ist, dass er komplementär an die gesuchte Basensequenz im zu untersuchenden Gewebe binden kann. Diesen Prozess nennt man Hybridisierung. Nach erfolgter Hybridisierung leuchtet die markierte Sonde unter dem Fluoreszenz-Mikroskop farbig auf (Levsky und Singer 2003).

Für die Fluoreszenz-in-situ-Hybridisierung wurden zwei Arten von FISH-Sonden verwendet. Dual Color Break. Apart Probes dienten zur Analyse chromosomaler Translokationen und Numerical Dual Color Probes zur Analyse von Genamplifikationen (Tabelle 2). Bei den Numerical Dual Color Probes markiert meist der grün fluoreszierende Teil der Sonde das gesuchte Gen und der orange fluoreszierende Teil eine Sequenz nahe dem Zentromer, welche relativ stabil ist und 
daher als interne Kontrolle genutzt werden kann. Nur bei zweien der hier verwendeten Sonden ist die Markierung umgekehrt und das orange Signal entspricht dem gesuchten Gen (Tabelle 3). Bei den Amplifikationssonden werden die Genkopienzahl und die Anzahl der Zentromer-Signale je Zellkern bestimmt. Daraus kann die Ratio, d. h. das Verhältnis von Genkopienzahl zur Anzahl der Zentromer-Signale berechnet werden. Die durchschnittliche Genkopienzahl lässt sich durch das Verhältnis der Anzahl der grünen Signale zur Zahl ausgewerteter Zellen bestimmen, wobei in einem normalen disomen Zellkern, welcher sich in der Interphase befindet, zwei Kopien jedes Gens und zwei Zentromere vorliegen. Folglich ergibt sich eine durchschnittliche Genkopienzahl von 2 sowie eine Ratio von 1. Weiterhin wurden die Zellen hinsichtlich einer möglichen Polysomie analysiert, welche durch das Vorhandensein von mindestens drei Zentromer-Signalen definiert ist. Bei einer Monosomie zeigt sich hingegen nur ein Zentromer-Signal. Um einen möglichen Genzugewinn zu quantifizieren, wurde neben der durchschnittlichen Genkopienzahl pro Zelle auch der Prozentsatz der Zellen angegeben, welche $\geq 5$ oder $\geq 15$ Genkopien aufwiesen. Diese Daten wurden in standardisierten Auswertebögen festgehalten.

Tabelle 2: Verwendete FISH-Sonden

\begin{tabular}{|c|c|c|c|}
\hline Alteration & Rezeptor & Verwendete Sonde & Hersteller \\
\hline \multirow[t]{5}{*}{ Amplifikation } & FGFR1 & $\begin{array}{l}\text { ZytoLight SPEC FGFR1/CEN8 Dual } \\
\text { Color Probe }\end{array}$ & $\begin{array}{l}\text { ZytoVision, } \\
\text { Bremerhaven, } \\
\text { Deutschland }\end{array}$ \\
\hline & FGFR2 & $\begin{array}{l}\text { ZytoLight SPEC FGFR2/CEN10 } \\
\text { Dual Color Probe }\end{array}$ & “" \\
\hline & FGFR3 & $\begin{array}{l}\text { ZytoLight SPEC FGFR3/CEN4 Dual } \\
\text { Color Probe }\end{array}$ & “ \\
\hline & FGF3,4,19 & $\begin{array}{l}\text { ZytoLight SPEC FGF 3,4,19/CEN } 11 \\
\text { Dual Color Probe }\end{array}$ & “6 \\
\hline & FGFR4 & $\begin{array}{l}\text { POSEIDON FGFR4 (5q35)/5q11.2 } \\
\text { Probe }\end{array}$ & $\begin{array}{l}\text { Kreatech, Amster- } \\
\text { dam, Niederlande }\end{array}$ \\
\hline \multirow[t]{3}{*}{ Translokation } & FGFR1 & $\begin{array}{l}\text { ZytoLight SPEC FGFR1 Dual Color } \\
\text { Break Apart Probe }\end{array}$ & $\begin{array}{l}\text { ZytoVision, } \\
\text { Bremerhaven, } \\
\text { Deutschland }\end{array}$ \\
\hline & FGFR3 & Agilent Sure FISH FGFR3 (BA) Probe & $\begin{array}{l}\text { Agilent } \\
\text { Technologies, } \\
\text { CA, USA }\end{array}$ \\
\hline & $\begin{array}{l}\text { FGFR1/ } \\
\text { FGFR2/ } \\
\text { FGFR3 }\end{array}$ & $\begin{array}{l}\text { SPEC FGFR3 Break Apart/ FGFR2/ } \\
\text { FGFR1 Quadruple Color Probe }\end{array}$ & $\begin{array}{l}\text { ZytoVision, } \\
\text { Bremerhaven, } \\
\text { Deutschland }\end{array}$ \\
\hline
\end{tabular}


Tabelle 3: Charakterisierung der Amplifikationssonden

\begin{tabular}{|c|c|c|c|}
\hline Rezeptor & Lokalisation & $\begin{array}{l}\text { Fluoreszenzfarbe } \\
\text { des Target-Gens }\end{array}$ & CEN \\
\hline FGFR1 & 8p11.23-p11.22. & $\begin{array}{l}\text { Grün } \\
\text { (Spectrum Green) }\end{array}$ & $\begin{array}{l}\text { D8Z2 } \\
\text { (Zentromer 8) }\end{array}$ \\
\hline FGFR2 & 10q26.12-q26.13 & Grün & D10Z1 \\
\hline FGFR3 & $4 \mathrm{p} 16.3$ & Grün & $\begin{array}{l}4 \mathrm{p} .11 \\
\text { (zentromernah) }\end{array}$ \\
\hline FGFR4 & $(5 q 35) / 5 q 11.2$ & $\begin{array}{l}\text { Rot } \\
\text { (Platinum Bright) }\end{array}$ & $\begin{array}{l}\text { 5q11.2 } \\
\text { (zentromernah) }\end{array}$ \\
\hline FGF3,4,19 & $11 q 13.3$ & $\begin{array}{l}\text { Orange } \\
\text { (Spectrum Orange) }\end{array}$ & D11Z1 \\
\hline
\end{tabular}

FGFR1 und FGFR3 wurden sowohl mit Amplifikations- als auch mit Translokationssonden untersucht. FGFR3 wurde zusätzlich mit der Quadruple Color Probe analysiert (Tabelle 4). Bei den Dual Color Break. Apart Probes hybridisiert der grün fluoreszierende Teil der Sonde (5'Signal) distal und der orange fluoreszierende Teil (3'-Signal) proximal eines typischen möglichen Bruchpunkts des FGFR-Gens. Liegt keine Translokation vor, verschmelzen das orange fluoreszierende 3'-Signal und das grün fluoreszierende 5'-Signal zu einer gelben Fluoreszenz. Im translozierten Fall sind das 5'-Signal und das 3'-Signal in einem gewissen Abstand einzeln zu erkennen. Der erforderliche Mindestabstand wurde als ein Signaldurchmesser festgelegt. In einem disomen Zellkern, welcher sich in der Interphase befindet, leuchten zwei gelb fluoreszierende Fusionssignale. Lag hingegen nur ein gelbes Fusionssignal und jeweils ein 5'- und ein 3'-Signal in erforderlichem Abstand vor, wurde dies als break apart gewertet. Das Fusionssignal war hierbei als obligate interne Kontrolle jeweils erforderlich.

In diesem Zusammenhang ist jedoch zu beachten, dass auch Schnittartefakte zum Auftreten einzelner 5'-/3'signale führen können, wenn der Tumorzellkern z. B. so angeschnitten wird, dass nur der rote oder nur der grüne Teil der Sonde im Schnitt sichtbar sind. Solche Schnittartefakte kommen meist nur in wenigen Zellen eines Tumors vor, wohingegen bei einer echten Translokation eine substantielle Anzahl von Zellen break apart-Phänomene zeigt. Um dies differenzieren zu können, wurde eine Kohorte von Plattenepithelkarzinomen und Tonsillen mit der FGFR1- und FGFR3-Translokationssonde hybridisiert und hinsichtlich des Auftretens von breake apart-Phänomenen sowie einzelnen orange oder grünen Signalen untersucht. Anschließend wurde aus diesen Ergebnissen für die jeweilige Sonde und das jeweilige Signalmuster ein Mittelwert bestimmt. 
Tabelle 4: Charakterisierung der Translokationssonden

\begin{tabular}{|c|c|c|c|}
\hline Rezeptor & $\begin{array}{l}\text { Bruchpunkt- } \\
\text { Region }\end{array}$ & $\begin{array}{l}\text { 3'-Signal der } \\
\text { Bruchpunkt- } \\
\text { Region in } \mathrm{kB}\end{array}$ & $\begin{array}{l}5^{6} \text {-Signal der } \\
\text { Bruchpunkt- } \\
\text { Region in } \mathrm{kB}\end{array}$ \\
\hline FGFR1 & 8p11.23-p11.22 & 605 & 600 \\
\hline FGFR3 & $4 \mathrm{p} 16.3$ & 184.229 & 315.551 \\
\hline (FGFR1/ & -- & -- & - \\
\hline FGFR2/) & -- & -- & -- \\
\hline FGFR3 & $4 \mathrm{p} 16.3$ & 525 & 800 \\
\hline
\end{tabular}

\subsubsection{Protokoll der Fluoreszenz-in-situ-Hybridisierung (FISH)}

Zur Vorbereitung und Hybridisierung der FISH-Sonden wurde der vollautomatische VP 2000 Prozessor (Abbott Molecular, Wiesbaden, Deutschland) verwendet. Im Folgenden werden die einzelnen Schritte stichpunktartig erläutert:

1) $2 \mu \mathrm{m}$ dünne Schnitte von den TMA-Blöcken anfertigen, auf Objektträger aufziehen und bei $37^{\circ} \mathrm{C}$ trocknen lassen

2) zum Entparaffinisieren Schnitt für 30 Minuten auf $60^{\circ} \mathrm{C}$ erhitzen

3) zwei Wasserbäder mit jeweils $37^{\circ} \mathrm{C}$ und $80{ }^{\circ} \mathrm{C}$ bereitstellen

4) Objektträger in Fach des VP2000 Prozessors einsetzen und Programm starten

5) automatisches Waschen im VP2000 Prozessor mit 2x jeweils 10 Minuten Xylol und dann mit absteigenden Konzentrationen von Isopropanol (2x jeweils fünf Minuten 100\% Isopropanol, eine Minute 96\% Isopropanol, eine Minute 80\% Isopropanol, eine Minute 70\% Isopropanol)

6) Schnitte bei $37^{\circ} \mathrm{C}$ fünf Minuten ruhen lassen

7) 0.2 molare Salzsäure (HCl) für 20 Minuten

8) waschen mit destilliertem Wasser für drei Minuten und dann mit 2x standard sodium citrate (SSC) -Waschpuffer für drei Minuten

9) inkubieren mit pretreatment solution $\left(80^{\circ} \mathrm{C}\right)$ für 30 Minuten

10) Waschen mit destilliertem Wasser für eine Minute und $2 x$ SSC-Waschpuffer für $2 x$ fünf Minuten

11) Hinzugeben der Protease bei $37^{\circ} \mathrm{C}$ für 90 Minuten

12) erneutes Waschen mit 2x SSC-Waschpuffer für 2x fünf Minuten

13) Hinzugeben von gepuffertem Formalin (4\%) für zehn Minuten

14) erneutes Waschen mit 2x SSC-Waschpuffer für $2 \mathrm{x}$ fünf Minuten sowie mit destilliertem Wasser für eine Minute 
15) Entnahme der Objektträger aus dem VP2000-Prozessor und Trocknenlassen der Schnitte bei $37^{\circ} \mathrm{C}$

16) je nach Gewebemenge ca. 5-10 $\mu$ l der entsprechenden Sonde auftropfen, Deckgläschen aufsetzen und mit Fixogum versiegeln

17) Hybridisierung mittels HyBrite VYSIS (Abott) bei $37^{\circ} \mathrm{C}$ über Nacht

18) am nächsten Tag: Proteinstrukturen bei $75^{\circ} \mathrm{C}$ für zehn Minuten denaturieren

19) Wasserbad auf $76{ }^{\circ} \mathrm{C}$ erwärmen, Post-Hybridisierungs-Puffer aufwärmen in 2x SSCWaschpuffer

20) Fixogum ablösen und Objektträger in 2xSSC-Waschpuffer stellen, bis sich das Deckgläschen ablösen lässt

21) Post-Hybridisierungs-Puffer bei genau $72{ }^{\circ} \mathrm{C}$ für zwei Minuten inkubieren

22) Eintauchen der Objektträger in 2x SSC-Waschpuffer

23) Schnitt trocknen, ca. $10 \mu$ l DAPI auftropfen und mit Deckgläschen versehen.

\subsubsection{Auswertung der Fluoreszenz-in-situ-Hybridisierung}

Die FISH-Präparate wurden an einem Fluoreszenz-Mikroskop (DM5500 B TL (BF) + Fluo Mikroskop, Leica, Wetzlar, Deutschland) mit dem 63er- oder 100er-Objektiv in den entsprechenden Filtern ausgewertet. Zur besseren Darstellung der Zellkerngrenzen wurde der DAPI und zur Analyse der Signale der Grün-/Orange-Mischfilter sowie der Grün- und der OrangeFilter verwendet. Die Fluoreszenz-Signale im an den Tumor angrenzenden Normalgewebe dienten als interne Kontrolle sowie zur Einschätzung der Qualität der Hybridisierung.

Für die Auswertung der Amplifikations-Sonden wurde die gesamte TMA-Stanze begutachtet und die drei Tumorareale mit der höchsten Genkopien-Anzahl ausgewählt. Wenn innerhalb eines Areals ein Bereich mit einer besonders hohen Zahl an Genkopien vorlag, wurde dieser vorzugsweise ausgewertet. In jedem der drei Areale wurden die Signale in 20 nebeneinander liegenden Zellkernen ausgezählt. Insgesamt wurden folglich 60 Tumorzellkerne beurteilt.

Als Bewertungskriterien wurden die folgenden Parameter herangezogen: das Verhältnis von Gen- zu Zentromer-Signalen (Ratio), die Anzahl der Zellen mit $\geq 5$ und $\geq 15$ Signalen sowie die durchschnittliche Genkopienzahl pro Zelle. Basierend auf diesen Kriterien wurden die Ergebnisse anhand eines Scores kategorisiert, welcher zuvor in einer Arbeit zu FGFR1Amplifikationen bei Plattenepithelkarzinomen der Lunge verwendet wurde (Schildhaus et al. 2012). 
(1) $\quad$ Hohes Amplifikationslevel wurde definiert als

a) Gen/Zentromer Ratio $\geq 2.0$ oder

b) durchschnittliche Genkopienzahl pro Zelle von $\geq 6.0$ oder

c) die Anzahl der Tumorzellen, die $\geq 15$ Zielsignale oder größere Cluster aufwiesen lag bei $\geq 10 \%$;

(2) Niedriggradige Amplifikation wurde definiert als die Prozentzahl der Tumorzellen, die $\geq 5$ Zielsignale aufwiesen war $\geq 50 \%$

(3) alle anderen Tumoren wurden als negativ bewertet.

Für die Auswertung der Translokationssonden wurden 50 zusammenhängende Tumorzellkerne auf das Auftreten von break apart-Phänomenen sowie auf zusätzliche 5'- oder 3'-Signale hin untersucht. Zur internen Kontrolle bedurfte es wenigstens eines gelben Fusionssignals, andernfalls wurde die Zelle aus der Wertung ausgeschlossen. Die FGFR1- und FGFR3Translokationssonden wurden zuvor an Zelllinien mit einer gesicherten FGFR1- oder FGFR3Translokation validiert. Für die Bewertung der Translokationen wurde zunächst ein Mittelwert aberranter Signale in 54 Tonsillen und 54 Plattenepithelkarzinomen des Oropharyngeal-Trakts bestimmt. Diese beiden hochproliferativen Gewebe wurden gewählt, da in der Literatur hierzu keine FGFR1- oder FGFR3-Gen-Rearrangements beschrieben sind und in hochproliferativen Geweben eine höhere Polysomie-Rate zu erwarten ist. In polysomen Zellen sind durch den Schnitt bedingte trunkierte aberrante Signale vermutlich häufiger zu finden als in Normalgewebe und mit dem Vorkommen im Tumorgewebe eher vergleichbar.

Die 54 Tonsillen und 54 Plattenepithelkarzinome des Oropharyngealtrakts lagen als FFPEMaterial vor. Von diesen Blöcken wurden mit Hämatoxylin-Eosin eingefärbte Schnitte (HESchnitte) sowie FISH-Präparate hergestellt, welche mit FGFR1- und FGFR3Translokationssonden hybridisiert wurden. Zunächst wurde im HE-Schnitt im Falle der Plattenepithelkarzinome das Tumorareal identifiziert, im FISH-Präparat lokalisiert und hinsichtlich break apart-Phänomenen oder zusätzlicher 5'- oder 3'-Signale untersucht. Der später festgelegte cut-off -Wert zur Definition einer Translokation in Primärtumoren und Metastasen kolorektaler Karzinome durfte nicht unter dem hier bestimmten Mittelwert aberranter Signale in hochproliferativen Geweben liegen.

Die Definition einer Translokation orientiert sich in dieser Arbeit an den Studien von Finelli et al. und Turkmen et al., welche Tumoren bei einem Auftreten von break apart-Phänomenen in $\geq 15 \%$ der Tumorzellen als transloziert werteten (Finelli et al. 1999; Turkmen et al. 2014). 


\subsubsection{RNA-in-situ-Hybridisierung (RNA-ISH)}

Die RNA-in-situ-Hybridisierung ist ein Verfahren, mit dem man semiquantitativ die Expression von messenger-RNA (mRNA) im Rahmen der Transkription eines bestimmten Gens ermitteln kann und sie in situ, d. h. im histologischen Kontext der einzelnen Zelle nachweisen kann (Wang et al. 2012). Die RNAScope bildet eine Weiterentwicklung der einfachen RNA-in-situHybridisierung, indem sie die spezifischen Hybridisierungssignale verstärkt und die unspezifischen unterdrückt (Wang et al. 2012). Dazu werden mehrere Zielsonden hergestellt, die an das RNA-Molekül binden. Die RNA-Sonden bestehen aus einer 18 bis 25 Basen langen, zur Zielregion komplementären Sequenz, einem Zwischenstück, und einer 14 Basen langen endständigen Sequenz, die auch Z-Sequenz genannt wird. Zwei Zielsonden à 18-25 Basen binden nun an eine RNA-Zielregion, die ca. 50 Basen lang ist, jede von ihnen hat eine unterschiedliche ZSequenz. Beide Z-Sequenzen zusammen genommen entsteht eine 28 Basen lange Region, an die der ,preamplifier“ binden kann, wobei dieser wiederum 20 Bindungsstellen für den „amplifier" bietet. An den ,amplifier" kann schließlich die Markierungssonde an 20 Bindungsstellen binden (Abbildung 2, (Wang et al. 2012)). Die Markierungssonde kann entweder mit einem fluoreszierenden Farbstoff beladen oder wie in diesem Fall mit einem Molekül (Alkalische Phosphatase, Meerrettich-Peroxidase) gekoppelt sein, durch das es bei Zugabe eines anderen Moleküls zur Farbreaktion kommt. An diesem Kollektiv wurde alkalische Phosphatase und fast red verwendet. Die Auswertung erfolgte mit einem herkömmlichen Lichtmikroskop bei 40bis 100facher Vergrößerung. Das Tumorgewebe lag in Formalin fixiert und in Paraffin eingebettet vor (FFPE). Die RNA-in-situ-Hybridisierung wurde im Labor der Firma Targos in Kassel durchgeführt, wobei der ACD RNAscope Assay (RUO) sowie das rote Detektions-Kit verwendet wurden (Advanced Cell Diagnostics, CA, USA).

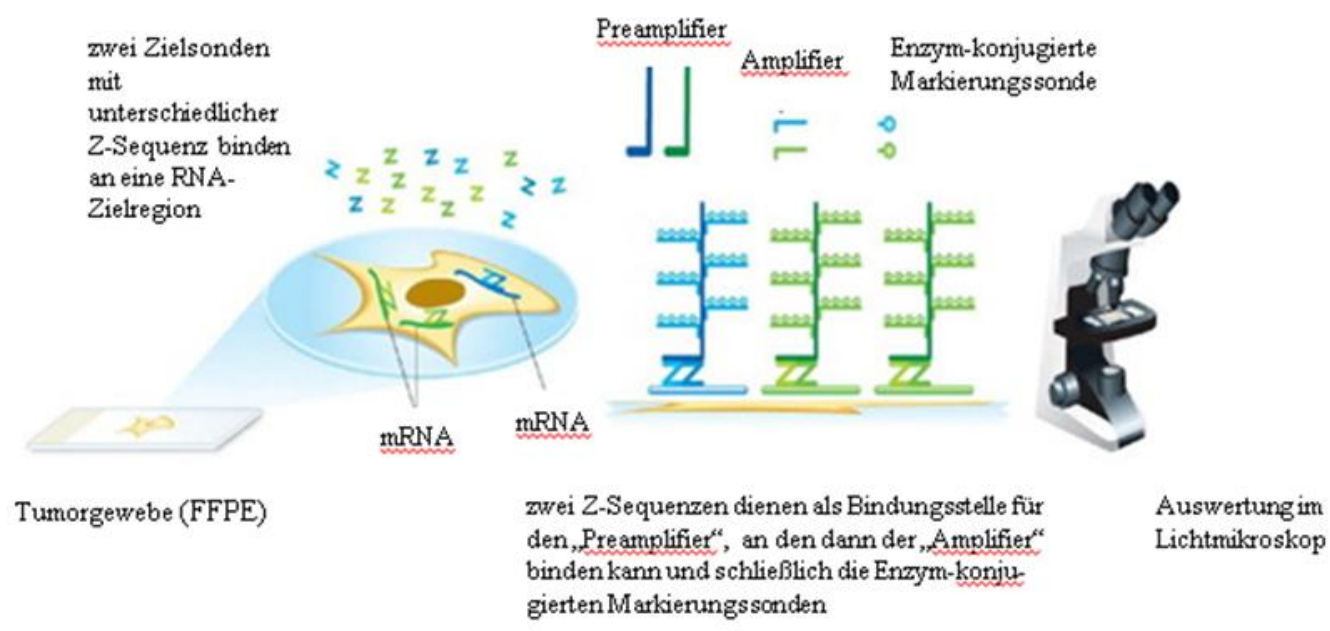

Abbildung 2: RNAScope-Verfahren, modifiziert nach Wang et al. (2012) 


\subsubsection{Protokoll der RNA-in-situ-Hybridisierung}

Im Folgenden wird das Protokoll der RNA-in-situ-Hybridisierung stichpunktartig dargestellt:

1) Anfertigen von $4 \mu \mathrm{m}$ dicken Schnitten von in Formalin fixiertem und in Paraffin eingebettetem Tumorgewebe (FFPE) und Aufziehen auf Superfrost Plus-Objektträger

2) über Nacht bei Raumtemperatur trocknen lassen

3) eine Stunde bei $60{ }^{\circ} \mathrm{C}$ im Ofen erhitzen

4) entparaffinisieren mit Xylene ( 2 × 5 min), 100\% EtOH ( 2 × 3 min), 96\% EtOH (1 x $2 \mathrm{~min}), 80 \% \mathrm{EtOH}(1 \times 2 \mathrm{~min}), 70 \% \mathrm{EtOH}(1 \times 2 \mathrm{~min})$

5) 5 min bei Raumtemperatur trocknen lassen

6) Vorbehandlung zur Hybridisierung: HybEZ Ofen auf $40{ }^{\circ} \mathrm{C}$ vorheizen und Feuchtigkeitskontrolltablett für $30 \mathrm{~min}$ hineinstellen

7) Mischen von $200 \mathrm{ml}$ 1x pretreat 2-Lösung, $180 \mathrm{ml}$ destilliertem Wasser und $20 \mathrm{ml} \mathrm{der}$ 10x pretreat 2-Lösung in einem Behälter

8) Behälter mit Folie abdecken und auf einer heißen Platte für 10-15 min auf höchster Stufe erhitzen

9) sobald die Lösung kocht, Temperatur auf $100-104{ }^{\circ} \mathrm{C}$ herabdrehen und köcheln lassen

10) währenddessen entparaffinisierte Objektträger je nach Größe der aufgezogenen Gewebeareale mit 5-8 Tropfen der pretreat 1-Lösung bedecken und 10 min lang bei Raumtemperatur inkubieren

11) Entfernen der pretreat 1-Lösung mit saugfähigem Papier

12) Objektträger mittels eines Halters sofort in destilliertes Wasser tauchen, Vorgang mit frischem Wasser nochmals wiederholen

13) Halter mit Objektträgern in leicht köchelnde 1x pretreat 2-Lösung tauchen und Behälter mit Folie abdecken; Kochzeit orientiert sich an Gewebetyp und untersuchtem FGFRezeptor

14) in destilliertem Wasser abkühlen lassen, wichtig ist, sie nicht in pretreat 2-Lösung abkühlen zu lassen

15) Waschen der Objektträger in destilliertem Wasser, dann in 100\% EtOH und an der Luft trocknen lassen

16) Markieren des Gewebeareals auf Objektträger mittels Permanent-Stift

17) Platzieren der Objektträger in HybEZ Ständer, je nach Größe des Gewebeareals ca. 5 Tropfen der pretreat 3-Lösung zugeben

18) Herausnehmen des im Ofen vorgewärmten HybEZ Feuchtigkeitskontrolltabletts, Einsetzen des HybEZ Slide Racks, Verschließen des Deckels und im Ofen gemäß der angegebenen Zeit bei $40{ }^{\circ} \mathrm{C}$ inkubieren 
19) Waschen in destilliertem Wasser

20) Hybridisierung: Objektträger in HybEZ Ständer platzieren und abhängig von der Gewebemenge ca. 4 Tropfen der entsprechenden Ziel- oder Kontrollsonde zugeben

21) HybEZ Ständer in HybEZ Feuchtigkeitskontrolltablett stellen und im Ofen für 2 Stunden bei $40{ }^{\circ} \mathrm{C}$ erhitzen (Ofen gut verschließen, um Verdunstung zu vermeiden)

22) Objektträger in 1x Waschpuffer 2 min lang waschen, Vorgang mit frischem Waschpuffer wiederholen

23) Amplifikation der Signale: Behandeln mit (je nach Gewebemenge) ca. 4 Tropfen AMP1, bis Gewebe vollständig benetzt ist

24) Objektträger im Feuchtigkeitskontrolltablett erneut für 30 min bei $40{ }^{\circ} \mathrm{C}$ im Ofen inkubieren

25) Waschen in $1 \mathrm{x}$ Waschpuffer

(Schritt 23-25 jeweils mit AMP2 (hier jedoch nur 15 min bei $40{ }^{\circ} \mathrm{C}$ im Ofen), AMP3 (30 min bei $40{ }^{\circ} \mathrm{C}$ im Ofen) und AMP4 (15 min bei $40{ }^{\circ} \mathrm{C}$ im Ofen) wiederholen. Bei AMP5 und AMP6 wird das Feuchtigkeitskontroll-Tablett nicht in den Ofen gegeben, sondern bei Raumtemperatur mit AMP5 30 min und mit AMP6 15 min lang inkubiert.)

26) Detektion der Signale: Herstellen einer roten Arbeitslösung mit Red A- und Red BLösung (Verhältnis 1:60)

27) Benetzen des Gewebes mit $75 \mu$ der roten Arbeitslösung

28) im Feuchtigkeitskontrolltablett für 10 min bei Raumtemperatur inkubieren

29) zweimaliges Waschen in destilliertem Wasser

30) Gegenfärbung und Eindecken: Gewebe für 15 Sekunden mit Mayer's Hämatoxylin blau gegenfärben, zweimalig in warmem Wasser waschen und 5 min lang inkubieren

31) in Xylol waschen und die Objektträger im Ofen 15 min lang bei $60^{\circ} \mathrm{C}$ trocknen

32) nach Abkühlen mit Aquatex eindeckeln

\subsubsection{Auswertung der RNA-in-situ-Hybridisierung}

Die Auswertung der RNA-in-situ-Hybridisierung erfolgte anhand der Empfehlungen des Herstellers (Tabelle 5). 
Tabelle 5: RNA-ISH-Auswertekriterien

\begin{tabular}{|c|c|}
\hline \multicolumn{2}{|c|}{ RNA-ISH-Bewertungs-Score (Wang et al. 2012) } \\
\hline Score 0 & $\begin{array}{l}\text { keine Färbung oder weniger als } 1 \text { Punkt in } \\
\text { je } 10 \text { Zellen bei } 40 \text { facher Vergrößerung }\end{array}$ \\
\hline Score 1 & $\begin{array}{l}\text { 1-3 Punkte pro Zelle bei } 20 \text {-40facher Ver- } \\
\text { größerung }\end{array}$ \\
\hline Score 2 & $\begin{array}{l}\text { 4-10 Punkte pro Zelle, sehr wenige Clus- } \\
\text { ter bei } 20-40 \text { facher Vergrößerung }\end{array}$ \\
\hline Score 3 & $\begin{array}{l}>10 \text { Punkte pro Zelle, weniger als } 10 \% \\
\text { der positiven Zellen haben Cluster bei } \\
\text { 20facher Vergrößerung }\end{array}$ \\
\hline Score 4 & $\begin{array}{l}>10 \text { Punkte pro Zelle, mehr als } 10 \% \text { der } \\
\text { Signale sind in Clustern gruppiert bei } \\
\text { 20facher Vergrößerung }\end{array}$ \\
\hline
\end{tabular}

Es wurde jeweils beurteilt, wie viel Prozent der Tumorzellen eines Falles einem jeweiligen Score entsprachen, z. B. Score 0: 0\%, Score 1: 10\%, Score 2: 50\%, Score 3: 40\%, Score 4: 0\%, sodass die Summe 100\% ergibt. Auf Grundlage dessen wurde der H-Score gemäß der folgenden Gleichung berechnet:

Score $0 * 0+$ score $1 * 1+$ score $2 * 2+$ score $3 * 3+$ score $4 * 4=\mathrm{x}$.

Im obigen Beispiel ergibt sich:

Score $0 * 0+$ Score $1 * 10+$ Score $2 * 50+$ Score $3 * 40+$ Score $4 * 0=230$.

In jedem Fall liegt das Ergebnis zwischen 0 und 400 maximal, wobei der cut-off bei einem HScore von $\geq 200$ gesetzt wurde. Fälle mit einem H-Score $\geq 200$ wurden als positiv bezüglich einer mRNA-Überexpression gewertet.

Als alternatives Kriterium für eine mRNA-Überexpression wurde der prädominante Score verwendet. Der prädominante Score bezeichnet den Score, der prozentual am häufigsten vertreten ist. Im Falle eines gleich häufigen Vorkommens mehrerer Scores wird der höchste gewählt. Eine mRNA-Überexpression wurde definiert ab einem prädominanten Score von 3. Schließlich wurden die Ergebnisse gemäß H-Score und die Ergebnisse gemäß prädominantem Score korreliert. Für die nachfolgenden statistischen Analysen wurde hingegen immer der HScore mit einem Schwellenwert von $\geq 200$ als Überexpressionskriterium zu Grunde gelegt.

\subsubsection{Molekulare Analysen}

\subsubsection{KRAS, NRAS, BRAF, PIK3CA}

Die Mutationsanalysen der Lebermetastasen für $K R A S$, NRAS und $B R A F$ wurden mittels der Qiagen therascreen kits (therascreen BRAF Pyro Kit, therascreen RAS Extension Pyro Kit, therascreen KRAS Pyro Kit, therascreen NRAS Pyro Kit) durchgeführt. Zunächst wurden die in Formalin 
fixierten und in Paraffin eingebetteten Gewebsschnitte (FFPE) deparaffinisiert und mit Hämatoxylin-Eosin eingefärbt. Für die DNA-Extraktion wurden unter dem Mikroskop relevante Tumorareale ausgewählt, abgekratzt und mittels des Qiagen AllPrep DNA/ RNA FFPE Kit (Qiagen, Hilden, Deutschland) wurde die DNA gemäß der Anweisung des Herstellers extrahiert (Jo et al. 2016). Nun wurden spezifische Regionen der extrahierten DNA mittels Primern im KRAS Pyro assay (Qiagen, Hilden, Deutschland) amplifiziert. Die amplifizierten DNASequenzen wurden nun fixiert, gewaschen und denaturiert. Nun wurde die Pyrosequenzierungsanalyse mit dem PyroMark Q24 Pyrosequencer (Qiagen, Hilden, Germany) durchgeführt. Mit dem KRAS Pyro Kit 24, V1 in Kombination mit dem RAS Extension Pyro Kit 24, V1 ist es möglich, Mutationen in den KRAS Codons 12, 13, 59, 61, 117 und 146 der humanen DNA zu identifizieren. Für den therascreen assay wurde die PyroMark Q24 MDx Plattorm und die Software Q24, Version 2.0.7 mit den KRAS PlugIn v1.2.0 und dem RAS Extention PlugIn v.1.2.1.2. verwendet (Jo et al. 2016).

Die PIK3CA-Mutationsanalyse der Lebermetastasen wurde mittels high resolution meltingAnalyse durchgeführt wie sie bei Ney et al. (Ney et al. 2012) beschrieben wurde. Die high resolution melting-Analyse ist eine effiziente und kostengünstige Methode, um Mutationen in doppelsträngiger DNA sichtbar zu machen (Reed et al. 2007). Hierzu wird zunächst eine PolymeraseKetten-Reaktion (PCR) durchgeführt, um den spezifischen DNA-Abschnitt zu vervielfältigen, in dem die Mutation erwartet wird. Die PCR-Produkte werden nun mit einem fluoreszierenden Farbstoff markiert, welcher ausschließlich doppelsträngige DNA bindet und dann hell aufleuchtet. Die PCR-Produkte werden auf ca. $90{ }^{\circ} \mathrm{C}$ erhitzt, sodass sich der DNADoppelstrang auftrennt. Der Schmelzpunkt eines PCR-Produkts wird dabei von der Basenabfolge bestimmt. Nach dem Auseinanderweichen des Doppelstrangs kann der fluoreszierende Farbstoff nicht mehr binden, sodass die Fluoreszenz abnimmt. Dieser Prozess wird zeitlich hochauflösend aufgezeichnet. Im Falle einer Mutation ist die Schmelzkurve verändert, welches beim Vergleich mit einer Wildtyp-DNA festgestellt werden kann. Für die Durchführung der high resolution melting-Analyse wurde der LightCycler 480 (Roche Diagnostics, Mannheim, Germany) verwendet. Zunächst wurde die DNA aus FFPE-Präparaten der Lebermetastasen isoliert, aufgereinigt und spektrometrisch (NanoDrop ND 1000 (Peqlab, Erlangen, Germany)) sowie über Agarose-Gelelektrophorese quantifiziert. Die PCR sowie die high resoultion meltingAnalyse wurden gemäß Anweisung des Herstellers durchgeführt. Die Schmelzkurven wurden mittels der Gene Scanning Software (Roche Diagnostics) ausgewertet und mit Wildtyp-DNA verglichen. Bei Vorhandensein einer Mutation wurde die Sanger-Sequenzierung zur genaueren Bestimmung durchgeführt. Tumoren mit auffälligen HRM-Schmelzkurven wurden nachfolgend zur Bestätigung der Mutation mit Sanger-Sequenzierung untersucht. 
Mittels der Sanger-Sequenzierung, auch Kettenabbruch-Methode genannt, lässt sich die Basenabfolge eines einzelsträngigen DNA-Abschnitts bestimmen. Die Methodik der SangerSequenzierung soll hier nur kurz umrissen werden. Es werden vier Ansätze bereitgestellt mit jeweils der zu bestimmenden einzelsträngigen DNA, einem zu deren 3'-Ende komplementären fluoreszenzmarkierten Primer, Desoxyribonucleosid-Triphosphate der vier Basen, eine DNA-Polymerase sowie Didesoxyribonucleosid-Triphosphate jeweils einer Base. Letztere führen bei Einbau zum Kettenabbruch an spezifischen Stellen. Nach Vermischen der vier Ansätze werden die DNA-Bruchstücke mittels Gel aufgetrennt und die komplementäre Basensequenz kann im Fluorometer ausgelesen werden (Montenarh 2007; Sanger und Coulson 1975). Für die Sanger-Sequenzierung wurde das BigDye Terminator v1.1 Cycle Sequencing Kit, der ABI Prism 3130 automatische Sequencer sowie zur Datenanalyse die Sequenzieranalyse Software (Applied Biosystems, Darmstadt, Germany) verwendet (Ney et al. 2012).

In den Primärtumoren wurde nur KRAS-Exon 2 analysiert.

\subsubsection{Analyse der Mikrosatelliteninstabilität (MSI)}

Mittels Immunhistochemie wurden die Lebermetastasen auf eine Mikrosatelliteninstabilität untersucht. Die Immunhistochemie basiert auf einer Bindung zwischen dem Antigen/ Epitop, welches im Gewebe vorliegt und einem spezifischen Antikörper. Dieser Primärantikörper wird wiederum von einem Sekundärantikörper gebunden, welcher mit einem Enzym gekoppelt ist, wodurch es nach Zugabe eines Substrats zur Farbreaktion kommt und die Bindung im Schnittpräparat sichtbar wird (Dietmaier et al. 1997).

Eine Mikrosatelliteninstabilität kann nun dadurch nachgewiesen werden, dass bestimmte Reparaturproteine (MLH1, MSH2, MSH6, PMS2) nicht exprimiert werden und daher - im Vergleich zum nicht-neoplastischen Stroma als interne Kontrolle - immunhistochemisch nicht angefärbt werden (Buecher et al. 2013). Die Immunhistochemie wurde unter Verwendung der unten aufgeführten, gebrauchsfertigen Antikörper gemäß dem in Göttingen etablierten Standardprotokoll durchgeführt (Tabelle 6).

Molekulare Analysen und MSI-Status lagen aus Routineuntersuchungen oder Analysen im Rahmen des MetastaSys-Projektes vor. 
Tabelle 6: Antikörper zur Analyse der Mikrosatelliteninstabilität

\begin{tabular}{lll}
\hline Proteine & Antikörper & Hersteller \\
\hline MLH1 & Clon ES05 & $\begin{array}{l}\text { Dako, Agilent technolo- } \\
\text { gies, Glostrup, Denmark }\end{array}$ \\
MSH2 & Clon FE11 \\
MSH6 & Clon Epi 49 \\
PMS2 & Clon EP51 & " \\
\hline
\end{tabular}

\subsubsection{Datenanalyse}

Die Datenanalyse wurde mit dem Statistik-Software-Programm R, Version 3.2.2 sowie mit dem SPSS Statistik Programm (SPSS 22.0, IBM, Armonk, NY, USA) durchgeführt. Das VennDiagramm zur Visualisierung der Primärtumoren mit FGFR-Aberrationen wurde mit dem $\mathrm{R}$ Softwarepaket (Version 1.6.17) erstellt. Für die statistischen Auswertungen zu den Überlebensdaten wurde das R Softwarepaket „Survival“ (Version 2.40) verwendet (Therneau 2015). Die Kaplan-Meier-Kurven für das Gesamt- und das krebsspezifische Überleben wurden mittels des Log-rank-Tests miteinander verglichen. Ferner wurden der exakte Test nach Fisher sowie der Chi-Quadrat-Test zum Vergleich von FGFR-positiven und -negativen Fällen hinsichtlich klinischer und molekularer Parameter verwendet. Mittels des t-Tests wurde das Alter der Patienten mit FGFR-positiven und -negativen Tumoren verglichen. Alle Tests waren zweiseitig; $\mathrm{p}<0,05$ wurde als signifikant gewertet. 


\section{Ergebnisse}

\section{1 mRNA-Überexpression von FGFR1-3}

Mittels RNA-in-situ-Hybridisierung (RNAScope) wurden 140 Primärtumoren und 63 Lebermetastasen hinsichtlich einer mRNA-Überexpression von FGFR1-3 untersucht.

Jeder Patientenfall ist in der Auswertung nur einmal vertreten, auch wenn von einzelnen Patienten mitunter mehrere Metastastasen untersucht wurden. Von den drei Patienten mit multiplen Metastasen wurden die Metastasen mit den höchsten H-Scores für FGFR3 in die Wertung eingeschlossen.

Die Ergebnisse sind in Tabelle 7 dargestellt, wobei die Prozentwerte immer auf die Anzahl der auswertbaren Fälle hin berechnet wurden.

\section{Tabelle 7: mRNA-Überexpression von FGFR1-3 (H-Score)}

\begin{tabular}{llll}
\hline Überexpression & \multicolumn{2}{l}{$\begin{array}{l}\text { Primärtumoren } \\
\text { positiv/auswertbar }\end{array}$} & $\begin{array}{l}\text { Lebermetastasen } \\
\text { positiv/auswertbar }\end{array}$ \\
\hline FGFR1 & $10 / 99(10,1 \%)$ & & $4 / 47(8,5 \%)$ \\
& & & $\begin{array}{l}\text { K: } 7 / 46(15,2 \%) \\
\text { R: } 3 / 53(5,7 \%)\end{array}$ \\
FGFR2 & $5 / 91 \quad(5,5 \%)$ & K: $4 / 36(11,1 \%)$ & $0 / 45(0 \%)$ \\
& & R: $1 / 55(1,8 \%)$ & $7 / 47(14,9 \%)$ \\
FGFR3 & $18 / 111(16,2 \%)$ & K: $11 / 58(19,0 \%)$ & \\
& & R: $7 / 53(13,2 \%)$ & \\
\hline
\end{tabular}

Tabelle 7: K, Kolon; R, Rektum; mRNA-Überexpression von FGFR1-3 gemessen mittels HScore $\geq 200$.

Die FGFR3-mRNA-Überexpression stellte mit $16,2 \%$ in den Primärtumoren und $14,9 \%$ in den Lebermetastasen für beide Entitäten die häufigste FGFR-Alteration dar. In Kolonkarzinomen war sie mit 19\% etwas häufiger zu beobachten als in Rektumkarzinomen mit 13,2\%. Der H-Score der FGFR3-überexprimierenden Lebermetastasen reichte von 200 bis 360, der prädominante Score lag in der Mehrzahl der Fälle bei 4 (Abbildung 3c und 3d, Tabelle 8), in 
zwei Fällen auch bei 2. Bei den Primärtumoren ergab sich ein ähnliches Bild mit H-Scores zwischen 200 und 340 und prädominanten Scores zwischen 2 und 4.

Die Primärtumoren, welche eine FGFR1-mRNA-Überexpression zeigten (10,1\%), wiesen HScores zwischen 210 und 340 und prädominante Scores von 2 oder 3 auf. In den Kolonkarzinomen war eine FGFR1-Überexpression mit 15,2\% häufiger zu beobachten als in Rektumkarzinomen mit 5,7\%. Bei den FGFR1-überexprimierenden Metastasen (8,5\%) lagen die HScores zwischen 200 und 260, die prädominanten Scores bei 2 oder 3 (Tabelle 8).

Eine FGFR2-mRNA-Überexpression fand sich in unserer Kohorte nur in Primärtumoren (5,5\%), jedoch nicht in Lebermetastasen. In den Primärtumoren trat die FGFR2Überexpression vor allem in Kolonkarzinomen $(11,1 \%)$, hingegen weniger in Rektumkarzinomen (1,8\%) auf. Bei den positiven Fällen zeigten sich H-Scores von 200 bis 310 sowie prädominante Scores zwischen 2 und 4.

Neben der Tatsache, dass die FGFR3-Überexpression in Primärtumoren und Metastasen die häufigste Alteration darstellt, lässt sich auch beobachten, dass FGFR1-, FGFR2- und FGFR3Überexpressionen häufiger in Kolonkarzinomen als in Rektumkarzinomen vorkommen, wobei sich dies prozentual am deutlichsten für FGFR2 zeigt. Wenn man sich die Lokalisation des Primärtumors bei den Lebermetastasen anschaut, haben drei der vier FGFR1-positiven Metastasen ihren Primarius im Kolon und eine im Rektum. Bei den FGFR3-positiven Metastasen ist das Verhältnis hingegen umgekehrt; dort befinden sich fünf der Primarien im Rektum und zwei im Kolon.

In insgesamt sechs Fällen zeigte sich eine mRNA-Überexpression von mehr als einem FGFRezeptor. Dabei handelte es sich um fünf Kolonkarzinome und ein Rektumkarzinom; in den Lebermetastasen konnte dieses Phänomen nicht beobachtet werden. In drei Fällen bestand eine simultane Überexpression von FGFR1 und FGFR3; in zwei Fällen wurden gleichzeitig FGFR2 und FGFR3 überexprimiert und in einem Fall zeigte sich eine Überexpression von FGFR1, FGFR2 und FGFR3 (Abbildung 3a und 3b; Tabelle 8 letzter Abschnitt).

Die einzelnen Fälle, die eine mRNA-Überexpression der verschiedenen FGFRs aufwiesen, die klinischen Daten, die molekulare Subtypisierung sowie eine Gegenüberstellung der Ergebnisse von Überexpression (RNA-ISH) und Genamplifikation (FISH) sind in Tabelle 8 dargestellt. Es sind sowohl die prädominanten Scores als auch die H-Scores angegeben, wobei für die im Folgenden dargestellten statistischen Analysen eine FGFR-Überexpression immer anhand des H-Scores mit einem Schwellenwert $\geq 200$ definiert wurde. 

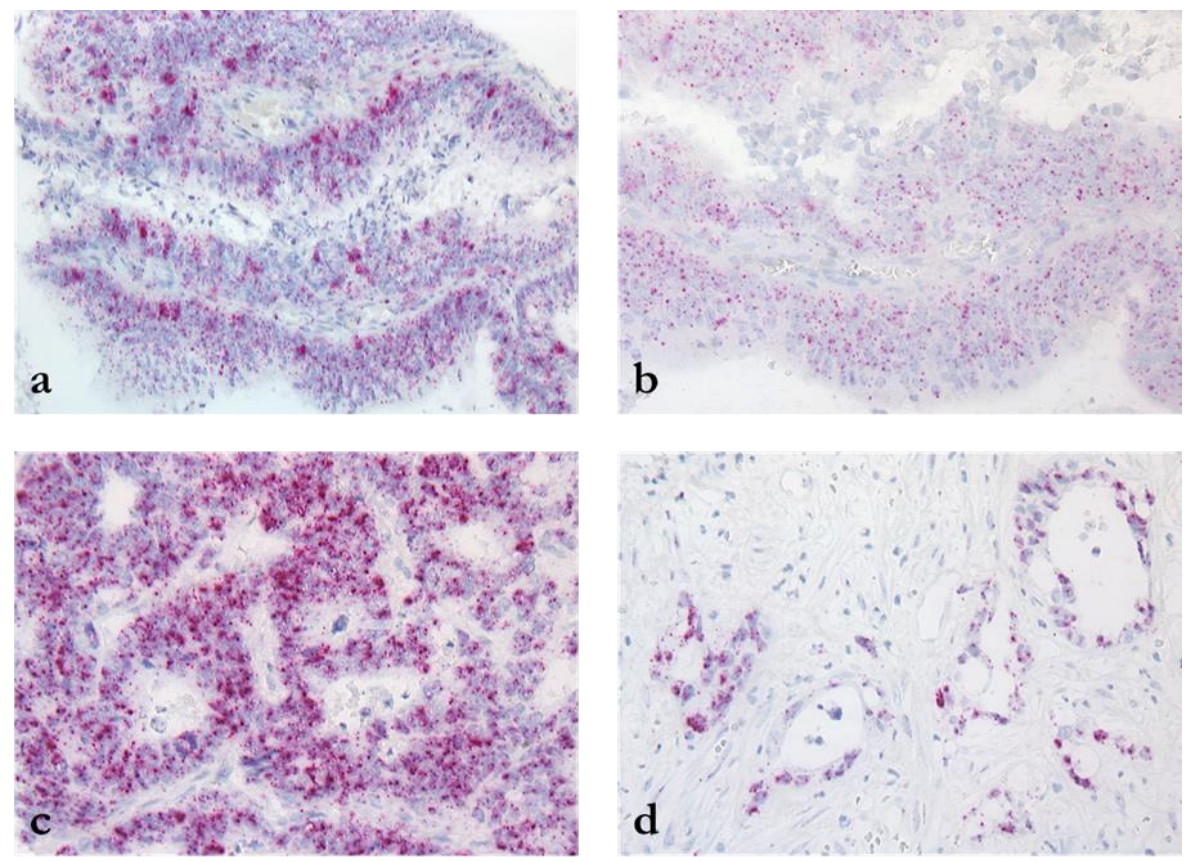

Abbildung 3: RNA-Überexpression in Primärtumoren und Lebermetastasen

a)+b) FGFR1 (a) und FGFR2 (b) überexprimierendes Kolonkarzinom; H-Score 250 und 220, präd. Score 3 für beide Rezeptoren; c) FGFR3 überexprimierende LM; H-Score 350, präd. Score 4; (d) FGFR3 überexprimierende LM, H-Score 360, präd. Score 4.

Präd. Score, prädominanter Score; LM, Lebermetastase.

Abbildung modifiziert nach Fromme et al. 2018 


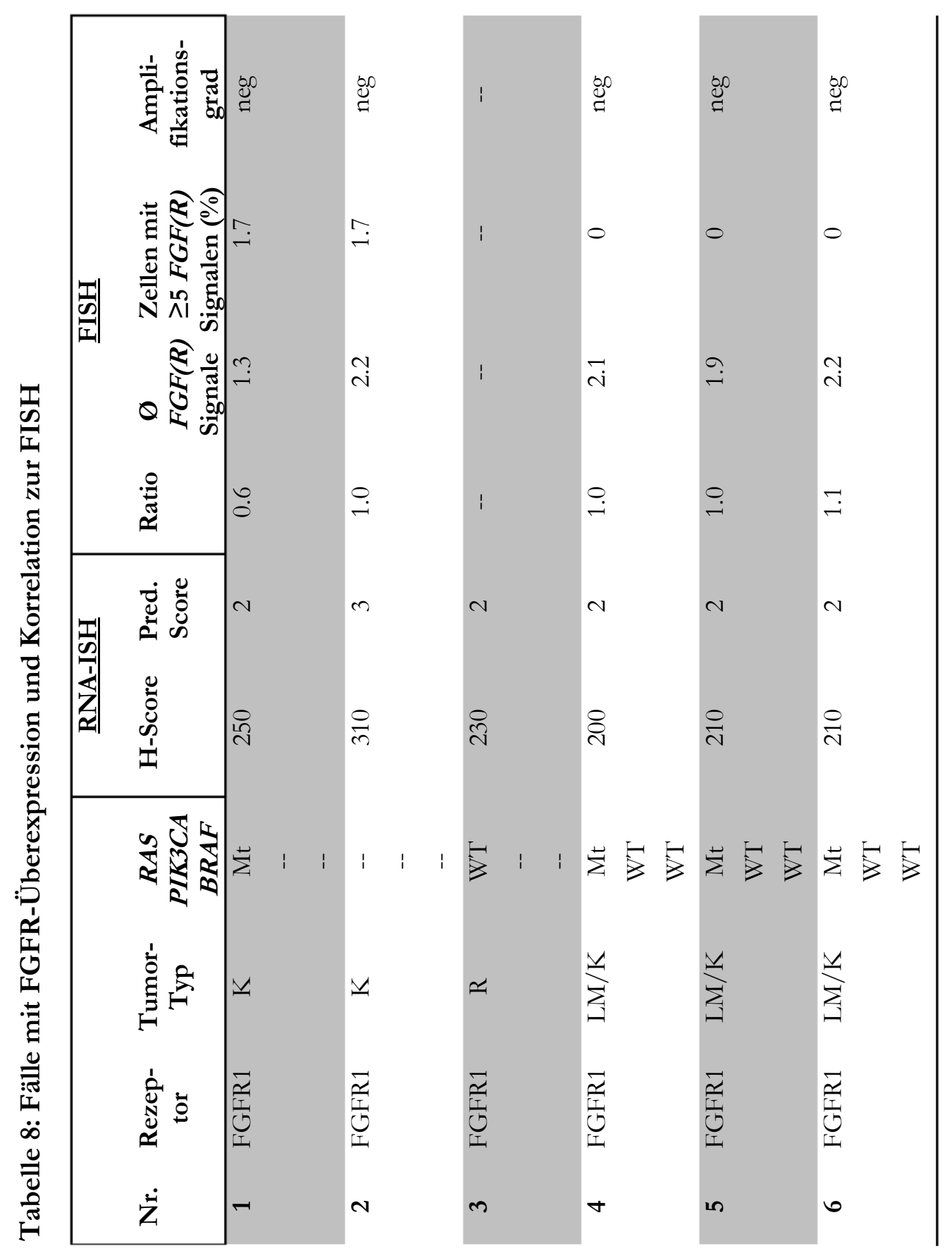




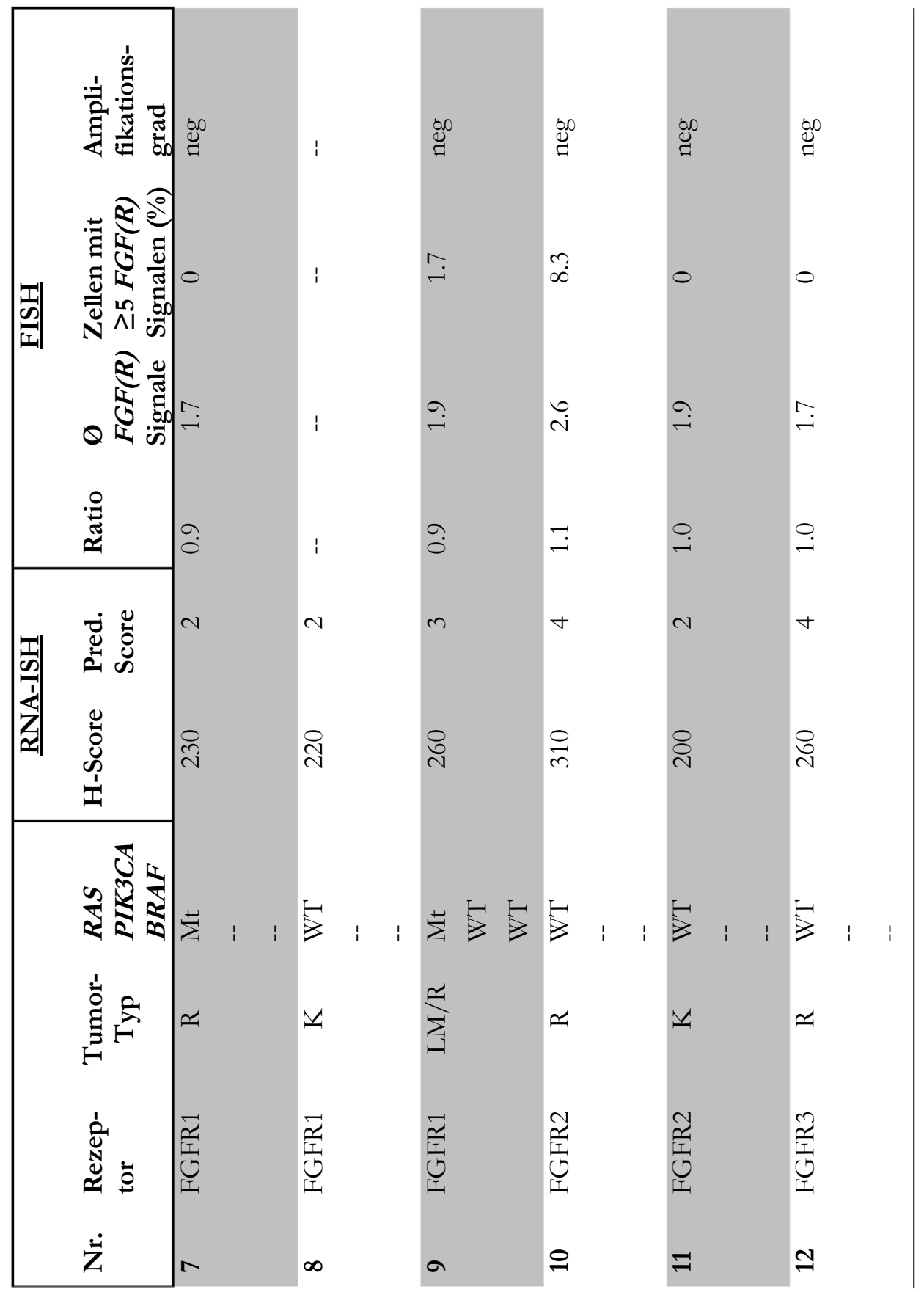




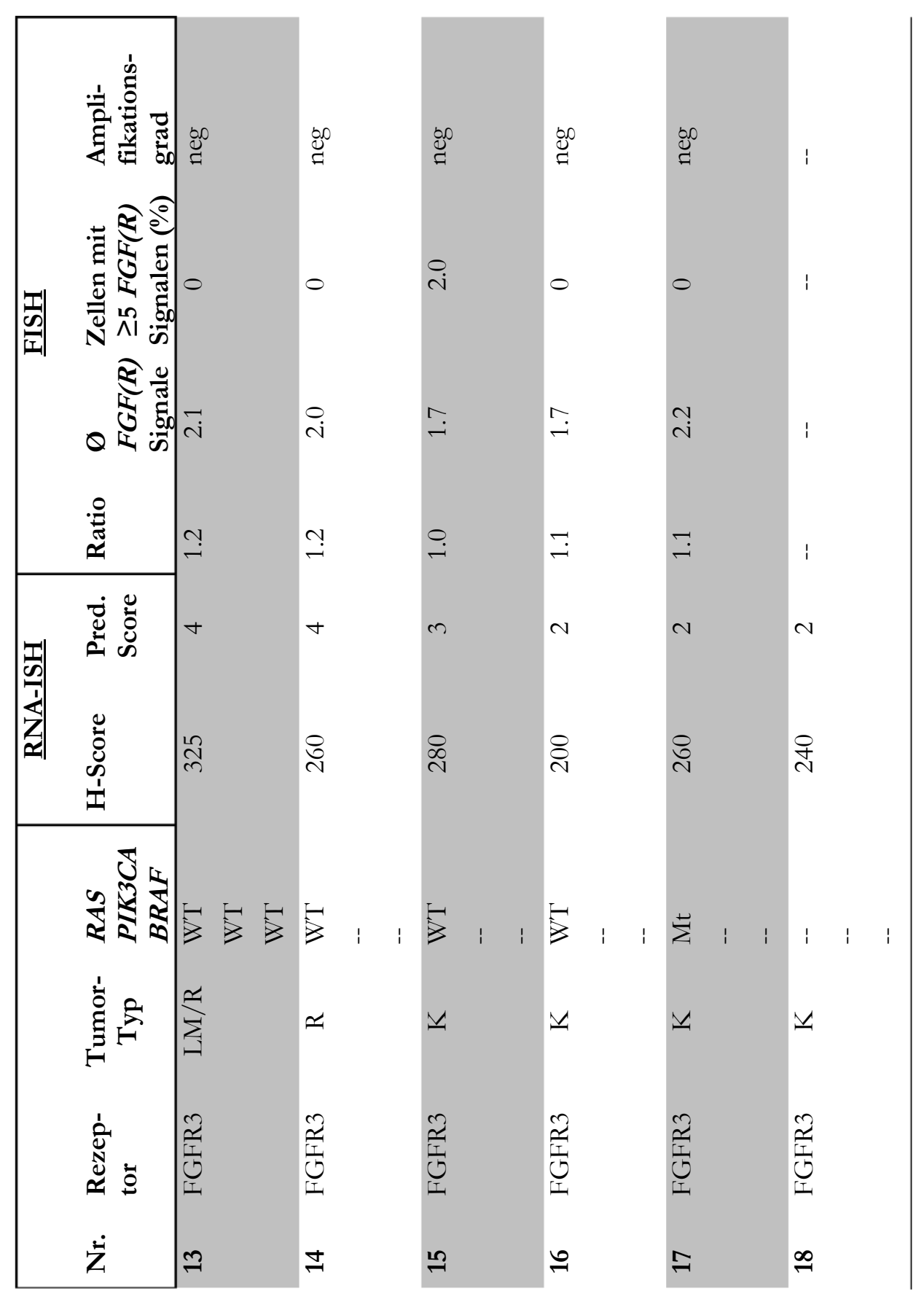




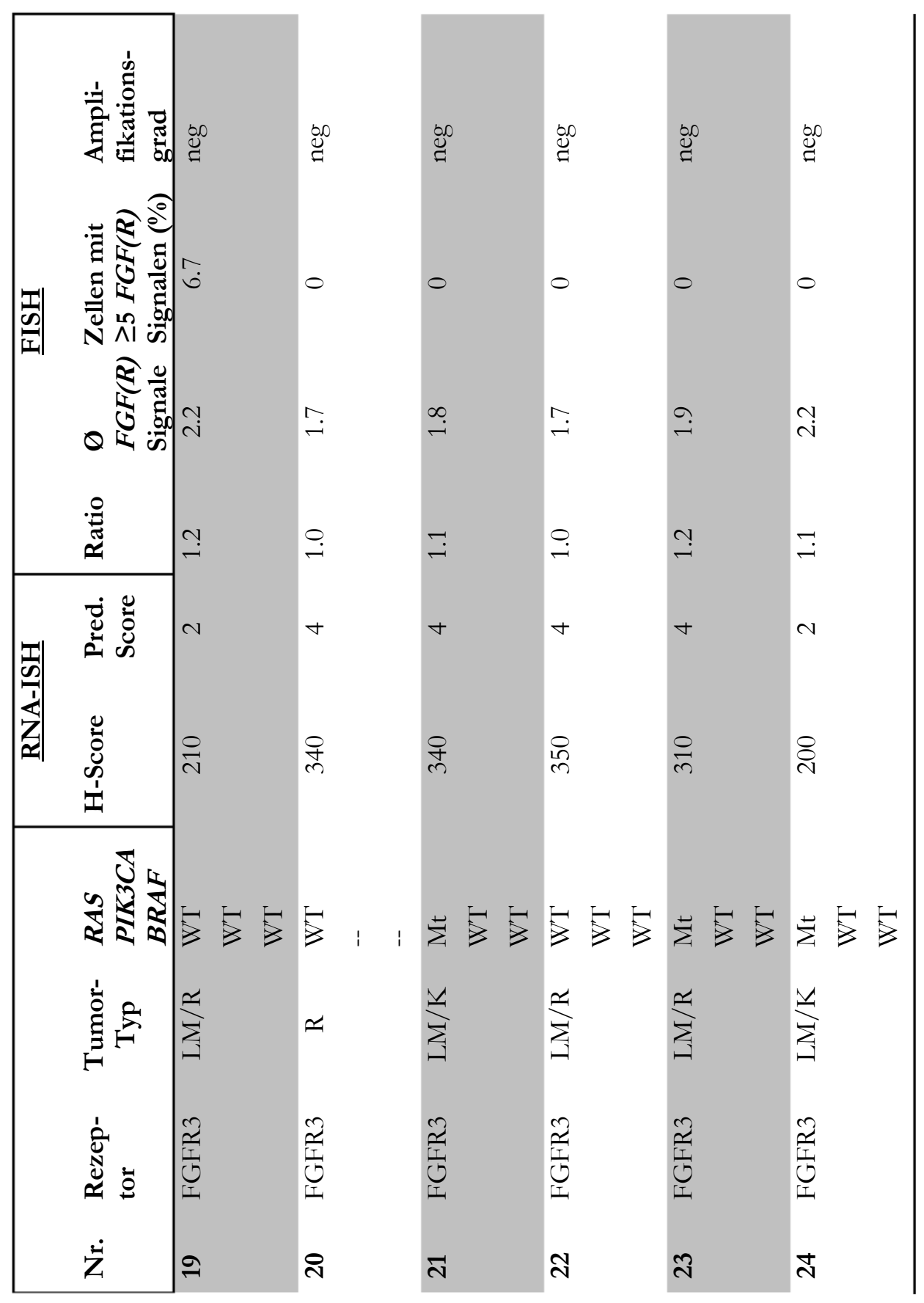




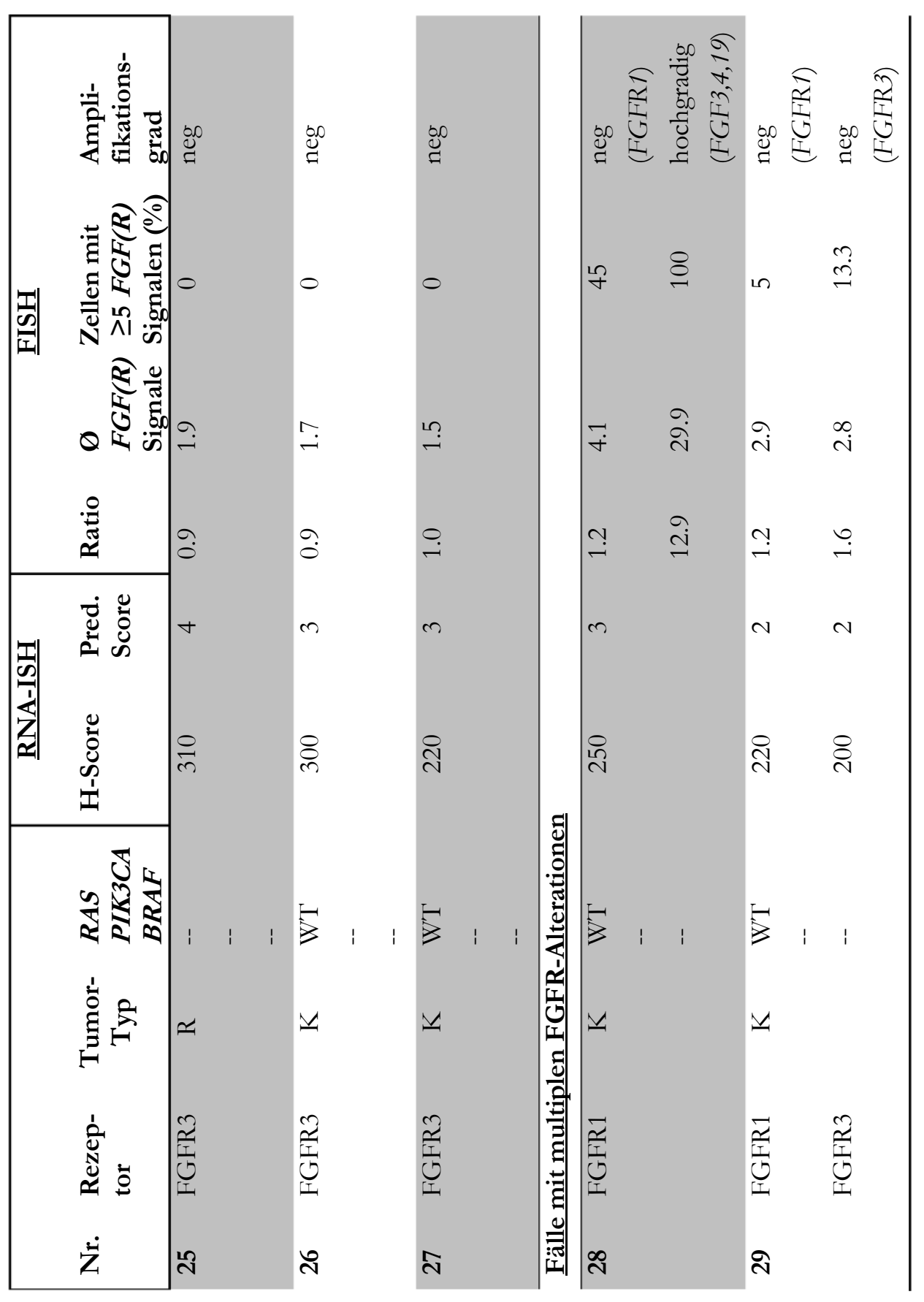




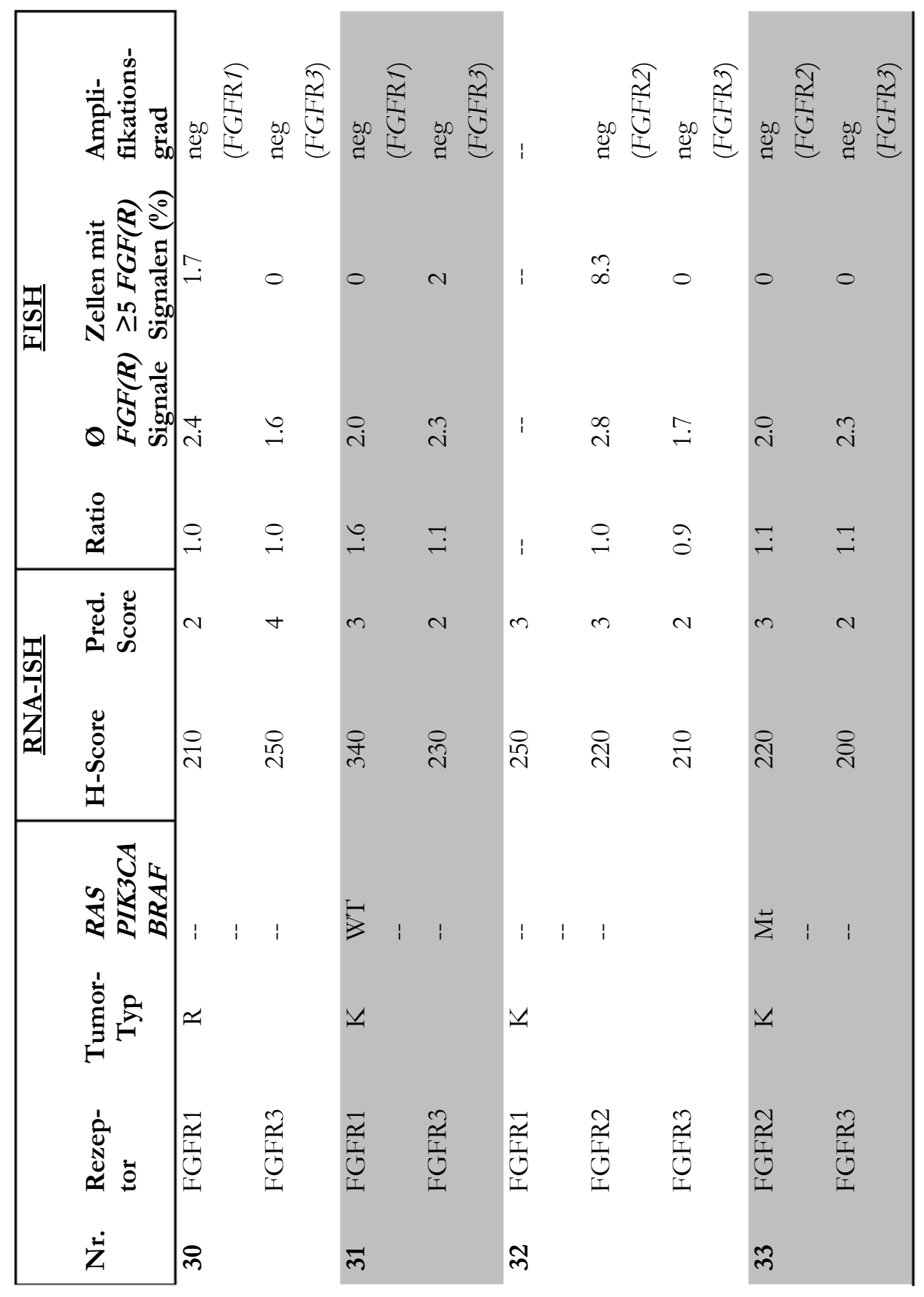




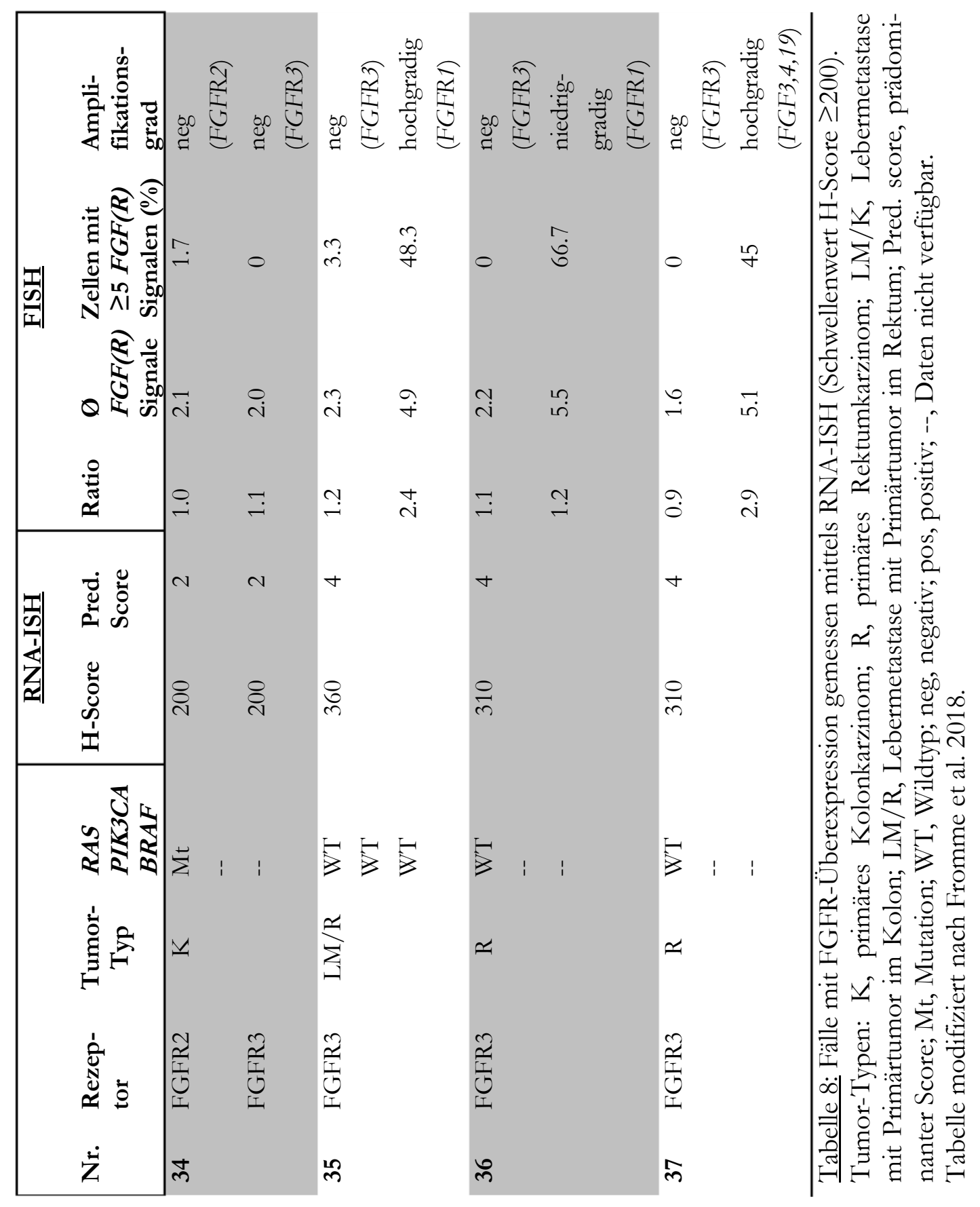


Als weiteres Kriterium für eine FGFR-Überexpression wurde neben dem H-Score auch der prädominante Score bestimmt, wobei ein Schwellenwert $\geq 3$ zugrunde gelegt wurde. Die Ergebnisse für eine FGFR-Überexpression gemäß prädominantem Score $\geq 3$ sind in Tabelle 9 zum Vergleich dargestellt. Es zeigen sich hier größtenteils geringere Prozentraten für die einzelnen Rezeptoren sowohl bei den Primarien als auch bei den Lebermetastasen. Einige Ergebnisse sind hingegen gleich geblieben, so z. B. die FGFR2- und die FGFR3Überexpressionsraten bei den Rektumkarzinomen sowie die Tatsache, dass es bei beiden Scores keine FGFR2-überexprimierenden Lebermetastasen gibt.

Tabelle 9: mRNA-Überexpression von FGFR1-3 (prädominanter Score)

\begin{tabular}{llll}
\hline Überexpression & \multicolumn{2}{l}{$\begin{array}{l}\text { Primärtumoren } \\
\text { positiv/auswertbar }\end{array}$} & $\begin{array}{l}\text { Lebermetastasen } \\
\text { positiv/auswertbar }\end{array}$ \\
\hline FGFR1 & $4 / 99 \quad(4,0 \%)$ & K: $4 / 46(8,7 \%)$ & $1 / 47(2,1 \%)$ \\
& & R: $0 / 53(0 \%)$ & $0 / 45(0 \%)$ \\
FGFR2 & $3 / 91 \quad(3,3 \%)$ & K: $2 / 36(5,6 \%)$ & \\
& & R: $1 / 55(1,8 \%)$ & $6 / 47(12,8 \%)$ \\
FGFR3 & $10 / 111(9,0 \%)$ & K: $3 / 58(5,2 \%)$ \\
& & R: $7 / 53(13,2 \%)$ & \\
\hline
\end{tabular}

Tabelle 9: mRNA-Überexpression von FGFR1-3 gemessen mittels prädominantem Score (Schwellenwert prädominanter Score $\geq 3$ ); K, Kolon; R, Rektum.

Die Ergebnisse bei Zugrundelegen des H-Scores sowie die Ergebnisse unter Berücksichtigung des prädominanten Scores wurden getrennt nach Primärtumoren und Metastasen statistisch miteinander korreliert. Bezüglich FGFR3 zeigte sich hier eine hochsignifikante Korrelation (Exakter Test nach Fisher $\mathrm{p} \leq 0,001)$ für die Kohorte der Metastasen. Hinsichtlich FGFR2 wurden bei Zugrundelegen beider Scores keine positiven Lebermetastasen beobachtet. Lediglich für FGFR1 ergab sich ein geringer Unterschied in den beiden Scores (Exakter Test nach Fisher, $\mathrm{p}=0,085)$. Bei den Primärtumoren korrelierten beide Scores für FGFR1, FGFR2 und FGFR3 hochsignifikant (Chi-Quadrat-Test $\mathrm{p} \leq 0,001)$. 


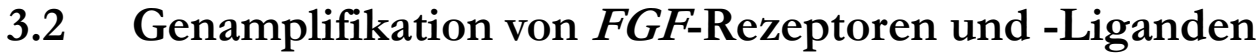

Mittels Fluoreszenz-in-situ-Hybridisierung wurden 140 Primärtumoren und 63 Lebermetastasen hinsichtlich Genamplifikationen der FGF-Rezeptoren 1-4 sowie der FGF-Liganden 3,4, und 19 untersucht.

Wie in Tabelle 10 dargestellt, konnten FGFR1-Genamplifikationen sowohl in Primärtumoren (6,3\%), als auch in Metastasen (4,8\%) gefunden werden. Vier der fünf FGFR1-amplifizierten Primärtumore stammten aus dem Rektum und auch bei den beiden FGFR1-amplifizierten Metastasen war der Primärtumor im Rektum lokalisiert. FGFR2-, FGFR3- und FGFR4Amplifikationen fanden sich weder in Primärtumoren noch in Metastasen. FGF3,4,19Amplifikationen traten in 2,2\% der Primärtumoren auf, hingegen nicht in den Metastasen (Tabelle 10).

Tabelle 10: FGFR-Genamplifikationen

\begin{tabular}{|c|c|c|c|}
\hline & $\begin{array}{l}\text { Primärtumoren } \\
\text { positiv/auswertbar }\end{array}$ & & $\begin{array}{l}\text { Lebermetastasen } \\
\text { positiv/auswertbar }\end{array}$ \\
\hline \multirow[t]{3}{*}{ FGFR1-Amplifikation } & $5 / 80(6,3 \%)$ & & $2 / 42(4,8 \%)$ \\
\hline & & $\mathrm{K}: 1 / 36(2,8 \%)$ & \\
\hline & & R: $4 / 44(9,1 \%)$ & \\
\hline \multirow[t]{3}{*}{ FGFR2-Amplifikation } & $0 / 96(0 \%)$ & & $0 / 46(0 \%)$ \\
\hline & & $\mathrm{K}: 0 / 52(0 \%)$ & \\
\hline & & R: $0 / 44(0 \%)$ & \\
\hline \multirow[t]{3}{*}{ FGFR3-Amplifikation } & $0 / 78(0 \%)$ & & $0 / 44(0 \%)$ \\
\hline & & $\mathrm{K}: 0 / 44(0 \%)$ & \\
\hline & & R: $0 / 34(0 \%)$ & \\
\hline \multirow[t]{3}{*}{ FGFR4-Amplifikation } & $0 / 70(0 \%)$ & & $0 / 34(0 \%)$ \\
\hline & & $\mathrm{K}: 0 / 40(0 \%)$ & \\
\hline & & R: $0 / 30(0 \%)$ & \\
\hline \multirow{3}{*}{$\begin{array}{l}\text { FGF3,4,19- } \\
\text { Amplifikation }\end{array}$} & $2 / 89(2,2 \%)$ & & $0 / 51(0 \%)$ \\
\hline & & $K: 1 / 43(2,3 \%)$ & \\
\hline & & R: $1 / 46(2,2 \%)$ & \\
\hline
\end{tabular}

Tabelle 10: K, Kolon; R, Rektum.

\subsubsection{FGFR1}

Von 80 auswertbaren, mit der FGFR1-Sonde hybridisierten Primärtumoren wiesen fünf (6,3\%) eine FGFR1-Amplifikation auf. Von diesen wiederum zeigten drei ein hohes Amplifi- 
kationsniveau (FGFR1/CEN8-Ratio $\geq 2,0$ oder durchschnittliche FGFR1-Genkopienzahl $\geq 6,0$ oder $\geq 15$ FGFR1-Genkopien/Zelle in $\geq 10 \%$ der Tumorzellen) mit einer FGFR1/CEN8-Ratio von 2,1, 3,0 und 4,4 und zwei ein geringes Amplifikationsniveau (Prozentzahl der Tumorzellen mit $\geq 5$ FGFR1-Genkopien ist $\geq 50 \%$ ) mit $\geq 5$ FGFR1-Genkopien pro Zelle in 60,0\% und 66,7\% der Tumorzellen (Tabelle 11). Bei einem der fünf FGFR1amplifizierten Primärtumoren lag eine $\mathrm{R} A S$-Mutation vor, die anderen waren $\mathrm{R} A S$-Wildtyp.

Bei den 42 auswertbaren Lebermetastasen betrug die Rate der FGFR1-amplifizierten Fälle 4,8\%. Beide FGFR1-amplifizierten Lebermetastasen zeigten ein hohes Amplifikationsniveau mit einer FGFR1/CEN8-Ratio von 2,4 und 2,0 (Abbildung 4, Tabelle 11). Der Primärtumor der Metastase mit einer Ratio von 2,0 sowie ein Lymphknoten wurden ebenfalls untersucht; interessanterweise zeigten beide kein hohes, sondern ein niedriges Amplifikationsniveau. Der Primärtumor stammte aus dem Kolon und wies eine FGFR1/CEN8-Ratio von 1,9, eine durchschnittliche FGFR1-Genkopienzahl von 5,0 sowie in 50\% Zellen $\geq 5$ FGFR1Genkopien auf. Ähnliche Werte zeigten sich in der Lymphknotenmetastase (FGFR1/CEN8Ratio 1,9, durchschnittliche FGFR1-Genkopienzahl 5,7 sowie $\geq 5$ FGFR1-Genkopien in 65\% der Zellen). In der molekularen Subtypisierung wiesen beide amplifizierten Metastasen weder eine $R A S$-, BRAF- oder PIK3CA-Mutation noch eine Mikrosatelliteninstabilität auf.
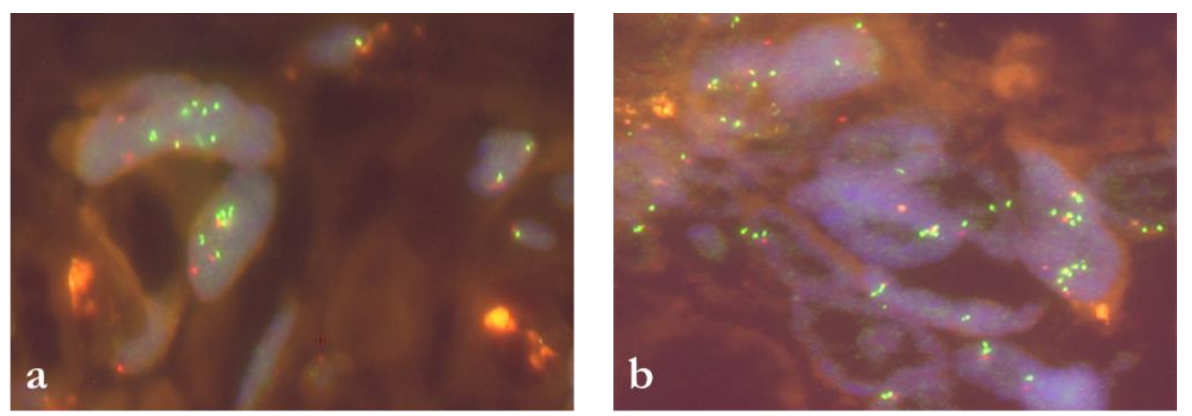

\section{Abbildung 4: FGFR1-amplifizierte Lebermetastasen}

a) Lebermetastase mit Primarius im Rektum, hohes Amplifikationsniveau für FGFR1 (Fromme et al. 2018), b) weitere Lebermetastase mit Primarius im Rektum, hohes Amplifikationsniveau für FGFR1 (Fromme und Schildhaus 2018)

Die durchschnittliche FGFR1/CEN8-Ratio der FGFR1-negativen Primärtumoren betrug 0,971 \pm 0,259 (Spanne 0,4-1,7) und die durchschnittliche FGFR1-Genkopienzahl lag bei 2,145 \pm 0,0646 (Spanne 1,2-4,2) pro Tumorzelle. Bei den Lebermetastasen betrug die durchschnittliche FGFR1/CEN8-Ratio 1,030 \pm 0,0341 (Spanne 0,5-1,4) und die durchschnittliche FGFR1Genkopienzahl 1,938 \pm 0,0554 (Spanne 1,1-2,7) pro Tumorzelle. 
Weiterhin fiel auf, dass 23 Primärtumoren und zehn Metastasen eine Ratio <1,0 aufwiesen, davon neun Primärtumoren und drei Lebermetastasen mit einer Ratio von 0,4 bis 0,6, was mitunter auch auf eine Polysomie der Zellkerne zurückzuführen war.

\subsubsection{FGFR2}

Von den mit der FGFR2-Sonde hybridisierten Tumorproben konnten 96 Primärtumoren und 46 Lebermetastasen ausgewertet werden. Hierbei fanden sich in beiden Kohorten keine FGFR2-amplifizierten Fälle. In den Primärtumoren betrug die durchschnittliche FGFR2/CEN10-Ratio 1,022 \pm 0,0148 (Spanne 0,7-1,6) und die durchschnittliche FGFR2Genkopienzahl 2,194 \pm 0,0450 (Spanne 1,5-4,4) pro Tumorzelle; in den Metastasen fand sich eine durchschnittliche FGFR2/CEN10-Ratio von 1,161 \pm 0,0274 (Spanne 0,8-1,7) und eine durchschnittliche FGFR2-Genkopienzahl von 2,131 \pm 0,0753 (Spanne 1,3-4,2). In fünf Fällen fanden sich mitunter einzelne amplifizierte Zellen mit $\geq 15$ FGFR2-Signalen in 1.7\% bis 4.4\% der Tumorzellen.

\subsubsection{FGFR3}

In den beurteilbaren 78 Primärtumoren und 44 Lebermetastasen fanden sich keine FGFR3amplifizierten Fälle. In den Primärtumoren lag die durchschnittliche FGFR3/CEN4-Ratio bei 1,057 \pm 0,0137 (Spanne 0,8-1,6) und die durchschnittliche FGFR3-Genkopienzahl bei 1,819 \pm 0,0397 (Spanne 1,2-2,9) pro Tumorzelle; in den Metastasen fand sich eine durchschnittliche FGFR3/CEN4-Ratio von 1,177 $\pm 0,0306$ (Spanne 0,7-1,9) und eine durchschnittliche FGFR3-Genkopienzahl von 2,070 \pm 0,0671 (Spanne 1,2-3,9). Eine Lebermetastase mit dem Primarius im Rektum verfehlte die Amplifikationskriterien nur knapp mit einer FGFR3/CEN4-Ratio von 1,9. Weiterhin wies diese Metastase eine durchschnittliche FGFR3Genkopienzahl von 3,9 auf und in 28,3\% der Tumorzellen konnten $\geq 5$ Signale beobachtet werden.

\subsubsection{FGFR4}

FGFR4-amplifizierte Fälle fanden sich keine in den auswertbaren 70 Primärtumoren und 34 Lebermetastasen. Die durchschnittliche FGFR4/CEN5-Ratio lag bei 1,022 \pm 0,0135 (Spanne 0,8-1,5) und die durchschnittliche FGFR4-Genkopienzahl bei 1,981 \pm 0,0443 (Spanne 1,4-3,9) pro Tumorzelle in den Primärtumoren. In den Metastasen fand sich eine durchschnittliche FGFR4/CEN5-Ratio von 0,958 \pm 0,0272 (Spanne 0,6-1,5) und eine durchschnittliche FGFR4-Genkopienzahl von 1,804 \pm 0,0389 (Spanne 1,5-2,7). Die Qualität der Signale war mit der FGFR4-Amplifikationssonde oft unzureichend, sodass für diese Sonde die Zahl nicht auswertbarer Fälle in beiden Kohorten am höchsten war. 


\subsubsection{FGF3,4,19}

Eine FGF3,4,19-Amplifikation zeigte sich in zwei der 89 auswertbaren Primärtumoren (2,2\%), jedoch in keiner der 51 beurteilbaren Lebermetastasen. In einem der beiden Fälle, einem Kolonkarzinom, ließ sich ein außergewöhnlich hohes Amplifikationsniveau mit einer FGF3,4,19/CEN11-Ratio von 12,9 und einer durchschnittlichen FGF3,4,19-Genkopienzahl von 29,9 beobachten. Die Anzahl der Tumorzellen mit $\geq 5$ FGF3,4,19-Signalen betrug nahezu 100\%. Die FGF3,4,19-Fluoreszenz-Signale waren insgesamt kleiner im Durchmesser (Abbildung 5a).

Die durchschnittliche FGF3,4,19/CEN11-Ratio der 87 FGF3,4,19-negativen Primärtumoren betrug 1,001 \pm 0,0116 (Spanne 0,8-1,3) und die durchschnittliche FGF3,4,19-Genkopienzahl 2,006 \pm 0,0314 (Spanne 1,0-2,8) pro Tumorzelle. Bemerkenswerterweise lag die durchschnittliche FGF3,4,19-Genkopienzahl in 39 Primärtumoren unter 2,0; in einem Fall lag sie sogar bei 1,0. Die FGF3,4,19/CEN11-Ratio lag mindestens bei 0,8. In der Kohorte der Lebermetastasen lag die durchschnittliche FGF3,4,19/CEN11-Ratio bei 1,138 \pm 0,0279 (Spanne 0,7-1,9) und die durchschnittliche FGF3,4,19-Genkopienzahl bei 2,241 \pm 0,0642 (Spanne 1,6-4,4) pro Tumorzelle.
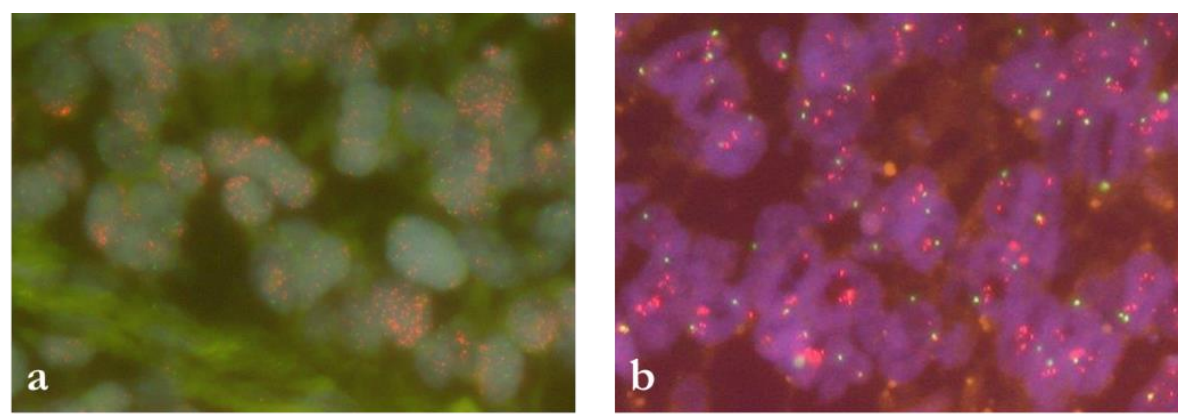

\section{Abbildung 5: FGF3,4,19-Amplifikation in den Primärtumoren}

a) rechtsseitig lokalisiertes Kolonkarzinom mit hohem Amplifikationsniveau für FGF3,4,19,

b) Rektumkarzinom mit ebenfalls hohem Amplifikationsniveau für FGF3,4,19 (Fromme et al. 2018) 


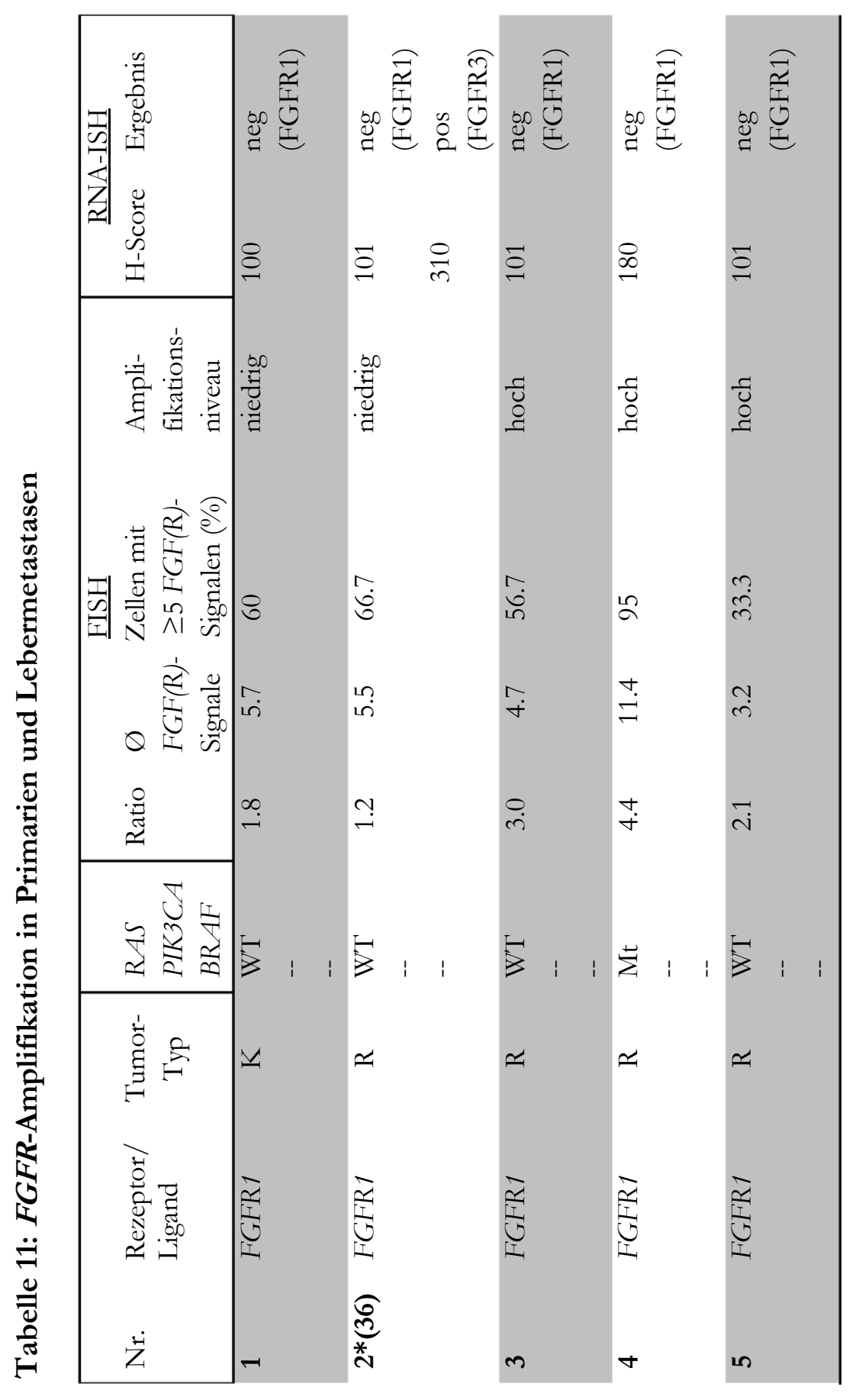




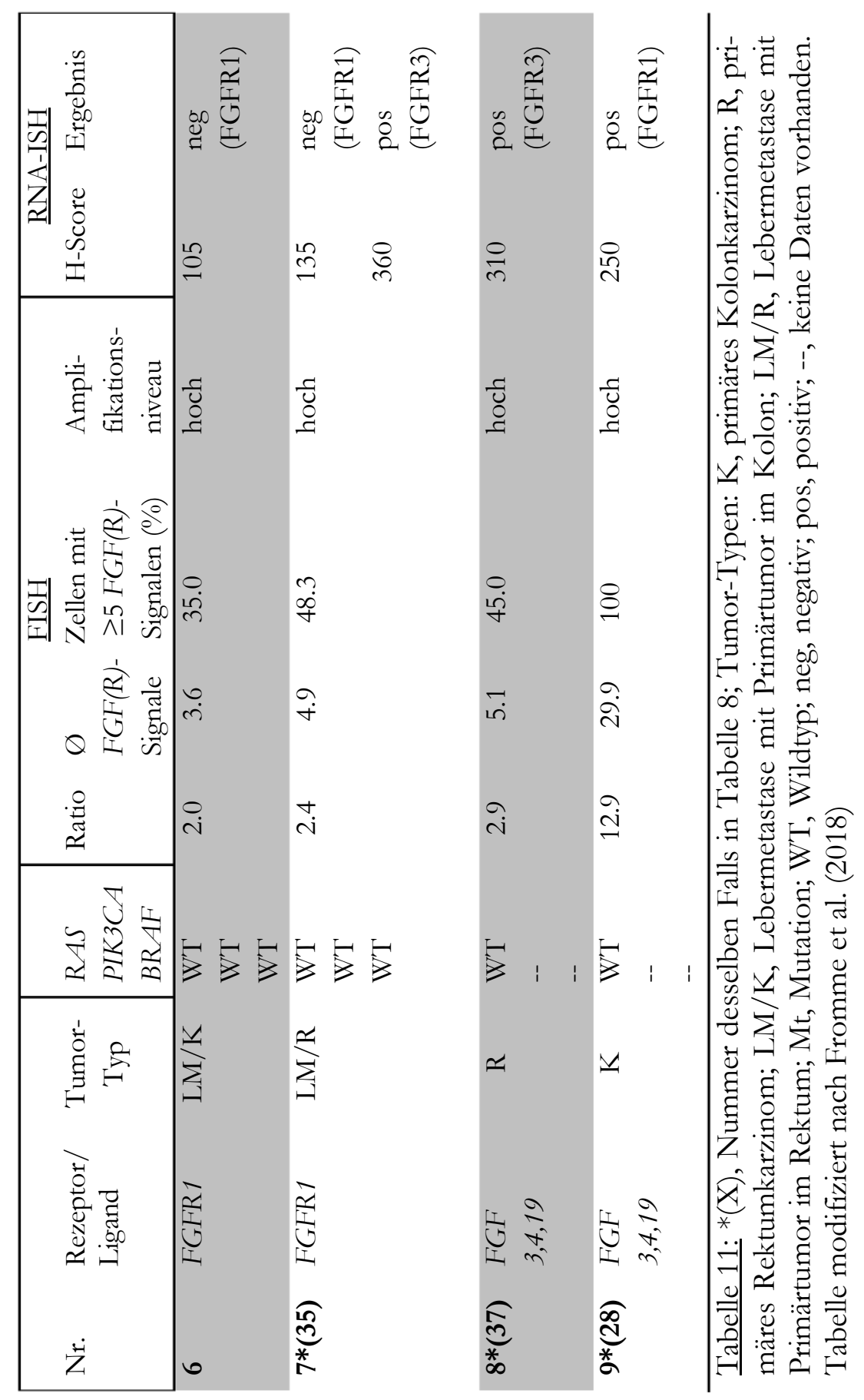




\subsection{Untersuchung auf Translokationen von FGFR1 und FGFR3}

\subsubsection{Mittelwertbestimmung aberranter Signale für die FGFR1- und FGFR3- Translokationssonden in Tonsillen und Plattenepithelkarzinomen}

Für die Auswertung der FGFR1- und FGFR3-Translokationssonden wurde zunächst ein Mittelwert der Zellen mit aberranten Signalen in Plattenepithelkarzinomen des Oropharyngealtrakts und Tonsillen bestimmt. Der Mittelwert wird im Folgenden zusammen mit dem Standardfehler des Mittelwerts in Prozent angegeben.

Von den mit der FGFR1-Translokationssonde hybridisierten Plattenepithelkarzinomen und Tonsillen konnten 95 von 108 Präparaten ausgewertet werden. Größtenteils fanden sich gute Fluoreszenz-Signale und ausreichend Gewebe. Der Mittelwert der Tumorzellen mit break apart-Phänomenen betrug 0,611\% \pm 0,1586, wobei maximal 10\% der Tumorzellen break aparts aufwiesen.

Überdies wurde auch das Auftreten von extra 5'-Signalen und extra 3'-Signalen in den Tumorzellen analysiert. Der Mittelwert der Tumorzellen mit extra 5'-Signalen betrug 2,4421\% \pm 0,21621 und der Median 2,00\%. Das Minimum der Tumorzellen mit extra 5'-Signalen lag bei 0\%, das Maximum bei 10\%. Ähnliche Werte zeigten sich bei den Zellen mit extra 3'-Signalen. Deren Mittelwert lag bei 2,5684\% \pm 0,19550 und der Median bei 2,00\%. Das Minimum der Zellen mit extra 3'-Signalen betrug 0\%, das Maximum 6\% (Tabelle 12).

Nach Hybridisierung mit der FGFR3-Translokationssonde konnten 92 von 108 Proben analysiert werden, wobei sich ein Mittelwert der Tumorzellen mit break apart-Phänomenen von 0,065\% $\pm 0,0372$ ergab. Die maximale Anzahl der gezählten Zellen mit break aparts betrug hier lediglich $2 \%$.

Der Mittelwert der Tumorzellen mit extra 5'-Signalen lag hier bei 1,5000\% \pm 0,18708 und der Median bei 1,00\%; das Maximum lag bei 8\% und das Minimum bei 0\%. Der Mittelwert der Zellen mit extra 3'-Signalen betrug 0,4565\% \pm 0,10754 und der Median 0,00\%; das Minimum lag bei $0 \%$ und das Maximum bei 6\% (Tabelle 12). 
Tabelle 12: Mittelwertbestimmung FGFR1- und FGFR3-Translokationssonde

\begin{tabular}{lllll}
\hline $\begin{array}{l}\text { Translokations- } \\
\text { Sonde }\end{array}$ & $\begin{array}{l}\text { Ermittelter MW } \\
\mathrm{BA}+3 \mathrm{SD}(\%)\end{array}$ & $\begin{array}{l}\text { Ermittelter MW } \\
\text { extra 5'-Signal } \\
\text { 3 SD }(\%)\end{array}$ & $\begin{array}{l}\text { Ermittelter MW } \\
\text { extra 36-Signal } \\
\text { 3 SD }(\%)\end{array}$ & $\begin{array}{l}\text { Publizierter } \\
\text { SW* } \%)\end{array}$ \\
\hline FGFR1 & 5,26 & 8,8 & 8,28 & \\
FGFR3 & 1,13 & 6,88 & 3,56 & 15
\end{tabular}

Tabelle 12: MW, Mittelwert; BA, break apart, SD, standard deviation; SW, Schwellenwert; *nur unter Einbeziehung von break aparts ermittelt

Nach der Methode von Finelli et al. können Schwellenwerte bestimmt werden durch den Mittelwert zuzüglich drei Standardabweichungen (Finelli et al. 1999). In Tabelle 12 sind die für dieses Kollektiv bestimmten Mittelwerte dargestellt. Daraus ergibt sich, dass der Schwellenwert zur Auswertung der Translokationssonden nicht unter den hier bestimmten Werten von 5,26\% für die FGFR1-Sonde und 1,13\% für die FGFR3-Sonde liegen sollte. Dies steht im Einklang mit der Literatur, die 15\% beschreibt (Finelli et al. 1999; Turkmen et al. 2014). Um falsch positive Ergebnisse zu vermeiden, wurde für die weiteren Analysen der von Finelli et al. herangezogene „strengere“ cut-off-Wert von 15\% angewendet (Finelli et al. 1999). Dieser wurde anhand von zytologischen Untersuchungen in Lymphozyten ermittelt. Die hier untersuchten Tonsillen und Plattenepithelkarzinome lagen hingegen als FFPE-Material vor, was den Unterschied in den Werten teilweise erklären kann. 


\subsubsection{Auswertung der $\boldsymbol{F G F R}$-Translokationssonden}

Zur Auswertung der Translokationen wurde wie oben beschrieben der von Finelli et al. definierte Schwellenwert zu Grunde gelegt, d. h. ein Tumor mit break apart-Phänomenen in mindestens 15\% der Tumorzellen wurde als positiv bezüglich einer FGFR-Translokation gewertet.

Tabelle 13: Auswertung der FGFR1- und FGFR3-Translokationssonden

\begin{tabular}{|c|c|c|}
\hline & Primärtumoren (\%) & Lebermetastasen (\%) \\
\hline \multirow[t]{3}{*}{ FGFR1-Translokation } & $0 / 81(0 \%)$ & $0 / 45(0 \%)$ \\
\hline & & \\
\hline & & \\
\hline \multirow[t]{3}{*}{ FGFR3-Translokation } & $0 / 93(0 \%)$ & $0 / 43(0 \%)$ \\
\hline & & \\
\hline & & \\
\hline
\end{tabular}

Tabelle 13: K, Kolon; R, Rektum.

\subsubsection{Ergebnisse der FGFR1-Translokationssonde}

Von den mit der FGFR1-Sonde hybridisierten Primärtumoren konnten 81 Tumoren ausgewertet werden. Es zeigte kein Tumor ein Rearrangement des für FGFR1 kodierenden Gens (Tabelle 13). Im Mittel wiesen die Primärtumoren 1,470\% \pm 0,2249 break apart-Phänomene auf, der Median lag bei 0,00\% und die Prozentzahl der break aparts reichte von 0 bis 10\%, wobei über die Hälfte der Primärtumoren kein break apart aufwies.

Extra 5'-Signale traten etwas häufiger in Primärtumoren auf. Der Mittelwert lag hier bei 6,00\% \pm 1,59668 und der Median bei 4,00\%. In den meisten Fällen lag die Zahl der Tumorzellen mit extra 5 -Signalen bei $2 \%$ (in 24,7\% der Fälle). Interessanterweise zeigten zwei Primärtumoren eine außergewöhnlich hohe Anzahl an extra 5'-Signalen. In einem Rektumkarzinom ließen sich in einem fokalen Areal in mehr als 90\% der Tumorzellen extra 5'-Signale beobachten, wohingegen das restliche Tumorgewebe Fusionssignale aufwies (Abbildung 6a und 6b). Ein Kolonkarzinom zeigte in über 90\% der Tumorzellen extra 5'-Signale (Abbildung 6c).

Der Mittelwert der extra 3'-Signale lag bei 3,5802\% \pm 0,32908 in den Primärtumoren, der Median bei 4,00\%, wobei die Spanne von 0\% bis 14\% extra 3'-Signale reichte.

Von den mit der FGFR1-Sonde hybridisierten Lebermetastasen konnten 45 Metastasen ausgewertet werden. Keine davon zeigte ein Rearrangement des für FGFR1 kodierenden Gens (Tabelle 13). Im Mittel zeigten die Lebermetastasen 1,438\% \pm 0,3080 break apart-Phänomene und der Median lag bei 0,00\%, wobei die Spanne von 0\% bis 10\% break aparts reichte. 
Bei den extra 5'-Signalen lag der Mittelwert bei 6,5333\% \pm 1,54449 und der Median bei 6,00\%. In den meisten Fällen lag die Zahl der Zellen mit extra 5'-Signalen bei 6\% (in 35,6\% der Fälle). In einer Lebermetastase konnten außergewöhnlich viele extra 5'-Signale beobachtet werden. Es zeigten sich in $72 \%$ der Tumorzellen extra 5'-Signale; davon in $24 \%$ der Zellen sogar jeweils zwei extra 5'-Signale und in 10\% der Zellen drei extra 5'-Signale (Abbildung 6d).

Der Mittelwert der extra 3'-Signale lag in den Lebermetastasen bei 3,1556\% \pm 0,28061, der Median bei 2,00\%, wobei die Spanne von $0 \%$ bis $8 \%$ extra 3'-Signalen reichte.

Bei der FGFR1-Translokationssonde zeigte sich somit kein nennenswerter Unterschied zwischen Primärtumoren und Metastasen.
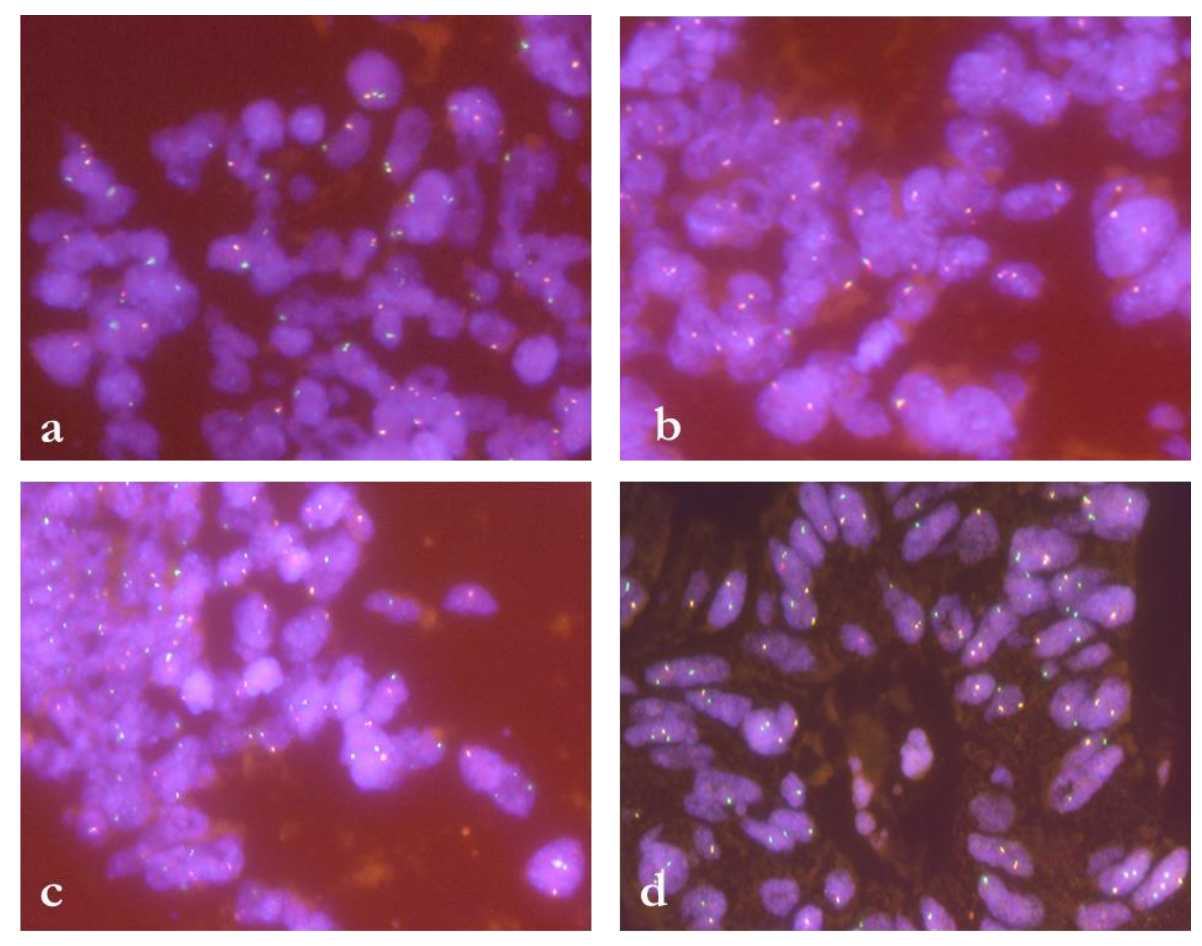

\section{Abbildung 6: FGFR1-break apart-Sonde, Fälle mit vermehrt extra 5'-Signalen}

a) + b) Rektum-Karzinom mit a) extra 5'-Signalen in fokalem Areal, b) verbleibendes Areal ohne extra 5'-Signale; c) Kolonkarzinom mit in bis zu 90\% der Tumorzellen extra 5'-Signale; d) Lebermetastase mit Primarius im Rektum, vermehrt extra 5'-Signale in gesamtem Tumorareal.

\subsubsection{Ergebnisse der FGFR3-Translokationssonde}

Von den mit der FGFR3-Translokationssonde hybridisierten Primärtumoren konnten 93 Tumoren ausgewertet werden. Auch hier zeigte kein Tumor ein Rearrangement des für FGFR3 kodierenden Gens (Tabelle 13). Im Mittel zeigten die Primärtumoren 1,247\% \pm 0,1858 break apart-Phänomene, der Median lag bei 0,00\%, wobei die Spanne von 0\% bis 8\% break aparts reichte. Bei den extra 5'-Signalen lag der Mittelwert bei 7,4624\% \pm 0,60475 und der Median 
bei $6,00 \%$. Es ergab sich ein Maximum von 28\% extra $5^{6}$-Signalen und rund 29\% der Fälle wiesen $\geq 10 \%$ extra grüne Signale auf.

Der Mittelwert der extra 3'-Signale lag bei $1,3548 \% \pm 0,18132$, der Median bei 0,00\%, wobei die Spanne von 0\% bis 6\% extra 3'-Signalen reichte.

Um die hohe Anzahl der extra 5'-Signale, welche vor allem in den Primärtumoren auftraten, $\mathrm{zu}$ verifizieren, wurden die betreffenden Primärtumoren zusätzlich mit der ZytoLight SPEC FGFR3 Break Apart/FGFR2/FGFR1 Quadruple Farbsonde hybridisiert. Mit dieser Sonde zeigte sich eine Reduktion der extra 5'-Signale (Tabelle 14).

\section{Tabelle 14: Hybridisierung mit der Quadruple-Sonde bezüglich FGFR3}

\begin{tabular}{|c|c|c|}
\hline Tumor-Typ & $\begin{array}{l}\text { FGFR3 BA Sonde Agilent } \\
\text { extra 5'-Signale }\end{array}$ & $\begin{array}{l}\text { FGFR3 BA Quadruple Sonde } \\
\text { extra 5'-Signale }\end{array}$ \\
\hline$\overline{\mathrm{R}}$ & 6 & 3 \\
\hline $\mathrm{R}$ & 7 & 0 \\
\hline $\mathrm{R}$ & 14 & 5 \\
\hline $\mathrm{R}$ & 13 & 6 \\
\hline $\mathrm{R}$ & 7 & 2 \\
\hline $\mathrm{R}$ & 6 & 1 \\
\hline $\mathrm{K}$ & 11 & 3 \\
\hline K & 7 & 2 \\
\hline K & 7 & 2 \\
\hline K & 9 & 2 \\
\hline $\mathrm{K}$ & 7 & 5 \\
\hline K & 7 & 2 \\
\hline K & 9 & 2 \\
\hline K & 6 & 2 \\
\hline $\mathrm{K}$ & 12 & 1 \\
\hline K & 9 & 1 \\
\hline $\mathrm{K}$ & 6 & 2 \\
\hline K & 6 & 3 \\
\hline
\end{tabular}

Tabelle 14: Reduktion der extra 5'-Signale bei Hybridisierung mit der Quadruple-Sonde (dargestellt sind Primärtumoren mit $>10 \%$ extra 5'-Signalen); K, Kolon; R, Rektum.

Von den mit der FGFR3-Translokationssonde hybridisierten Lebermetastasen konnten 43 Metastasen ausgewertet werden. Keine davon zeigte ein Rearrangement des FGFR3-Gens (Tabelle 13). Im Mittel zeigten die Lebermetastasen 0,791\% \pm 0,2413 break aparts und der Median lag bei $0,00 \%$, wobei die Spanne von $0 \%$ bis $8 \%$ break aparts reichte. Bei den extra 5'- 
Signalen lag der Mittelwert bei 5,9070\% \pm 0,61345 und der Median ebenfalls bei 6,00\%. Es ergab sich ein Maximum von 22\% extra 5'-Signalen (Abbildung 7).

Der Mittelwert der extra 3'-Signale lag bei 1,5814\% \pm 0,25394, der Median bei 2,00\%, wobei die Spanne von $0 \%$ bis 6\% extra 3'-Signalen reichte.
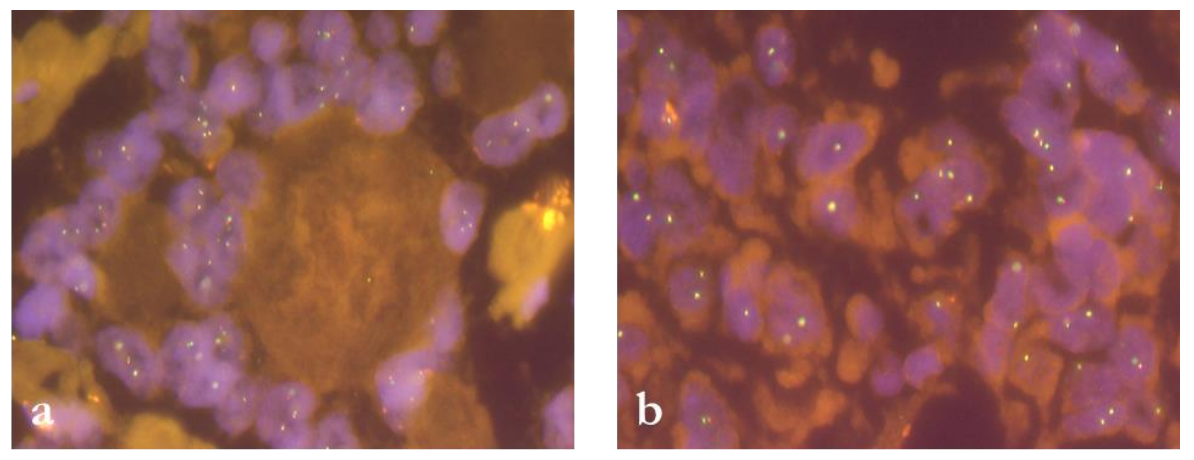

Abbildung 7: Fluoreszenz-in-situ-Hybridisierung mit FGFR3-Translokationssonde

Vereinzelt extra 5'-Signale in a) Lebermetastase mit Primarius im Rektum, b) Lebermetastase mit Primarius im Kolon

Zusammenfassend bleibt festzuhalten, dass weder in Primärtumoren noch in Lebermetastasen FGFR1- oder FGFR3-Rearrangements beobachtet werden konnten bei einem cut-off von 15\%.

\subsection{Zusammenschau der verschiedenen FGFR-Signalweg-Alterationen}

In der Zusammenschau der verschiedenen FGFR-Signalweg-Alterationen wiesen 30 Primärtumoren, davon 17 Kolon- und 13 Rektumkarzinome, und 12 Metastasen eine Alteration der FGF-Rezeptoren oder -Liganden auf. Darunter gab es auch Fälle, welche multiple FGFRezeptor- oder -Liganden-Alterationen zeigten (Tabelle 8, „Fälle mit multiplen FGFRAlterationen"). Es handelte sich dabei um neun Primärtumoren, davon sechs meist rechtsseitig gelegene Kolonkarzinome und drei Rektumkarzinome sowie eine Lebermetastase mit dem Primärtumor im Rektum. Eine Zusammenschau der verschiedenen, sich teils überschneidenden FGFR-Aberrationen ist für die Primärtumoren im Venn-Chart dargestellt (Abbildung 8). Eine FGFR1-Amplifikation trat entweder isoliert auf oder war mit einer FGFR3-mRNAÜberexpression vergesellschaftet. FGF3,4,19-Amplifikationen waren in beiden Fällen mit einer FGFR-mRNA-Überexpression vergesellschaftet; einmal mit einer FGFR1-, im anderen Fall mit einer FGFR3-Überexpression. Jedoch bleibt festzuhalten, dass in den Fällen, in denen eine genomische Amplifikation und eine mRNA-Überexpression gleichzeitig auftraten, diese nie den gleichen Rezeptor betrafen. Eine mRNA-Überexpression von mehr als einem FGFRezeptor wurde in mehreren Fällen beobachtet (Tabelle 8, „Fälle mit multiplen FGFRAlterationen“). Die Patienten, welche mehrere FGFR-Alterationen aufwiesen $(n=10)$, hatten 
über die gesamte Kohorte hinweg ein signifikant höheres Alter als Patienten mit nur einer FGFR-Alteration ( $\mathrm{n}=32$; $\mathrm{t}$-Test $\mathrm{p}=0,027,71$ vs. 80 Jahre).

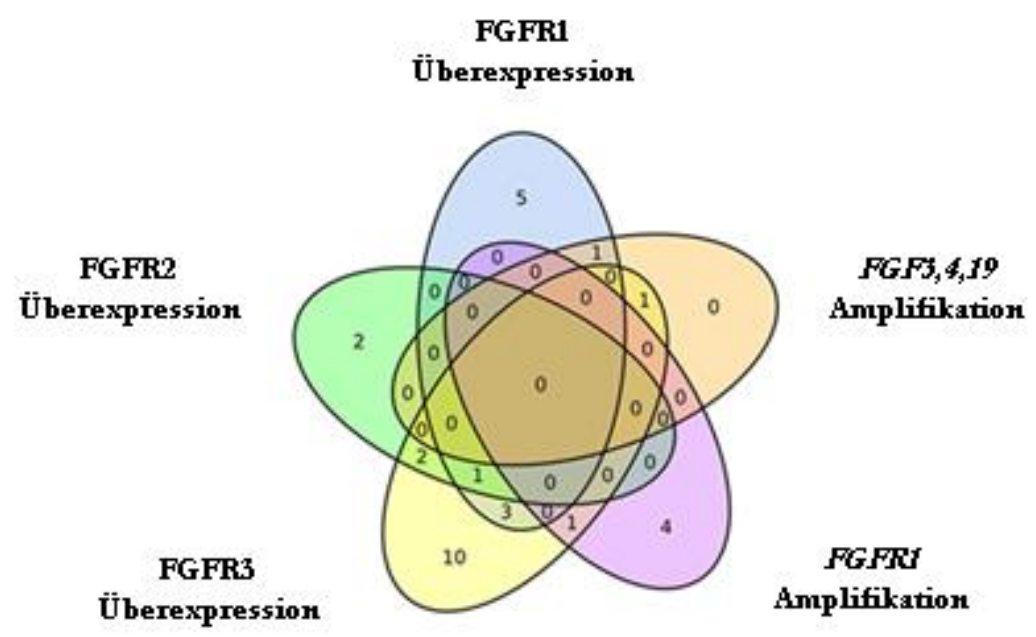

Abbildung 8: Alterationen von FGF-Rezeptoren und -Liganden in Primärtumoren

Einige Primärtumoren zeigen mehrere FGFR-Alterationen, modifiziert nach Fromme et al. (2018)

\subsection{Korrelation der Ergebnisse}

\subsubsection{Korrelation von $\boldsymbol{F G F ( R ) - G e n a m p l i f i k a t i o n ~ u n d ~ m R N A - U ̈ b e r e x p r e s s i o n ~ m i t ~}$ klinisch-pathologischen Daten}

Für die Kohorte der Lebermetastasen fand sich kein signifikanter Zusammenhang zwischen FGFR1-Amplifikationen und Überexpressionen von FGFR1 oder FGFR3 und klinisch pathologischen Parametern wie Alter des Patienten, Geschlecht oder Lokalisation des Primärtumors (Kolon vs. Rektum, rechtsseitiges vs. linksseitiges Kolon).

Jedoch zeigte sich eine signifikante Korrelation zwischen dem Vorhandensein von FGF(R)Alterationen und dem Gesamt- und krebsspezifischen Überleben der Patienten. Bei den Metastasen ging die FGFR3-mRNA-Überexpression mit einem signifikant kürzeren Gesamtüberleben (Log-rank-Test, $\mathrm{p}=0,0152, \mathrm{HR}=3,14$ [1,19-8,31]; Abbildung 9B, Tabelle 15) sowie krebsspezifischen Überleben einher (Log-rank-Test, $\mathrm{p}=0,00497, \mathrm{HR}=3,8[1,4-10,35])$. 

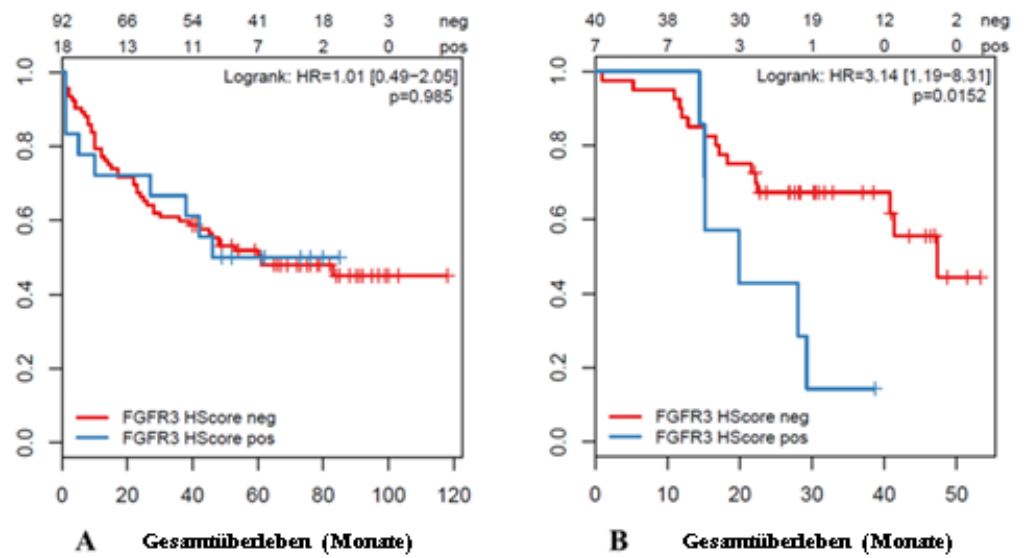

\section{Abbildung 9: Prognostische Relevanz einer FGFR3-Überexpression}

Gesamtüberleben in Monaten von Patienten mit FGFR3-mRNA-Überexpression in Primärtumoren (A) und in Metastasen (B), modifiziert nach Fromme et al. 2018

Auch für Metastasen mit einer FGFR1-Amplifikation fand sich ein signifikant reduziertes Gesamtüberleben (Log-rank-Test, $\mathrm{p}=0,00111, \mathrm{HR}=8,83$ [1,82-42,95], 12,6 vs. 47,4 Monate, Tabelle 15, Abbildung 10B).

Da jedoch nur zwei Metastasen eine FGFR1-Amplifikation aufwiesen, ist die Anzahl positiver Fälle sehr gering und weitere Studien mit größeren Fallzahlen sind erforderlich, um die Ergebnisse zu bestätigen. Für die Metastasen, welche eine FGFR1-mRNA-Überexpression aufwiesen, fand sich kein signifikanter Zusammenhang mit dem Gesamt- oder krebsspezifischen Überleben.

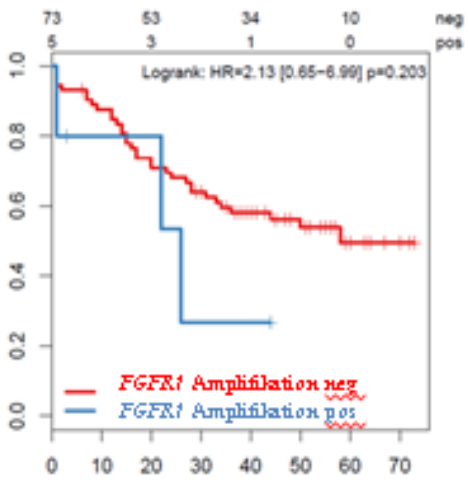

A Gesammiberleben (Monate)

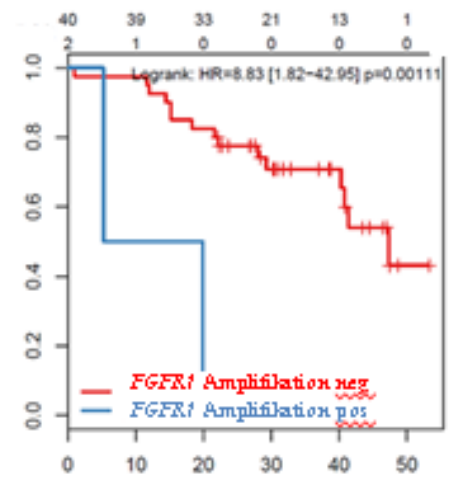

B Gesamtiberleben (Monate)

\section{Abbildung 10: Prognostische Relevanz einer FGFR1-Amplifikation}

Gesamtüberleben in Monaten von Patienten mit einer FGFR1-Amplifikation in Primärtumoren (A) und in Metastasen (B) 
Die Primärtumoren, welche eine FGFR1- oder FGF3,4,19-Amplifikation oder eine FGFR1-, FGFR2- oder FGFR3-Überexpression aufwiesen, zeigten keine positive Korrelation mit klinisch-pathologischen Parametern wie Alter, Geschlecht, Größe des Primärtumors, Lokalisation des Primärtumors beim Kolonkarzinom (rechtsseitiges vs. linksseitiges Kolon), bestehender Lymphknoteninfiltration, bestehender Fernmetastasierung oder dem Gesamtüberleben. Im Gegensatz zu den Metastasen oligometastasierter kolorektaler Karzinome bestand in kolorektalen Primärtumoren kein Zusammenhang zwischen einer FGFR3-Überexpression und dem Gesamtüberleben der Patienten (Log-rank-Test, $\mathrm{p}=0,985$, HR=1,01 [0,49-2,05]; Abbildung 9A). Da aus der Kohorte der Primärtumoren 33 Tumoren (23,6\%) bereits Fernmetastasen gebildet hatten, wurde diese Subgruppe nochmals gesondert hinsichtlich einer Korrelation zwischen einer FGFR3-Überexpression und dem Gesamtüberleben der Patienten analysiert. Auch hier zeigte sich kein signifikanter Zusammenhang zwischen einer FGFR3Überexpression und dem Gesamtüberleben der Patienten (Log-rank-Test, p=0,992).

Ferner wurden die bereits fernmetastasierten Primärtumoren (M1) mit den nicht metastasierten Primärtumoren (M0) hinsichtlich des Auftretens einer FGF(R)-Genamplifikation oder FGFR-Überexpression mittels des Chi-Quadrat-Tests und des exakten Tests nach Fisher verglichen. Auch hier zeigte sich kein signifikanter Unterschied zwischen den beiden Gruppen. 


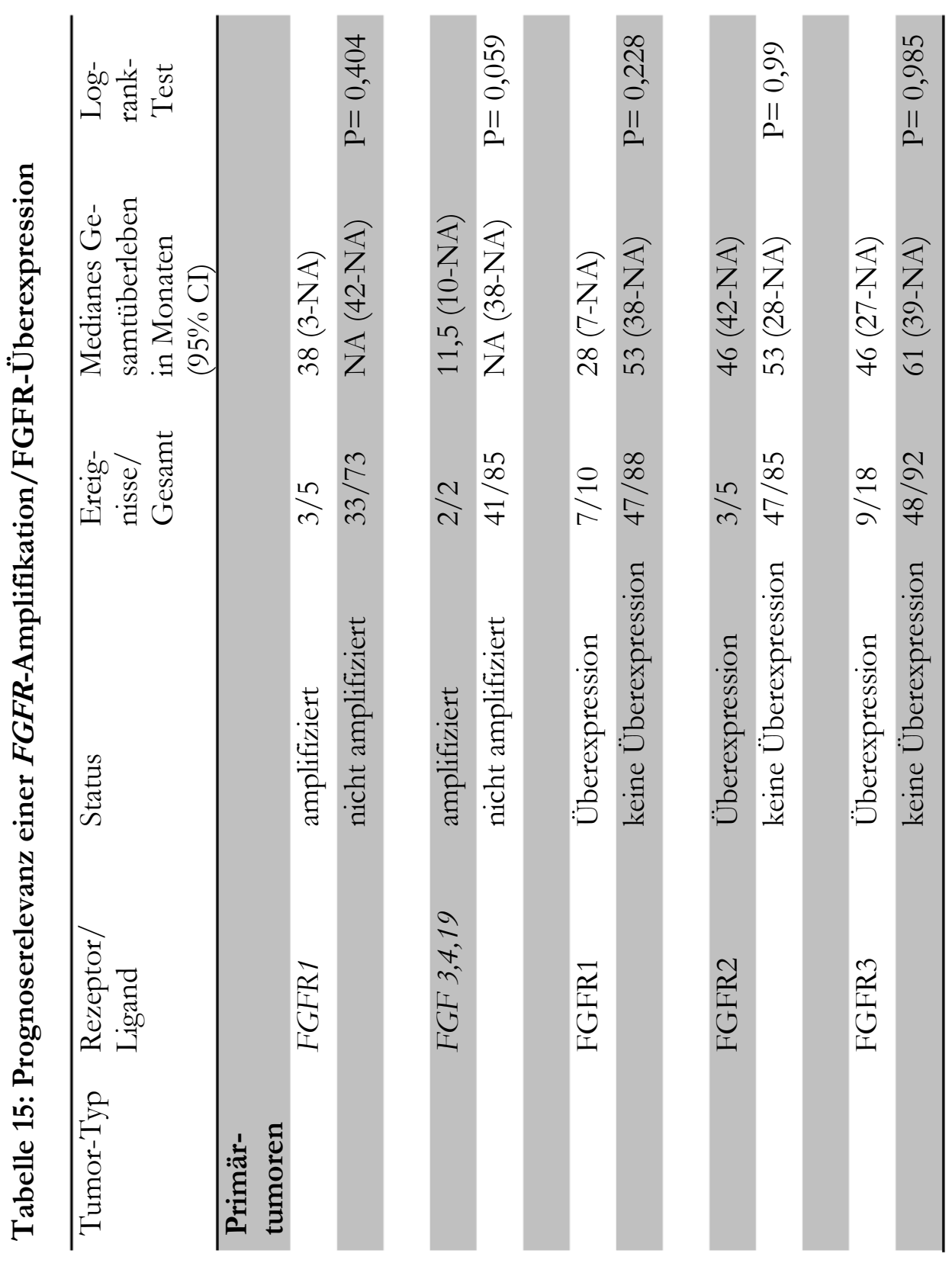




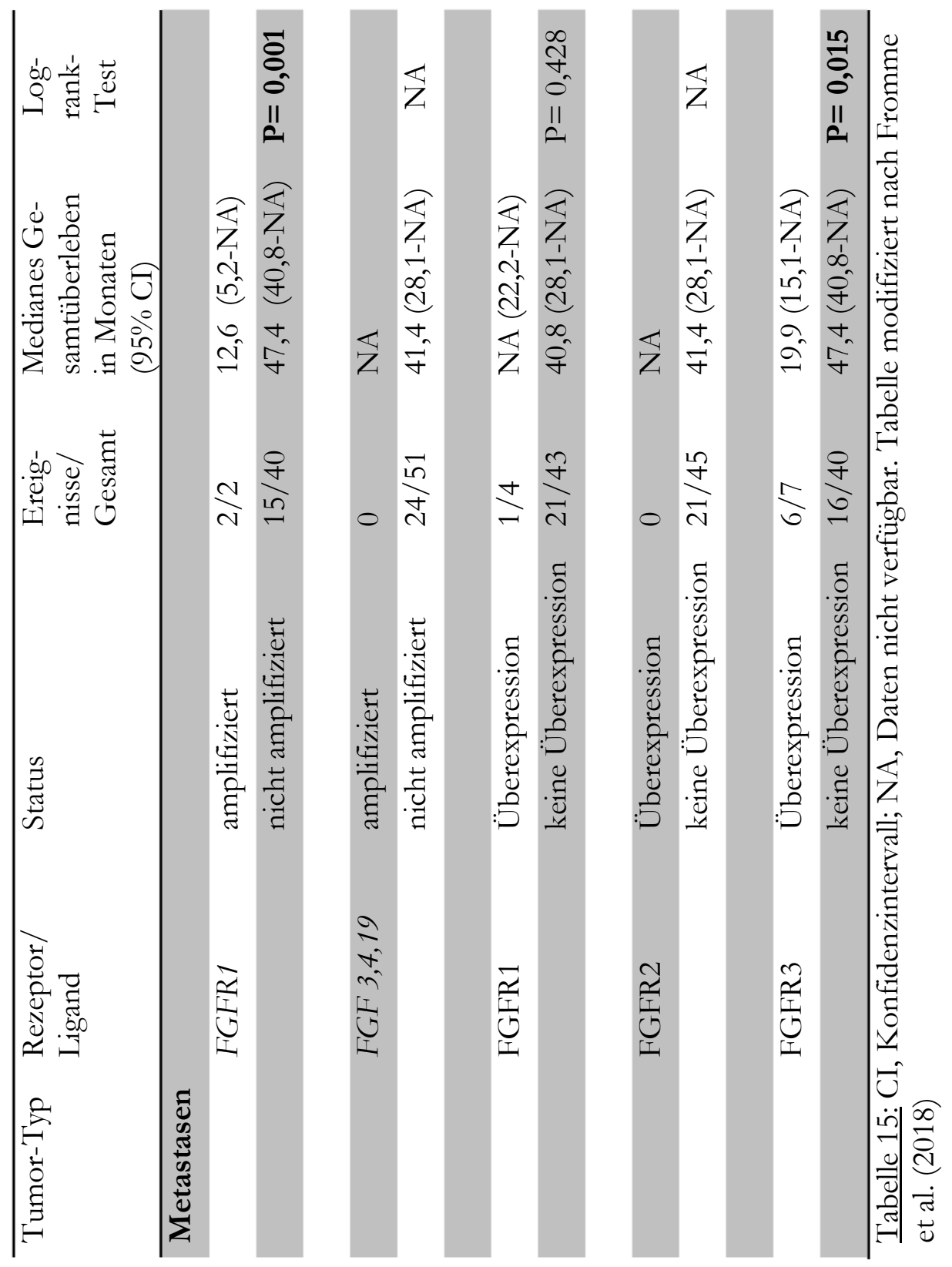


Von drei Patienten mit oligometastasiertem kolorektalen Karzinom untersuchten wir mehr als eine Lebermetastase (Tabelle 16). Bei einem Patienten wurden insgesamt fünf Lebermetastasen metachron reseziert. Dieser Patient hatte zuvor eine Chemotherapie in Kombination mit EGFR-Antikörpern erhalten. Bemerkenswerterweise zeigten nur die drei zuletzt aufgetretenen Metastasen, welche im Rahmen einer Hemihepatektomie entfernt wurden, eine FGFR3Überexpression. Die beiden zuvor resezierten Metastasen wiesen keine FGFR-Alteration auf (Tabelle 16 1.1-1.5). Von zwei weiteren Patienten untersuchten wir ebenfalls mehr als eine Lebermetastase; in einem der beiden Fälle traten die Metastasen synchron, im anderen metachron auf. Bei diesen Patienten zeigte sich kein Unterschied im FGFR-Expressionsverhalten zwischen den Metastasen (Tabelle 16, 2.1-2.4 und 3.1-3.2).

Tabelle 16: Patienten mit multiplen synchronen oder metachronen Metastasen

\begin{tabular}{|c|c|c|c|c|c|c|c|}
\hline Nr. & $\begin{array}{l}\text { Lage } \\
\text { des } \\
\text { Primär- } \\
\text { tumors }\end{array}$ & $\begin{array}{l}\text { Zeitspanne } \\
\text { vom Auftre- } \\
\text { ten der ers- } \\
\text { ten bis zu } \\
\text { weiteren } \\
\text { Metastasen } \\
\text { (Monate) }\end{array}$ & $\begin{array}{r}\quad \underline{\text { RNA }} \\
\text { FGFR1 } \\
\text { H-Score } \\
\text { Ergebnis }\end{array}$ & $\begin{array}{l}\text { FGFR2 } \\
\text { H-Score } \\
\text { Ergebnis }\end{array}$ & $\begin{array}{l}\text { FGFR3 } \\
\text { H-Score } \\
\text { Ergebnis }\end{array}$ & $\begin{array}{l}\text { Ampli- } \\
\text { fikation } \\
\\
\text { FGFR1 } \\
\text { Ratio/ } \\
\text { GCN/Ampli- } \\
\text { fikations- } \\
\text { niveau }\end{array}$ & $\begin{array}{c}\text { Molekulare } \\
\text { Subtypisie- } \\
\text { rung } \\
\\
\text { RAS/ } \\
B R A F / \\
P I K 3 C A\end{array}$ \\
\hline 1.1 & $\mathrm{R}$ & 0 & $\begin{array}{c}0 \\
\text { (neg) }\end{array}$ & $\begin{array}{c}100 \\
\text { (neg) }\end{array}$ & $\begin{array}{c}160 \\
\text { (neg) }\end{array}$ & $\begin{array}{c}1.2 / 2.4 \\
(\mathrm{neg})\end{array}$ & $\begin{array}{l}\text { W'T } \\
\text { W'T } \\
\text { WT }\end{array}$ \\
\hline 1.2 & & 8 & $\begin{array}{c}100 \\
\text { (neg) }\end{array}$ & $\begin{array}{c}45 \\
\text { (neg) }\end{array}$ & $\begin{array}{c}140 \\
\text { (neg) }\end{array}$ & $\begin{array}{c}1.2 / 2.5 \\
\text { (neg) }\end{array}$ & $\begin{array}{l}\text { WT } \\
\text { W'T } \\
\text { W'T }\end{array}$ \\
\hline 1.3 & & 10 & $\begin{array}{c}120 \\
\text { (neg) }\end{array}$ & $\begin{array}{c}100 \\
\text { (neg) }\end{array}$ & $\begin{array}{c}320 \\
\text { (pos) }\end{array}$ & $\begin{array}{c}1.2 / 2.5 \\
\text { (neg) }\end{array}$ & $\begin{array}{l}\text { WT } \\
\text { WT } \\
\text { W'T }\end{array}$ \\
\hline 1.4 & & 10 & $\begin{array}{c}100 \\
\text { (neg) }\end{array}$ & $\begin{array}{c}100 \\
\text { (neg) }\end{array}$ & $\begin{array}{c}260 \\
\text { (pos) }\end{array}$ & $\begin{array}{c}1.1 / 2.1 \\
\text { (neg) }\end{array}$ & $\begin{array}{l}\text { WT } \\
\text { WT } \\
\text { WT }\end{array}$ \\
\hline $\begin{array}{l}1.5 \\
*(22)\end{array}$ & & 10 & $\begin{array}{c}20 \\
\text { (neg) }\end{array}$ & $\begin{array}{c}100 \\
\text { (neg) }\end{array}$ & $\begin{array}{c}350 \\
\text { (pos) }\end{array}$ & $\begin{array}{c}1.3 / 2.5 \\
\text { (neg) }\end{array}$ & $\begin{array}{l}\text { WT } \\
\text { W'T } \\
\text { W'T }\end{array}$ \\
\hline 2.1 & $\mathrm{R}$ & 0 & NA & NA & NA & $\begin{array}{c}1.1 / 2.0 \\
\text { (neg) }\end{array}$ & $\begin{array}{l}\text { WT } \\
\text { W'T } \\
\text { W'T }\end{array}$ \\
\hline
\end{tabular}




\begin{tabular}{|c|c|c|c|c|c|c|c|}
\hline \multirow{2}{*}{ Nr. } & \multirow{2}{*}{$\begin{array}{l}\text { Lage } \\
\text { des } \\
\text { Primär- } \\
\text { tumors }\end{array}$} & \multirow{2}{*}{$\begin{array}{l}\text { Zeitspanne } \\
\text { vom Auftre- } \\
\text { ten der ers- } \\
\text { ten bis zu } \\
\text { weiteren } \\
\text { Metastasen } \\
\text { (Monate) }\end{array}$} & \multicolumn{3}{|c|}{ RNA-Überexpression } & \multirow{2}{*}{$\begin{array}{l}\text { Ampli- } \\
\text { fikation } \\
\text { FGFR1 } \\
\text { Ratio/ } \\
\text { GCN/Ampli- } \\
\text { fikations- } \\
\text { niveau }\end{array}$} & \multirow{2}{*}{$\begin{array}{c}\frac{\text { Molekulare }}{\text { Subtypisie- }} \\
\text { rung } \\
\text { RAS/ } \\
B R A F / \\
P I K 3 C A\end{array}$} \\
\hline & & & $\begin{array}{l}\text { FGFR1 } \\
\text { H-Score } \\
\text { Ergebnis }\end{array}$ & $\begin{array}{l}\text { FGFR2 } \\
\text { H-Score } \\
\text { Ergebnis }\end{array}$ & $\begin{array}{l}\underline{\text { FGFR3 }} \\
\text { H-Score } \\
\text { Ergebnis }\end{array}$ & & \\
\hline 2.2 & & 0 & NA & $\begin{array}{c}100 \\
\text { (neg) }\end{array}$ & $\begin{array}{c}140 \\
\text { (neg) }\end{array}$ & $\begin{array}{c}1.0 / 1.8 \\
\text { (neg) }\end{array}$ & $\begin{array}{l}\text { W'T } \\
\text { W'T } \\
\text { W'T }\end{array}$ \\
\hline 2.3 & & 0 & NA & NA & NA & $\begin{array}{c}1.2 / 2.3 \\
\text { (neg) }\end{array}$ & $\begin{array}{l}\text { W'T } \\
\text { W'T } \\
\text { W'T }\end{array}$ \\
\hline 2.4 & & 0 & NA & $\begin{array}{c}100 \\
\text { (neg) }\end{array}$ & $\begin{array}{c}100 \\
\text { (neg) }\end{array}$ & $\begin{array}{c}1.0 / 2.0 \\
\text { (neg) }\end{array}$ & $\begin{array}{l}\text { W'T } \\
\text { W'T } \\
\text { W'T }\end{array}$ \\
\hline 3.1 & $\mathrm{~K}+\mathrm{R}^{1}$ & 0 & $\begin{array}{c}105 \\
\text { (neg) }\end{array}$ & $\begin{array}{c}110 \\
\text { (neg) }\end{array}$ & $\begin{array}{c}130 \\
\text { (neg) }\end{array}$ & $\begin{array}{c}0.5 / 1.2 \\
\text { (neg) }\end{array}$ & $\begin{array}{l}\text { Mt } \\
\text { WT } \\
\text { WT }\end{array}$ \\
\hline 3.2 & & NA & $\begin{array}{c}0 \\
\text { (neg) }\end{array}$ & $\begin{array}{c}130 \\
\text { (neg) }\end{array}$ & $\begin{array}{c}140 \\
\text { (neg) }\end{array}$ & $\begin{array}{c}0.5 / 1.1 \\
(\mathrm{neg})\end{array}$ & $\begin{array}{l}\text { Mt } \\
\text { WT } \\
\text { WT }\end{array}$ \\
\hline
\end{tabular}

Tabelle 16: *(X), Nummer des gleichen Falls in Tabelle 8; K, Kolon; R, Rektum; WT, Wildtyp; Mt, Mutation; GCN, durchschnittliche Genkopienzahl; neg, negativ; pos, positiv; NA, Daten nicht verfügbar.

${ }^{1}$ Dieser Patient litt gleichzeitig an einem Kolon- (Zökum) sowie Rektumkarzinom, sodass unklar ist, welches Karzinom die Metastasen verursacht hat.

Tabelle modifiziert nach Fromme et al. (2018)

In der Kohorte der Lebermetastasen standen für insgesamt 28 Patienten Therapiedaten zur Verfügung. Davon erhielten zehn Patienten eine VEGF-Antikörper-Therapie in den sechs Monaten vor Resektion der Lebermetastasen. Die anti-VEGF-Therapie wurde hierbei immer in Kombination mit einer Chemotherapie verabreicht; in einem Fall erhielt der Patient zusätzlich EGFR-Antikörper. Beim Vergleich der Patienten, welche eine anti-VEGF-Therapie erhielten, mit den Patienten, welche lediglich eine Chemotherapie und gegebenenfalls EGFRAntikörper bekamen, zeigte sich keine positive Korrelation zwischen einer anti-VEGFTherapie und einer FGFR-Amplifikation oder -Überexpression. Soweit anhand dieser kleinen Fallzahl beurteilbar, besteht somit kein Zusammenhang zwischen einer vorangegangenen VEGF-Antikörpertherapie und dem Auftreten von FGFR-Alterationen. Jedoch sind größere Studien notwendig, um diese Annahme zu bestätigen. 


\subsubsection{Korrelation von FGFR-Genamplifikation und mRNA-Überexpression mit molekularen Subtypen}

Die FGFR3-überexprimierenden Lebermetastasen $(\mathrm{n}=7)$ zeigten in mehr als $50 \%$ der Fälle einen RAS-Wildtyp und in allen Fällen einen BRAF- und PIK3CA-Wildtyp (Tabelle 8). Bei den Lebermetastasen mit einer FGFR1-Überexpression ( $\mathrm{n}=4$ ) lag $\mathrm{R} A S$ jeweils mutiert vor; für $B R A F$ und PIK3CA zeigte sich jedoch ein Wildtyp. Die beiden FGFR1-amplifizierten Metastasen wiesen einen Wildtyp für $R A S, B R A F$ und PIK3CA auf (Tabelle 11).

Insgesamt konnten für die Lebermetastasen keine statistisch signifikanten Korrelationen zwischen dem Auftreten von FGFR-Amplifikation oder FGFR-Überexpressionen und dem Mutationsstatus von $\mathrm{R} A S, B R A F$ und PIK3CA beobachtet werden.

Aus der Kohorte der Lebermetastasen wies nur eine Metastase eine Mikrosatelliteninstabilität auf $(1,8 \%)$. Diese Metastase zeigte weder eine genetische noch eine auf das Expressionsniveau bezogene FGFR-Alteration; RAS, BRAF und PIK3CA lagen als Wildtyp vor.

Bei den Primärtumoren zeigten nur drei der 18 FGFR3-überexprimierenden Tumoren eine RAS-Mutation. Von den Primärtumoren mit einer FGFR2-Überexpression $(n=5)$ und denen mit einer FGFR1-Überexpression ( $\mathrm{n}=10$ ) zeigten jeweils zwei eine $\mathrm{R} A S$-Mutation (Tabelle 8). Aus der Gruppe der Primärtumoren mit einer FGFR-Amplifikation zeigte einer der fünf FGFR1-amplifizierten und keiner der beiden FGF3,4,19-amplifizierten Tumoren eine RASMutation (Tabelle 11).

Zusammenfassend bestand bei den Primärtumoren keine statistisch signifikante Korrelation zwischen dem Auftreten einer FGFR-Amplifikation oder FGFR-Überexpression und dem RAS-Mutationsstatus. Beim Vergleich der Primärtumoren, welche eine einzelne FGFRAlteration aufwiesen, und denen mit mehreren FGFR-Alterationen zeigte sich statistisch kein signifikant häufigeres Auftreten von $\mathrm{R} A S$-Mutationen. 


\section{Diskussion}

Mit einer geschätzten Letalität von ca. 51.000 Individuen in den USA für das Jahr 2018 ist das kolorektale Karzinom hinter dem Bronchialkarzinom die zweithäufigste krebsbedingte Todesursache. Vor allem im metastasierten Stadium ist die Prognose der Patienten trotz moderner Therapieoptionen immer noch sehr schlecht mit einer relativen 5-Jahres-Überlebensrate von ca. $13,8 \%$ (SEER).

Patienten mit oligometastasierten kolorektalen Karzinomen bilden eine relevante Subgruppe mit sehr unterschiedlichem klinischem Verlauf der Erkrankung. Bei manchen ist ein Langzeitüberleben möglich, andere entwickeln innerhalb relativ kurzer Zeit eine multilokuläre Metastasierung und haben eine sehr schlechte Prognose. Um hier die Patienten zu identifizieren, bei denen trotz leitliniengerechter Therapie ein Aufhalten des Tumorprogresses nicht suffizient gelingt, bedarf es aussagekräftiger prognostischer Marker. Die Patienten mit einem ungünstigen Verlauf der Erkrankung sollten dann gezielt in klinische Studien eingeschlossen werden, um für sie individuelle und effektive Therapieoptionen zu finden. Hier ist das Feld der personalisierten Medizin von Bedeutung. Mittels Tyrosinkinase-Inhibitoren können für das Tumorwachstum entscheidende molekulare Signalwege gezielt blockiert werden bei verhältnismäßig geringeren systemischen Nebenwirkungen im Vergleich zu einer Chemotherapie. Die FGF-Rezeptoren und -Liganden sind bereits in verschiedenen Tumoren als vielversprechende molekulare Zielstrukturen beschrieben worden. In dieser Arbeit wurde nun die Bedeutung von FGFR- und FGF-Alterationen im kolorektalen Karzinom umfassend untersucht.

Die Prävalenz von FGFR-Alterationen wurde sowohl auf der genomischen als auch auf der RNA-Expressionsebene ermittelt. Hierzu wurden mit der FISH und der RNA-ISH zwei insitu-Verfahren verwendet. Diese haben den Vorteil, dass die Alterationen direkt im Zellkern der einzelnen Tumorzelle dargestellt werden können und störende Effekte des Tumorstromas nicht mit einfließen, was insbesondere bei den FGF-Rezeptoren, welche auch von Fibroblasten exprimiert werden, von Bedeutung ist.

In der Literatur sind FGFR-Alterationen in kolorektalen Karzinomen bislang nur selten beschrieben worden. Darüber hinaus beziehen sich die meisten Daten, die bisher publiziert wurden, lediglich auf die Primärtumoren. Einzelne Autoren berichten von FGFR1Amplifikationen sowie FGFR1-mRNA-Überexpressionen in primären kolorektalen Karzinomen (CancerGenomeAtlas 2012; Goke et al. 2013; Kwak et al. 2015). Ferner beschreiben Mathur et al. eine FGFR2-Amplifikation in einer Zelllinie des kolorektalen Karzinoms (NCI- 
H716), welche aus Aszites gewonnen wurde, sowie eine vermehrte FGFR2-Expression in vier kolorektalen Primärtumoren sowie einer Lymphknotenmetastase (Mathur et al. 2014). Desnoyers et al. beobachteten eine Co-Überexpression von FGF19 und FGFR4 in Kolonkarzinomen und konnten zeigen, dass durch Hemmung von FGF19 und der daraus resultierenden FGFR4-Inhibition das Tumorwachstum kolorektaler Karzinome in Xenografts in vivo gehemmt werden konnte (Desnoyers et al. 2008). Dem gegenüber steht eine aktuelle Publikation von Karkera et al., in der mittels FISH-Analyse keinerlei Genamplifikationen von FGFR1-4 in kolorektalen Karzinomen gefunden wurden (Karkera et al. 2017).

\section{Genomische FGFR-Alterationen in primären und oligometastasierten KRK}

Im Gegensatz zur Arbeit von Karkera et al. zeigen die vorliegenden Daten, dass Amplifikationen von FGFR1 sowohl in Primärtumoren als auch in Lebermetastasen oligometastasierter kolorektaler Karzinome vorkommen. Ebenso finden sich Amplifikationen des Genclusters der wichtigsten Liganden FGF3,4 und 19 in Primärtumoren. Die Genamplifikationen wurden anhand des FGFR-Scores definiert, welcher von Schildhaus et al. zuvor in einer Arbeit zu FGFR1-Amplifikationen in Plattenepithelkarzinomen der Lunge verwendet wurde (Schildhaus et al. 2012). In den kolorektalen Primärtumoren zeigte sich eine FGFR1-Amplifikation in insgesamt 6,3\% der Fälle. Von ähnlichen Zahlen berichten Kwak et al. und Göke et al. Erstere konnten FGFR1-Amplifikationen in 3,8\%, letztere in 5,3\% primärer kolorektaler Karzinome zeigen. Die Amplifikationskriterien, welche in diesen beiden Studien verwendet wurden, unterscheiden sich in einigen Punkten von den hier gewählten. Der Auswertealgorithmus, welchen Kwak et al. verwendeten, orientierte sich an dem für EGFR-Amplifikationen (Vorhandensein von EGFR-Genclustern und Ratio EGFR-Genkopienzahl zu Chromosom $\geq 2$ oder $\geq 15$ EGFR-Genkopien pro Zelle in $\geq 10 \%$ der Zellen) (Kwak et al. 2015). Bezüglich der Definition eines hohen Amplifikationsniveaus (Gen/Zentromer Ratio $\geq 2,0$ oder Anzahl der Tumorzellen, die $\geq 15$ Zielsignale oder größere Cluster aufwiesen von $\geq 10 \%$ ) ähnelt dieser der hier verwendeten, es fehlt jedoch die Amplifikationsdefinition über die durchschnittliche Genkopienzahl (durchschnittliche Genkopienzahl pro Zelle von $\geq 6,0$ ). Weiterhin wird nicht zwischen hoch- und niedriggradigem Amplifikationsniveau unterschieden. Ein niedriggradiges Amplifikationsniveau wurde in dieser Arbeit definiert, wenn der Prozentsatz der Tumorzellen, welche mindestens fünf Gensignale enthielten, bei mindestens $50 \%$ lag. Dies war bei zweien der fünf FGFR1-amplifizierten Primärtumoren der Fall. Die biologische Relevanz des Unterschieds zwischen hochgradiger und niedriggradiger Amplifikation ist noch unklar, jedoch erscheint die Gefahr geringer, möglicherweise therapeutisch relevante Alterationen zu verpassen, wenn auch die niedriggradigen Amplifikationen als FISH positiv gewertet werden. Dar- 
über hinaus ließ sich ein Fall beobachten, bei dem der Primärtumor und die Lymphknotenmetastase niedriggradige Amplifikationen zeigten, die Lebermetastase jedoch eine hochgradige Amplifikation. Dies lässt vermuten, dass es im Verlauf der Tumorerkrankung zu einer stärkeren Betonung bestimmter genomischer Alterationen und den entsprechenden Signalwegen kommen kann. Folglich erscheint es sinnvoll, auch niedriggradigen Amplifikationen eine Bedeutung beizumessen. In der Publikation von Göke et al. wurde dies getan. Eine niedriggradige Amplifikation wurde hier definiert, wenn zwei bis neun überschüssige Genkopien im Verhältnis zur Anzahl der Referenzsignale in $\geq 20 \%$ der Zellkerne auftraten. Eine hochgradige Amplifikation wurde definiert, wenn die Anzahl der Genkopien mindestens neunfach höher als die Anzahl der Referenzsignale in $\geq 20 \%$ der Zellkerne war oder Cluster auftraten (Goke et al. 2013). Auch wenn sich die einzelnen Definitionen von den in dieser Arbeit verwendeten unterscheiden, wurden hier ebenso niedrig- und hochgradige Amplifikationen als FISH positiv bewertet.

In der Kohorte der Lebermetastasen ließen sich FGFR1-Amplifikationen in 4,8\% der Fälle nachweisen. Da in den wenigen Publikationen zu FGFR in kolorektalen Karzinomen vor allem die Primärtumoren analysiert wurden, fehlen bezüglich der Metastasen jegliche Vergleichsdaten.

Neben FGFR1- fanden sich FGF3,4,19-Amplifikationen in 2,2\% der Primärtumoren. Eine konstitutive Expression von FGF3 wurde bereits von Galdemard et al. in karzinogenen Klonen einer Zelllinie des Kolonkarzinoms beschrieben; sie zeigte sich jedoch nicht in nichtkarzinogenen Klons derselben Zelllinie (Galdemard et al. 2000). Desnoyers et al. beschreiben eine Co-Expression von FGF19 und dem entsprechenden Rezeptor FGFR4 in Primärtumoren des Kolons sowie in einigen humanen Kolonkarzinom-Zelllinien (Desnoyers et al. 2008). Unal et al. fanden hingegen keine positive Korrelation zwischen immunhistochemischer Expression von FGF19 und Progredienz des Tumors hinsichtlich lokaler Infiltration und Lymphknotenbefall bei Patienten mit nicht-fernmetastasierten kolorektalen Karzinomen (Unal et al. 2013).

Neben den amplifizierten Fällen fiel in einigen Primärtumoren und Metastasen eine geringe FGFR1/CEN8-Ratio auf. Anteilig war diese bedingt durch eine häufiger vorkommende Polysomie der Zellkerne (>2 Zentromersignale/Tumorzelle), welche mitunter auch durch eine Amplifikation von repetitiven Sequenzen am Zentromer bedingt sein kann. Als weiterer ursächlicher Mechanismus kommt eine Deletion des FGFR1-Gens oder angrenzender Bereiche der Sonde in Betracht. 
Primärtumoren und Lebermetastasen wurden ebenso auf FGFR1- und FGFR3Translokationen untersucht. Mit den eingesetzten Verfahren zeigten sich bei einem cut-off-Wert von 15\% keinerlei Genrearrangements von FGFR1 oder FGFR3. Einzelne Fälle wiesen vermehrt 5'-Signale in den Tumorzellkernen auf.

Mit der FGFR1-Translokationssonde zeigten sich drei Fälle, zwei Primärtumoren und eine Lebermetastase, mit einer ungewöhnlich hohen Anzahl von zusätzlichen 5'-Signalen. In einem der beiden Primärtumoren war dies ein fokales Phänomen, in den beiden anderen Fällen ein homogenes Verteilungsmuster. Die FGFR1-Translokationssonde ist so beschaffen, dass sie an eine Basensequenz von 605kB distal des FGFR1-Gens (3'-Signal) und an eine Basensequenz von 600kB proximal des FGFR1-Gens bindet (5'-Signal) (ZytoVision 2018). Somit sind die Basensequenzen von ähnlicher Länge und sollten eine ähnliche Spezifität aufweisen. Denkbar wäre, dass repetitive Sequenzen im Bindungsbereich des grün fluoreszierenden Teils der Sonde zum Auftreten von vermehrten 5'-Signalen führen. Da diese das 5'-Ende betreffen, erscheinen sie jedoch primär unspezifisch und sind eher als sondenbedingte Artefakte zu werten. Als Kontrolle und Referenz wurden jeweils die Signale im angrenzenden Normalgewebe herangezogen.

Auch bei der Auswertung der FGFR3-Translokationssonde zeigte sich ein verstärktes Auftreten von zusätzlichen 5'-Signalen, jedoch nicht in dem Ausmaß wie bei der FGFR1Translokationssonde. Um die Anzahl an zusätzlichen 5'-Signalen anhand ausgewählter Fälle zu reevaluieren, verwendeten wir die ZytoLight SPEC FGFR3 Break Apart/FGFR2/FGFR1 Quadruple Color Probe. In den ausgewerteten Fällen zeigte sich eine Reduktion von zusätzlichen 5'-Signalen. FGFR3-Rearrangements zeigten sich bei dem verwendeten cut-off von 15\% keine. Die Quadruple-Sonde bindet eine Basensequenz auf dem Chromosom 4 (p16.3) von 800kb distal des FGFR3-Gens (5'-Signal) und eine Sequenz von 525kb proximal des FGFR3-Gens (3'-Signal) (Biosb.com 2018). Im Vergleich dazu bindet die zuvor verwendete Agilent Sure FISH FGFR3-Translokationssonde eine etwa nur halb so lange Basensequenz von 315,551kB distal des FGFR3-Gens (5'-Signal) und von 184,229kB proximal des FGFR3-Gens (3'-Signal) (GenomicsAgilent). Somit wäre es möglich, dass die Quadruple-Sonde aufgrund ihrer längeren Zielsequenz präziser für das FGFR3-Gen ist und weniger häufig unspezifisch bindet. Als unspezifische Bindungsstellen wären z. B. repetitive Elemente in der DNA distal des FGFR3Gens denkbar. Schließlich wäre es möglich, dass eine Polysomie der Zellkerne vorliegt und dass jedoch die 3'-Signale im Fluoreszenz-Mikroskop nicht sichtbar sind aufgrund der Tatsache, dass die Zentromer-Region möglicherweise in den decoilten DNA-Abschnitten liegt, wohingegen der grün-fluoreszierende Teil der Sonde in der sichtbaren gecoilten DNA bindet. Letztendlich können diese Fragen jedoch nicht abschließend geklärt werden. 
Insgesamt bleibt festzuhalten, dass mit den eingesetzten Verfahren keine FGFR1- oder FGFR3-Translokationen in Primärtumoren und Lebermetastasen kolorektaler Karzinome beobachtet werden konnten. Den Einzelfällen mit zusätzlichen 5'-Signalen liegen wahrscheinlich sondenbedingte Artefakte zugrunde.

Aufgrund der mitunter im kolorektalen Gewebe vorhandenen Nekrosen und Schleimhautextravasate konnte eine relativ hohe Anzahl von Tumorstanzen mangels hinreichender Signalqualität nicht ausgewertet werden. Bei den Primärtumoren, die mit der FGFR4Amplifikationssonde hybridisiert wurden, lag die Quote mit 50\% nicht auswertbarer Fälle am höchsten; bei den Lebermetastasen war ebenfalls die FGFR4-Amplifikationssonde am schlechtesten auszuwerten (38,2\% Ausfallrate). Auch für die anderen FISH-Sonden sind die Ausfallraten nicht unerheblich. Daher ist davon auszugehen, dass die Zahl FGFRamplifizierter Fälle eigentlich noch höher liegt als es unsere Zahlen zeigen.

\section{FGFR-Alterationen auf der mRNA-Expressionsebene}

Die mRNA-Expressionsanalyse von FGFR1-3 erfolgte in dieser Arbeit mittels RNAScope, einer aktuellen und hocheffizienten Weiterentwicklung des RNA-ISH-Analyseverfahrens, welches 2012 von Wang et al. beschrieben wurde. Im Gegensatz zur bisher verwendeten real-time RT-PCR bietet die RNAScope den Vorteil, dass die RNA-Expression in situ in der einzelnen Tumorzelle und im histologischen Kontext untersucht werden kann. Damit wird vermieden, dass z. B. das Tumorstroma oder bestehende Nekrosen das Ergebnis verfälschen (Wang et al. 2012). Die Nachteile, welche den bislang verfügbaren RNA-ISH-Techniken zu Grunde lagen, wurden hier überwunden, indem die Spezifität sowie die Visualisierung der Bindung zwischen RNA-Sonde und Ziel-mRNA verbessert wurden. Die Spezifität wird erreicht durch das erforderliche Binden von zwei Z-Sequenzen, was eine unspezifische Hybridisierung verhindern soll. Durch die dann folgende sequentielle Bindung des „preamplifiers“, des „,amplifiers" und der Enzym-beladenen Markierungssonde wird eine vielfache Signalverstärkung erreicht (Wang et al. 2012).

In den untersuchten Kohorten zeigten 10,1\% der Primärtumoren und 8,5\% der Lebermetastasen eine FGFR1-Überexpression, welche über einen H-Score $\geq 200$ definiert wurde. Dies deckt sich mit den Zahlen von Kwak et al, die in primären kolorektalen Karzinomen eine FGFR1-Überexpressionsrate von 11,7\% beschreiben. Göke et al. berichten sogar von einer Rate von 24,2\% (Goke et al. 2013; Kwak et al. 2015). Jedoch wurde in beiden Publikationen nicht der H-Score als Maß für eine Überexpression verwendet. Kwak et al. definierten eine mRNA-Überexpression ab einem prädominanten Score von 3 oder 4 (Kwak et al. 2015). Bei 
Goke et al. wurden Färbegrad 3 und 4 als positiv gewertet, wobei nicht klar wird, welche Definitionskriterien hier zugrunde liegen (Goke et al. 2013).

In der vorliegenden Arbeit fand der prädominante Score ebenfalls Berücksichtigung und ist mitaufgeführt, jedoch wurde der H-Score favorisiert, da dieser einfacher auswertbar und besser reproduzierbar erscheint.

Korrelation von genomischen FGFR-Alterationen und Alterationen auf der Expressionsebene Bemerkenswert ist, dass in unserer Kohorte genomische FGFR-Amplifikationen und mRNAÜberexpressionen zwar simultan auftraten, jedoch nie denselben Rezeptor betrafen. Somit scheint die Amplifikation eines Gens nicht zwangsläufig zur vermehrten Ablesung desselben zu führen und damit nicht zur mRNA-Überexpression. Gründe hierfür können in verschiedenen epigenetischen Regulationsmechanismen liegen, darunter unter anderen Methylierung und Inaktivierung eines Gens sowie die Histon-Code-Hypothese (Jenuwein und Allis 2001; Montenarh 2007).

Umgekehrt zeigte sich in vielen Fällen eine mRNA-Überexpression ohne das Vorhandensein einer Genamplifikation. Hier dürften ebenfalls über die Genetik hinausgehende epigenetische und weitere regulatorische Mechanismen zugrunde liegen.

\section{Prognostische Bedeutung von FGFR-Alterationen in kolorektalen Karzinomen}

In der vorliegenden Arbeit konnte gezeigt werden, dass FGFR-Alterationen sowohl in Form von Amplifikationen als auch in Form von mRNA-Überexpressionen in einer substantiellen Zahl von Primärtumoren und Lebermetastasen oligometastasierter kolorektaler Karzinome vorkommen. In den Primärtumoren fanden sich FGFR1- (6,3\%) und FGF3,4,19- (2,2\%) Amplifikationen. Translokationen von FGFR1 oder FGFR3 konnten im Gegensatz zu vielen anderen Tumorentitäten keine beobachtet werden. Ferner fanden sich RNAÜberexpressionen von FGFR1 (10,1\%), FGFR2 (5,5\%) und FGFR3 (16,2\%).

Die Metastasen zeigten auf der genomischen Ebene FGFR1-Amplifikationen in 4,8\% der Fälle. Weiterhin fanden sich Überexpressionen von FGFR1 (8,5\%) und FGFR3 (14,9\%). Im Gegensatz zu den Primarien waren in den Metastasen keine FGF3,4,19-Amplifikationen oder FGFR2-Überexpressionen zu beobachten, sodass diesen vermutlich eine geringere Bedeutung im metastasierten Stadium des KRK zukommt. Weder in Primärtumoren noch in Metastasen zeigten sich Amplifikationen von FGFR2, FGFR3 und FGFR4 oder Translokationen von FGFR1 und FGFR3. Die FGFR3-Überexpression stellte in beiden Kohorten die häufigste Alteration dar, sodass sie im kolorektalen Karzinom von besonderer Bedeutung zu sein scheint. Einzelne Fälle zeigten sogar mehrere FGFR-Alterationen; teils in Form von Überex- 
pressionen mehrerer Rezeptoren; teils in Form eines Nebeneinanders von Genamplifikation und Überexpression.

Die FGFR3-Überexpression stellt nicht nur die häufigste Alteration in primären und oligometastasierten KRK dar, sondern ist in den Metastasen, wenn sie mittels RNA-ISH im metastatischen Gewebe bestimmt wird, auch mit einem statistisch signifikant reduzierten Gesamtüberleben assoziiert (medianes Gesamtüberleben 19,9 vs. 47,4 Monate, $\mathrm{HR}=3,14, \mathrm{p}=0,0152$ ).

In Primärtumoren hat eine FGFR3-Überexpression, wenn sie im Primarius bestimmt wird, hingegen keine Auswirkungen auf die Prognose der Patienten $(H R=1,01, p=0,985)$. Dies gilt auch für die Gruppe von Primärtumoren, welche bereits Fernmetastasen gebildet haben. Folglich legen diese Daten nahe, dass die Bestimmung der FGFR-Alterationen vor allem in den Metastasen erfolgen sollte, da sie hier erstens biologisch und prognostisch relevanter erscheinen und zweitens auch erst spät in der Tumorprogression auftreten können wie das Beispiel eines Patienten mit mehreren metachronen Metastasen zeigt, bei dem erst die zuletzt aufgetretenen Metastasen eine FGFR3-Überexpression aufweisen. Die FGFR3-Überexpression charakterisiert somit eine Subgruppe der Patienten mit metastasiertem KRK und geht mit einer signifikant schlechteren Prognose einher. Daher könnten vor allem diese Patienten von einer Therapie mit FGFR3-Tyrosinkinase-Inhibitoren profitieren und sollten in aktuelle klinische Studien mit FGFR-Inhibitoren eingeschlossen werden.

Für eine FGFR1-Amplifikation fand sich ebenfalls eine statistische Assoziation mit einem kürzeren Gesamtüberleben in der Kohorte der Metastasen (medianes Überleben 12,6 vs. 47,4 Monate, $\mathrm{HR}=8,83)$. Da jedoch insgesamt nur zwei Metastasen eine FGFR1-Amplifikation aufwiesen, ist die Anzahl positiver Fälle sehr gering, und weitere Studien mit höheren Fallzahlen sind erforderlich, um diese Beobachtung zu bestätigen.

Sato et al. beschreiben in ihrer Arbeit eine positive Korrelation zwischen einer FGFR1Überexpression in den Primärtumoren und dem Auftreten von Lebermetastasen. Die Überexpression wurde dabei mittels qRT-PCR ermittelt (Sato et al. 2009). In unserer Kohorte konnte dieses Phänomen nicht beobachtet werden. Lediglich einer von zehn FGFR1überexprimierenden Primärtumoren war in unserer Kohorte bereits metastasiert. Ferner war die Quote der FGFR1-Überexpression in den Lebermetastasen mit 8,5\% geringer als in den Primärtumoren mit 10,1\%. Ferner berichtet Jang von einer Überexpression von FGFR1 in Zelllinien kolorektaler Karzinome, die reziprok mit einer FGFR3-Expression korreliert (Jang 2005). Dies konnte am vorliegenden Kollektiv nicht beobachtet werden, zeigten sich doch vier Primärtumoren mit einer simultanen Überexpression von FGFR1 und FGFR3. 
$\underline{\text { Relevanz der verschiedenen Methoden zur Bestimmung prädiktiver Biomarker }}$

Aktuell wird eine Vielzahl von selektiven und nicht-selektiven FGFR-TyrosinkinaseInhibitoren in klinischen Studien auf ihre Wirksamkeit und Verträglichkeit getestet (s. Anhang). Um gezielt Patienten, welche von einer anti-FGFR-Therapie profitieren könnten in diese Studien einzuschließen, bedarf es geeigneter prädiktiver Biomarker. Da es durch viele verschiedene Mechanismen, darunter genomische sowie Alterationen auf der Expressionsebene oder eine Kombination derselben, zu einer übermäßigen Aktivierung des FGFRSignalwegs kommen kann, ist bislang noch weitgehend unklar, welche Alterationen die geeignetsten Prädiktoren für ein Ansprechen auf FGFR-Inhibitoren darstellen. Wie bereits beschrieben werden zunehmend Alterationen auf der Expressionsebene anstelle von genomischen Alterationen in aktuellen Studien favorisiert (Goke et al. 2015; Joerger et al. 2017; Wynes et al. 2014). Auch wenn auf Grundlage dieser Arbeit keine Aussage darüber getroffen werden kann, welcher Biomarker der geeignetere ist, konnte sehr wohl gezeigt werden, dass die FGFR3-Überexpression in Metastasen kolorektaler Karzinome mit einer Prävalenz von 14,9\% sowohl die häufigste FGFR-Alteration ist als auch einen relevanten negativen Prognosefaktor darstellt. Diese Daten und die von Joerger et al. publizierte aktuelle klinische Studie machen FGFR3 zu einem potentiellen molekularen Target im KRK und die FGFR3Überexpression zu einem möglichen prädiktiven Biomarker (Joerger et al. 2017). Daher sollten Patienten mit einer FGFR3-Überexpression in klinische Studien mit FGFR-Inhibitoren eingeschlossen werden. Die Bedeutung, welche der FGFR3-Überexpression in metastasierten kolorektalen Karzinomen zukommt, wird in der vorliegenden Arbeit erstmals beschrieben. Insbesondere die Patientengruppe mit einer ungünstigen Prognose sollte in Studien mit FGFRTyrosinkinase-Inhibitoren eingeschlossen werden und könnte von einer zielgerichteten Therapie profitieren. Valide Methoden zur Aus- und Bewertung der verschiedenen Biomarker wurden in dieser Arbeit ausführlich beschrieben.

\section{Limitationen der Arbeit}

Bei der vorliegenden Arbeit handelt es sich um eine retrospektive Studie, d. h. auf die Vollständigkeit und Qualität der klinischen sowie pathologischen Daten konnte kein Einfluss genommen werden. Die Lebermetastasen waren vergleichsweise sehr gut charakterisiert und es standen lückenlose Daten zu klinischen Parametern wie Geschlecht, Alter, Lokalisation des Primarius, Gesamtüberleben und krebsspezifischem Überleben zur Verfügung. Die molekularen Analysen hinsichtlich RAS, BRAF und PIK3CA sowie die Analyse der MSI waren lückenlos vorhanden. Therapiedaten zu der in den sechs Monaten vor Resektion der Metastasen durchgeführten Behandlung waren von fast $50 \%$ der Patienten verfügbar. Bei den Primärtu- 
moren waren hingegen keine Therapiedaten vorhanden. Die klinischen Parameter sowie Daten zum Gesamtüberleben waren weitestgehend vollständig. Das krebsspezifische Überleben wurde für die Primärtumoren nicht ermittelt; ebenso wurde die $R A S$-Analyse nur in beschränktem Umfang durchgeführt. Nichtsdestotrotz konnten anhand der verfügbaren Daten valide Korrelationen zwischen klinisch-pathologischen Parametern sowie molekularen Subtypen und dem Auftreten von FGFR-Alterationen erstellt werden.

Das Tumorgewebe der Primärtumoren sowie der Lebermetastasen wurde anhand von tissue microarrays untersucht. Das bedeutet, dass im Gegensatz zu einem größeren Gewebeareal auf Einzelschnitten nur ca. $1 \mathrm{~mm}$ durchmessende Stanzen jedes Tumors beurteilt wurden und eine möglicherweise bestehende intratumorale Heterogenität somit nicht erfasst wurde. Das Phänomen der intratumoralen Heterogenität wurde z. B. für FGFR-Alterationen in Bronchialkarzinomen beobachtet (Schildhaus et al. 2013). Daher ist anzunehmen, dass FGFR-Alterationen im KRK vermutlich noch häufiger vorkommen, als es unsere Daten zeigen.

Insbesondere bei den TMAs der Primärtumoren war es gelegentlich der Fall, dass randständige Tumorstanzen nicht vollständig auf dem Schnitt vorhanden waren, d. h. dass sie beim Schneiden nicht erfasst wurden oder dass das Gewebe beim Aufziehen auf den Objektträger vermutlich abgeschwommen war. Bei den TMAs der Lebermetastasen war dies nicht der Fall, vermutlich weil hier nur bis zu 64 Stanzzylinder in einen Empfängerblock eingesetzt wurden, wohingegen es bei den Primärtumoren 140 waren. Darüber hinaus war bei den Lebermetastasen jede Metastase mit zwei Stanzen vertreten, sodass bei schlechter Auswertequalität der ersten auf die zweite Stanze ausgewichen werden konnte. Bei den Primärtumoren war zwar jeder Fall mit zwei Stanzen vertreten, jedoch enthielt nur eine Stanze Tumorgewebe und die andere Normalgewebe. Dies ist ein Grund für die höhere Anzahl von nicht beurteilbaren Fällen bei den Primärtumoren. Auch wenn die Tatsache, dass die Tumoren anhand von TMAs untersucht wurden, sicherlich als eine Limitation der Arbeit genannt werden muss, überwiegen bei weitem die Vorteile dieser Methode gegenüber einzelnen Schnitten eines jeden Tumors. So lässt sich eine hohe Anzahl von Tumoren auf nur einem Objektträger untersuchen und eine schnellere Befundung ist folglich möglich. Im Gegensatz zu Einzelschnitten mit größerem Gewebeareal musste hier nur eine Tumorstanze bei den Primärtumoren oder zwei Stanzen bei den Metastasen beurteilt werden und es konnte eine große Zahl von Tumoren auf nur einem Objektträger ausgewertet werden. Auch die Vorbehandlung und Hybridisierung wurde erleichtert, da diese nur an einem Schnitt erfolgen musste und durch die geringe Stanzgröße weniger Reagenzien benötigt wurden (Kononen et al. 1998). Generell sind TMAs in Fällen, bei denen nur wenig Gewebe zur Verfügung steht, sehr hilfreich, um einerseits Gewebe einzusparen und 
trotzdem eine umfassende molekularpathologische Analyse durchführen zu können (Kallioniemi et al. 2001).

Diese Arbeit bietet die bislang umfassendste Analyse von Alterationen in den FGFRezeptoren und -Liganden auf der genomischen sowie auf der Expressionsebene in primären und oligometastasierten kolorektalen Karzinomen. Dessen ungeachtet sind die Fallzahlen insbesondere bei den Lebermetastasen nicht hoch, sodass weitere Studien nötig und wünschenswert sind, um die hier dargelegten Ergebnisse zu bestätigen. Da vor allem die FGFR3Überexpression in weit fortgeschrittenen KRK auftritt, sollten in diese Studien auch multilokulär fernmetastasierte kolorektale Karzinome mit Metastasen in Lunge und Gehirn miteingeschlossen werden.

\section{Schlussfolgerung}

FGFR-Alterationen sind insgesamt eher selten in kolorektalen Karzinomen zu beobachten. Gleichwohl definieren sie aber eine spezifische Subgruppe in primären und metastasierten KRK. Die FGFR3-Überexpression ist hierbei die häufigste Alteration in Primarien und Metastasen und ist in letzteren mit einem signifikant reduzierten Gesamtüberleben assoziiert. Damit identifiziert sie eine neue Subgruppe von Patienten mit oligometastasiertem KRK mit einem hohen Progressionsrisiko. FGFR3 stellt überdies ein potenzielles molekulares Target für eine personalisierte Therapie mit FGFR-Tyrosinkinase-Inhibitoren dar. FGFR1- und FGFR2Überexpressionen wurden ebenfalls beobachtet, ihnen scheint jedoch keine prognostische Bedeutung zuzukommen. Genomische FGFR-Alterationen kommen in Form von FGFR1Amplifikationen in beiden Kohorten, in Form von FGF3,4,19-Amplifikationen hingegen nur in Primarien vor. Eine positive Korrelation zwischen FGFR1-Amplifikationen und einem kürzeren Gesamtüberleben ist auf Grundlage der vorliegenden Daten ebenfalls zu vermuten, kann jedoch aufgrund der geringen Zahl von positiven Fällen nicht postuliert werden. Hier bedarf es weiterer Studien. FGFR1- und FGFR3-Translokationen waren weder in Primärtumoren noch in Metastasen mit den hier verwendeten Methoden nachweisbar. 


\section{$5 \quad$ Zusammenfassung}

Das Outcome der Patienten mit metastasiertem kolorektalen Karzinom ist bislang unbefriedigend. Es fehlt an effektiven Therapieoptionen und an prognostischen sowie prädiktiven Biomarkern. Patienten mit oligometastasierten kolorektalen Karzinomen und einer begrenzten Zahl von Metastasen in der Leber bilden eine klinische Subgruppe mit einem sehr heterogenen Krankheitsverlauf. Anhand der vorliegenden Daten erscheint die FGFR3-Überexpression in dieser Subgruppe als ein negativer Prognostikator und FGFR3 als ein potentielles molekulares Target.

Die in der Einleitung formulierten Fragen können nun auf Grundlage dieser Arbeit wie folgt beantwortet werden:

i) Wie ist die Prävalenz von FGFR- und FGF-Alterationen in primären kolorektalen Karzinomen?

In den Primärtumoren zeigten sich FGFR1- in 6,3\% und FGF3,4,19Amplifikationen in 2,2\%. Ferner waren RNA-Überexpressionen von FGFR1 in 10,1\%, FGFR2 in 5,5\% und FGFR3 in 16,2\% zu beobachten. FGFR2-, FGFR3oder FGFR4-Amplifikationen fanden sich weder in Primärtumoren noch in Metastasen. Bei dem verwendeten cut-off zeigten sich keine FGFR1- oder FGFR3Translokationen.

ii) Wie ist die Prävalenz derselben in Lebermetastasen oligometastasierter kolorektaler Karzinome?

Die Lebermetastasen wiesen FGFR1-Amplifikationen in 4,8\% sowie FGFR1- und FGFR3-Überexpressionen in 8,5\% und 14,9\% auf. Auch hier zeigten sich weder FGFR2-, FGFR3- oder FGFR4-Amplifikationen noch FGFR1- oder FGFR3Translokationen. 
iii) Haben FGFR- und FGF-Alterationen eine prognostische Bedeutung in kolorektalen Karzinomen?

FGFR-Alterationen sind ein negativer Prognostikator in Metastasen kolorektaler Karzinome, jedoch nicht in den Primärtumoren. Die FGFR3-Überexpression ist signifikant mit einem kürzeren Gesamtüberleben in den metastasierten (Log-rankTest, $\mathrm{p}=0,0152 \mathrm{HR}=3,14$ [1,19-8,31]), jedoch nicht in den primären KRK (Logrank-Test, $\mathrm{p}=0,985, \quad \mathrm{HR}=1,01 \quad[0,49-2,05])$ assoziiert. Auch die FGFR1Amplifikation scheint mit einem kürzeren Gesamtüberleben assoziiert zu sein und einen negativen Prognostikator darzustellen.

iv) Besteht eine Korrelation der FGFR- und FGF-Alterationen mit den molekularen Subtypen des KRK?

Eine statistisch signifikante Korrelation zwischen FGFR- und FGF-Alterationen und den molekularen Subtypen des KRK besteht in den untersuchten Kohorten nicht. Die prognostisch relevante FGFR3-Überexpression ist in den Metastasen in weniger als 50\% der Fälle mit $\mathrm{R} A S$-Mutationen assoziiert, was hinsichtlich einer potentiellen anti-FGFR-Therapie von entscheidender Bedeutung ist.

Diese Studie ist die bislang umfassendste Analyse zu FGFR-Alterationen in primären und metastasierten KRK. Die vorliegenden Ergebnisse legen nahe, dass Patienten mit metastasierten KRK und einer FGFR3-Überexpression gezielt in klinische Studien mit FGFRInhibitoren eingeschlossen werden sollten und von der zielgerichteten Therapie profitieren könnten. 


\section{$6 \quad$ Anhang}

\subsection{Auswahl aktueller klinischer Studien zu FGFR-Inhibitoren}

\subsubsection{Nicht-selektive FGFR-Inhibitoren (ClinicalTrials.gov)}

\begin{tabular}{|c|c|c|c|c|c|}
\hline Wirkstoff & Sponsor & Tumor-Typ & $\begin{array}{l}\text { Molekulare } \\
\text { Targets }\end{array}$ & Phase & $\begin{array}{l}\text { Clinical } \\
\text { trials.gov ID }\end{array}$ \\
\hline $\begin{array}{l}\text { Nintedanib } \\
\text { und Pem- } \\
\text { brolizumab }\end{array}$ & $\begin{array}{l}\text { Gustave Roussy, } \\
\text { Villejuif, Val de } \\
\text { Marne, Frank- } \\
\text { reich }\end{array}$ & $\begin{array}{l}\text { Fortgeschrittene Tu- } \\
\text { moren (darunter } \\
\text { NSCLC, Urothelkar- } \\
\text { zinome, Nierenzell- } \\
\text { karzinome, KRK etc.) }\end{array}$ & $\begin{array}{l}\text { Nintedanib: } \\
\text { VEGFR1-3, } \\
\text { FGFR1-3, PDGFR, } \\
\text { RET } \\
\text { Pembrolizumab: } \\
\text { IgG4, anti-PD1 }\end{array}$ & $\overline{\mathrm{Ib}}$ & $\begin{array}{l}\text { NCT02856425 } \\
\text {-> ausgesetzt, } \\
\text { „safety event“ }\end{array}$ \\
\hline Nintedanib & $\begin{array}{l}\text { Roswell Park } \\
\text { Cancer Institute }\end{array}$ & $\begin{array}{l}\text { Fortgeschrittene/ } \\
\text { therapierefraktäre } \\
\text { kolorektale } \\
\text { Karzinome }\end{array}$ & $\begin{array}{l}\text { VEGFR, FGFR, } \\
\text { PDGFR }\end{array}$ & $\mathrm{I} / \mathrm{II}$ & NCT02393755 \\
\hline Pazopanib & $\begin{array}{l}\text { Samsung Medi- } \\
\text { cal Center, } \\
\text { Republic of } \\
\text { Korea }\end{array}$ & $\begin{array}{l}\text { Refraktäre solide } \\
\text { Tumoren mit FGFR2- } \\
\text { Amplifikation oder - } \\
\text { Mutation }\end{array}$ & $\begin{array}{l}\text { FGFR1-2, } \\
\text { VEGFR1-3, } \\
\text { PDGFR, cKIT }\end{array}$ & -- & NCT02450136 \\
\hline Ponatinib & $\begin{array}{l}\text { Sameek } \\
\text { Roichowdhury }\end{array}$ & $\begin{array}{l}\text { Fortgeschrittene soli- } \\
\text { de Tumoren mit ge- } \\
\text { nomischen Alteratio- } \\
\text { nen in FGFR1-4, } \\
\text { RET, KIT }\end{array}$ & $\begin{array}{l}\text { FGFR, KIT, } \\
\text { PDGFR, RET } \\
\text { FLT3, ABL1 }\end{array}$ & II & NCT02272998 \\
\hline $\begin{array}{l}\text { Lucitanib } \\
\text { E-3810 }\end{array}$ & Servier & $\begin{array}{l}\text { Metastasierte, Östro- } \\
\text { gen-Rezeptor-positive } \\
\text { Mammakarzinome mit } \\
\text { FGFR1- } \\
\text { Amplifikation, } 11 q^{-} \\
\text {Amplifikation oder } \\
\text { keine dieser beiden } \\
\text { Amplifikationen }\end{array}$ & $\begin{array}{l}\text { FGFR1-2, } \\
\text { VEGFR1-3, } \\
\text { PDGFR }\end{array}$ & II & $\begin{array}{l}\text { NCT02053636 } \\
\text { (FINESSE) } \\
\text {->Studie abge- } \\
\text { schlossen }\end{array}$ \\
\hline
\end{tabular}

\subsubsection{Selektive FGFR-Inhibitoren (ClinicalTrials.gov)}

\begin{tabular}{llllll}
\hline Wirkstoff & Sponsor & Tumor-Typ & FGFR-Profil & Phase & $\begin{array}{l}\text { Clinical } \\
\text { trials.gov ID }\end{array}$ \\
\hline BGJ 398 & $\begin{array}{l}\text { Novartis Phar- } \\
\text { maceuticals }\end{array}$ & $\begin{array}{l}\text { Fortgeschrittene soli- } \\
\text { de Tumoren mit }\end{array}$ & FGFR 1-3 & I & NCT01697605 \\
& & & & \\
& FGFR-Alterationen & & \\
& & & \\
& & & & \\
& & & &
\end{tabular}




\begin{tabular}{|c|c|c|c|c|c|}
\hline Wirkstoff & Sponsor & Tumor-Typ & FGFR-Profil & Phase & $\begin{array}{l}\text { Clinical } \\
\text { trials.gov ID }\end{array}$ \\
\hline BGJ 398 & $\begin{array}{l}\text { Novartis Phar- } \\
\text { maceuticals }\end{array}$ & $\begin{array}{l}\text { Fortgeschrittene soli- } \\
\text { de Tumoren mit } \\
\text { FGFR1-3 Alteratio- } \\
\text { nen (FGFR1- } \\
\text { amplifizierte SqCLC, } \\
\text { Blasenkarzinome mit } \\
\text { FGFR3- } \\
\text { Mutation/Fusion, } \\
\text { fortgeschrittene Tu- } \\
\text { moren mit FGFR1- } \\
\text { oder FGFR2- } \\
\text { Amplifikation oder } \\
\text { FGFR3-Mutation) }\end{array}$ & s.o. & $\mathrm{I}$ & NCT01004224 \\
\hline BGJ 398 & $\begin{array}{l}\text { Novartis Phar- } \\
\text { maceuticals }\end{array}$ & $\begin{array}{l}\text { Solide Tumoren und } \\
\text { hämatologische Neo- } \\
\text { plasien mit genomi- } \\
\text { schen FGFR- } \\
\text { Alterationen }\end{array}$ & s.o. & II & $\begin{array}{l}\text { NCT02160041 } \\
\text {->Studie abge- } \\
\text { schlossen }\end{array}$ \\
\hline BGJ398 & $\begin{array}{l}\text { University of } \\
\text { Chicago }\end{array}$ & $\begin{array}{l}\text { Plattenepithelkarzi- } \\
\text { nome des Kopf- und } \\
\text { Halsbereichs mit } \\
\text { genetischen FGFR1-3- } \\
\text { Alterationen (Amplifi- } \\
\text { kationen, Mutationen) }\end{array}$ & s.o. & $\mathrm{IIa}$ & NCT02706691 \\
\hline BGJ398 & $\begin{array}{l}\text { Novartis Phar- } \\
\text { maceuticals }\end{array}$ & $\begin{array}{l}\text { Fortgeschrittenes } \\
\text { cholangiozelluläres } \\
\text { Karzinom mit } \\
\text { FGFR2- } \\
\text { Fusion/anderer ge- } \\
\text { nomischer FGFR- } \\
\text { Alteration }\end{array}$ & s.o. & II & NCT02150967 \\
\hline BGJ398 & $\begin{array}{l}\text { Memorial Sloan } \\
\text { Kettering Cancer } \\
\text { Center }\end{array}$ & $\begin{array}{l}\text { Harnblasenkarzinome, } \\
\text { nicht-muskelinvasive } \\
\text { Urothelkarzinome }\end{array}$ & s.o. & -- & NCT02657486 \\
\hline $\begin{array}{l}\text { INCB } \\
054828\end{array}$ & $\begin{array}{l}\text { Incyte Corpora- } \\
\text { tion }\end{array}$ & $\begin{array}{l}\text { Myeloi- } \\
\text { sche/lymphatische } \\
\text { Neoplasien mit } \\
\text { FGFR1- } \\
\text { Rearrangement }\end{array}$ & $\begin{array}{l}\text { FGFR } \\
\text { 1-3 Inhibitor }\end{array}$ & II & NCT03011372 \\
\hline $\begin{array}{l}\text { INCB } \\
054828\end{array}$ & $\begin{array}{l}\text { Incyte Coprora- } \\
\text { tion }\end{array}$ & $\begin{array}{l}\text { Fortgeschrittenes } \\
\text { cholangiozelluläres } \\
\text { Karzinom mit/ohne } \\
\text { FGF(R)-Alteration, } \\
\text { insbesondere FGFR2- } \\
\text { Translokation }\end{array}$ & s.o. & II & NCT02924376 \\
\hline LY3076226 & $\begin{array}{l}\text { Eli Lilly and } \\
\text { Company }\end{array}$ & $\begin{array}{l}\text { Fortgeschritte- } \\
\text { ne/metastasierte Tu- } \\
\text { moren (insbesondere } \\
\text { Blasenkarzinome mit } \\
\text { FGFR3-Alteration) }\end{array}$ & FGFR3-Inhbitor & I & $\begin{array}{l}\text { NCT02529553 } \\
\text {->Studie abge- } \\
\text { schlossen }\end{array}$ \\
\hline $\begin{array}{l}\text { BAY } \\
1163877 \\
\text { (Rogarati- } \\
\text { nib) }\end{array}$ & Bayer & $\begin{array}{l}\text { Refraktä- } \\
\text { re/metastasierte solide } \\
\text { Tumoren }\end{array}$ & Pan-FGFR-Inhibitor & I & NCT01976741 \\
\hline ARQ 087 & ArQule & $\begin{array}{l}\text { Fortgeschrittene soli- } \\
\text { de Tumoren mit ge- } \\
\text { nomischen FGFR- } \\
\text { Alterationen }\end{array}$ & FGFR1-3 Inhibitor & $\mathrm{I} / \mathrm{II}$ & NCT01752920 \\
\hline
\end{tabular}




\begin{tabular}{|c|c|c|c|c|c|}
\hline Wirkstoff & Sponsor & Tumor-Typ & FGFR-Profil & Phase & $\begin{array}{l}\text { Clinical } \\
\text { trials.gov ID }\end{array}$ \\
\hline ARQ 087 & ArQule & $\begin{array}{l}\text { Fortgeschrittenes } \\
\text { cholangiozelluläres } \\
\text { Karzinom mit } \\
\text { FGFR2- } \\
\text { Rearrangement }\end{array}$ & s.o. & II & NCT03230318 \\
\hline TAS-120 & $\begin{array}{l}\text { Taiho Oncology, } \\
\text { Inc. }\end{array}$ & $\begin{array}{l}\text { Fortgeschrittene soli- } \\
\text { de Tumoren/multiple } \\
\text { Myelome mit FGF(R)- } \\
\text { Alterationen }\end{array}$ & Pan-FGFR-Inhibitor & $\mathrm{I} / \mathrm{II}$ & NCT02052778 \\
\hline PRN1371 & $\begin{array}{l}\text { Principia Bi- } \\
\text { opharma, Inc. }\end{array}$ & $\begin{array}{l}\text { Fortgeschrittene soli- } \\
\text { de Tumoren/ weiter- } \\
\text { führend mit Tumoren } \\
\text { mit genomischen } \\
\text { Alterationen der } \\
\text { FGFRs 1-4 }\end{array}$ & FGFR1-4 Inhibitor & I & NCT02608125 \\
\hline $\begin{array}{l}\text { JNJ- } \\
42756493\end{array}$ & $\begin{array}{l}\text { Janssen Research } \\
\text { and Develop- } \\
\text { ment, LLC }\end{array}$ & $\begin{array}{l}\text { Fortgeschritte- } \\
\text { ne/refraktäre solide } \\
\text { Tumoren oder Lym- } \\
\text { phome }\end{array}$ & Pan-FGFR-Inhibitor & I & $\begin{array}{l}\text { NCT01703481 } \\
\text {-> Studie } \\
\text { abgeschlossen }\end{array}$ \\
\hline Debio1347 & $\begin{array}{l}\text { Debiopharm } \\
\text { International SA }\end{array}$ & $\begin{array}{l}\text { Fortgeschrittene soli- } \\
\text { de Tumoren mit gene- } \\
\text { tischen Alterationen in } \\
\text { FGFR1-3 }\end{array}$ & FGFR1-3 Inhibitor & I & NCT01948297 \\
\hline FGF 401 & $\begin{array}{l}\text { Novartis Phar- } \\
\text { maceuticals }\end{array}$ & $\begin{array}{l}\text { HCC und solide Tu- } \\
\text { moren mit FGFR4 } \\
\text { und KLB-Expression }\end{array}$ & FGFR4-Inhibitor & $\mathrm{I} / \mathrm{II}$ & NCT02325739 \\
\hline
\end{tabular}




\subsection{Ergebnisse ausgewählter klinischer Studien zu FGFR-Inhibitoren}

\subsubsection{Nicht-selektive FGFR-Inhibitoren (ClinicalTrials.gov)}

\begin{tabular}{|c|c|c|c|c|c|}
\hline Wirkstoff & $\begin{array}{l}\text { Molekulare } \\
\text { Targets }\end{array}$ & Tumor-Typ & Phase & Ergebnis & Referenz \\
\hline Dovitinib & $\begin{array}{l}\text { FGFR, } \\
\text { PDGFR, } \\
\text { VEGFR, } \\
\text { c-kit, CSF-1 }\end{array}$ & $\begin{array}{l}\text { Fortgeschrittenes } \\
\text { nicht- } \\
\text { kleinzelliges } \\
\text { Bronchial-Ca., } \\
\text { KRK (nach } \\
\text { Progress unter } \\
\text { anti-VEGF- } \\
\text { Therapie) }\end{array}$ & II & $\begin{array}{l}\text { Einer von sieben Patienten } \\
\text { zeigte ein Gesamtansprechen, } \\
\text { disease control rate ebenfalls } \\
1 / 7 \text {, progression-free survival 1,9 } \\
\text { Monate; drei von zehn Pati- } \\
\text { enten hatten schwere NW, } \\
\text { darunter vaskuläre, infekti- } \\
\text { onsbedingte, gastrointestinale } \\
\text { NW. }\end{array}$ & NCT01676714 \\
\hline Dovitinib & s.o. & $\begin{array}{l}\text { Tumoren mit } \\
\text { Alterationen in } \\
\text { FGFR, PDGFR, } \\
\text { VEGF, FLT3, } \\
\text { cKIT, RET, Trk, } \\
\text { CSF-1R }\end{array}$ & II & $\begin{array}{l}\text { Zehn von } 80 \text { Patienten zeig- } \\
\text { ten eine stable disease, bei } 1 \\
\text { von } 80 \text { zeigte sich ein partiel- } \\
\text { les Ansprechen; das progressi- } \\
\text { on-free survival lag bei } 2,4 \text { Mo- } \\
\text { naten, das Gesamtüberleben } \\
\text { bei } 13,5 \text { Monaten. } 32 \text { von } 80 \\
\text { Patienten hatten schwere NW } \\
\text { (v.a. gastrointestinale } \\
\text { NW und thromboembolische } \\
\text { Ereignisse). }\end{array}$ & NCT01831726 \\
\hline Dovitinib & s.o. & $\begin{array}{l}\text { fortgeschrittenes } \\
\text { Nierenzell- } \\
\text { karzinom }\end{array}$ & II & $\begin{array}{l}\text { Bei Patienten mit fortge- } \\
\text { schrittenem Nierenzell-Ca. } \\
\text { zeigten sich unter Dovitinib } \\
\text { ein medianes progression-free } \\
\text { survival von 3,7 Monaten } \\
\text { sowie ein Gesamtüberleben } \\
\text { von 11,8 Monaten. } \\
\text { In der Subgruppe, welche } \\
\text { zuvor VEGFR- sowie } \\
\text { mTOR-Inhibitoren erhalten } \\
\text { hatte, betrug nach acht Wo- } \\
\text { chen die disease control rate } \\
\text { 52,7\%. Als häufigste NW } \\
\text { zeigten sich Übelkeit, Durch- } \\
\text { fall, Erbrechen. }\end{array}$ & $\begin{array}{l}\text { NCT00715182 } \\
\text { (Escudier et al. } \\
\text { 2014) }\end{array}$ \\
\hline Dovitinib & s.o. & $\begin{array}{l}\text { EGFR2-negative } \\
\text { metastatische } \\
\text { Mammakarzi- } \\
\text { nome, FGFR1- } \\
\text { Amplifikation } \\
\text { (silver ISH) und } \\
\text { Hormonrezep- } \\
\text { torstatus wurden } \\
\text { analysiert }\end{array}$ & II & $\begin{array}{l}\text { Von } 81 \text { Patienten wurde eine } \\
\text { stable disease bei fünf Patien- } \\
\text { ten mit FGFR1-Amplifikation } \\
\text { und positivem Hormonstatus } \\
\text { beobachtet sowie bei einem } \\
\text { FGFR1-negativen und Hor- } \\
\text { monrezeptor-positivem. } \\
\text { Weiterhin wurde mittels } \\
\text { qPCR auf Amplifikationen } \\
\text { von FGFR1, FGFR2 und } \\
\text { FGF3 hin untersucht; die } \\
\text { FGF(R) alterierte und Hor- } \\
\text { monrezeptor-positive Gruppe } \\
\text { zeigte eine durchschnittliche } \\
\text { Reduktion der Tumormasse } \\
\text { von } 21,1 \% \text { im Vergleich zu } \\
\text { einer Zunahme der Tumor- } \\
\text { masse von } 12 \% \text { in der Grup- } \\
\text { pe von Tumoren ohne } \\
\text { FGFR-Alterationen. }\end{array}$ & $\begin{array}{l}\text { NCT00958971 } \\
\text { (Andre et al. } \\
\text { 2013) }\end{array}$ \\
\hline
\end{tabular}




\begin{tabular}{|c|c|c|c|c|c|}
\hline Wirkstoff & $\begin{array}{l}\text { Molekulare } \\
\text { Targets }\end{array}$ & Tumor-Typ & Phase & Ergebnis & Referenz \\
\hline $\begin{array}{l}\text { Lucitanib } \\
\text { E-3810 }\end{array}$ & $\begin{array}{l}\text { FGFR1-2, } \\
\text { VEGFR1-3, } \\
\text { PDGFR }\end{array}$ & $\begin{array}{l}\text { Fortgeschrittene } \\
\text { solide Tumoren, } \\
\text { weiterführend } \\
\text { dann mit } \\
\text { FGFR1- oder } \\
11 q 12-14 \text { - Amp- } \\
\text { lifikation oder } \\
\text { bestehender } \\
\text { Sensibilität ge- } \\
\text { genüber anti- } \\
\text { angiogener Be- } \\
\text { handlung }\end{array}$ & $\mathrm{I} / \mathrm{IIa}$ & $\begin{array}{l}\text { In der Angiogenese-sensitiven } \\
\text { Gruppe betrug die Ansprech- } \\
\text { rate } 26 \%(7 / 27) \text { und das } \\
\text { progression-free survival } 25 \text { Wo- } \\
\text { chen. In der Gruppe der } \\
\text { Patienten mit Mamma-Ca mit } \\
\text { FGF-Alteration konnte in } \\
\text { 50\% (6/12) ein partielles } \\
\text { Ansprechen erreicht werden, } \\
\text { das mediane progression-free } \\
\text { survival betrug 40,4 Wochen. } \\
\text { Tolerable NW, am häufigsten } \\
\text { Bluthochdruck, } \\
\text { Asthenie, Proteinurie } \\
\text { (NCT02053636). }\end{array}$ & $\begin{array}{l}\text { NCT01283945 } \\
\text { (Soria et al. } \\
\text { 2014) }\end{array}$ \\
\hline $\begin{array}{l}\text { JNJ- } \\
42756493\end{array}$ & Pan-FGFR & $\begin{array}{l}\text { Fortgeschrittene } \\
\text { solide Tumoren }\end{array}$ & & $\begin{array}{l}\text { In der Gruppe der Patienten, } \\
\text { deren Tumoren FGFR- } \\
\text { Alterationen aufwiesen, zeig- } \\
\text { ten fünf von } 23 \text { ein Anspre- } \\
\text { chen, darunter Urothel- und } \\
\text { Endometriumkarzinome } \\
\text { sowie Glioblastome mit } \\
\text { FGFR2- oder FGFR3- } \\
\text { Translokationen; bei } 16 \text { Pati- } \\
\text { enten konnte eine stable disease } \\
\text { erreicht werden. }\end{array}$ & $\begin{array}{l}\text { (Tabernero et } \\
\text { al. 2015) }\end{array}$ \\
\hline Nintedanib & $\begin{array}{l}\text { VEGFR, } \\
\text { FGFR, } \\
\text { PDGFR }\end{array}$ & $\begin{array}{l}\text { Fortgeschrittene } \\
\text { kolorektale Kar- } \\
\text { zinome }\end{array}$ & & $\begin{array}{l}\text { In einer Phase-II-Studie } \\
\text { konnte gezeigt werden, dass } \\
\text { die Kombination aus Ninte- } \\
\text { danib und Chemotherapie } \\
\text { der Standardkombination aus } \\
\text { Chemotherapie und Bevaci- } \\
\text { zumab nicht unterlegen war; } \\
\text { bei einzelnen, stark vorbe- } \\
\text { handelten Patienten schnitt } \\
\text { die Kombination sogar etwas } \\
\text { besser ab hinsichtlich des } \\
\text { progression-free survivals und der } \\
\text { Lebensqualität }\end{array}$ & $\begin{array}{l}\text { (Rossi et al. } \\
\text { 2017) }\end{array}$ \\
\hline $\begin{array}{l}\text { Lenvatinib } \\
(\mathrm{E} 7080)\end{array}$ & $\begin{array}{l}\text { FGFR, } \\
\text { VEGFR, } \\
\text { PDGFR, } \\
\text { RET, KIT }\end{array}$ & & & $\begin{array}{l}\text { In einer Phase-I-Studie zeig- } \\
\text { ten } 15,6 \% \text { der Tumore ein } \\
\text { Ansprechen; eine stable disease } \\
\text { für mindestens } 23 \text { Wochen } \\
\text { konnte bei } 24,7 \% \text { der Patien- } \\
\text { ten erreicht werden. }\end{array}$ & $\begin{array}{l}\text { (Hong et al. } \\
\text { 2015) }\end{array}$ \\
\hline
\end{tabular}




\subsubsection{Selektive FGFR-Inhibitoren (ClinicalTrials.gov)}

\begin{tabular}{|c|c|c|c|c|c|}
\hline Wirkstoff & $\begin{array}{l}\text { Molekulares } \\
\text { Profil }\end{array}$ & Tumor-Typ & Phase & Ergebnis & Referenz \\
\hline BGJ398 & FGFR1-3 & $\begin{array}{l}\text { FGFR3-mutierte } \\
\text { Harnblasen- und } \\
\text { Urothelkarzinome, } \\
\text { FGFR1- amplifizierte } \\
\text { SqCLC }\end{array}$ & $\mathrm{I}$ & $\begin{array}{l}\text { Sieben Tumore } \\
\text { (FGFR1-amplifizierte } \\
\text { sqNSCLC und } \\
\text { FGFR3-mutierte } \\
\text { Harnblasen-/Urothel- } \\
\text { karzinome zeigten ein } \\
\text { partielles Ansprechen. }\end{array}$ & $\begin{array}{l}\text { NCT01004224, } \\
\text { (Nogova et al. } \\
\text { 2017) }\end{array}$ \\
\hline BGJ398 & s.o. & $\begin{array}{l}\text { Cholangiokarzinome } \\
\text { mit FGFR2-Fusion, } \\
\text { FGFR1-amplifizierte } \\
\text { Mammakarzinome }\end{array}$ & & $\begin{array}{l}\text { Bei vier von fünf } \\
\text { Patienten mit FGFR3- } \\
\text { mutierten Urothelkar- } \\
\text { zinomen konnte eine } \\
\text { Reduktion der Tu- } \\
\text { mormasse beobachtet } \\
\text { werden; ein partielles } \\
\text { Ansprechen zeigte } \\
\text { sich bei einem Patien- } \\
\text { ten mit einem FGFR1- } \\
\text { amplifizierten } \\
\text { SqNSCLC. Ebenso } \\
\text { zeigte sich eine Re- } \\
\text { duktion der Tumor- } \\
\text { masse bei cholangio- } \\
\text { zellulären Karzinomen } \\
\text { mit FGFR2-Fusion } \\
\text { und FGFR1- } \\
\text { amplifizierten } \\
\text { Mammakarzinomen. }\end{array}$ & $\begin{array}{l}\text { (Sequist et al. } \\
\text { 2014) }\end{array}$ \\
\hline $\begin{array}{l}\text { BAY } \\
1163877 \\
\text { (Rogaratinib) }\end{array}$ & Pan-FGFR & $\begin{array}{l}\text { Fortgeschrittene } \\
\text { Urothelkarzinome }\end{array}$ & I & $\begin{array}{l}\text { Tumorverkleinerung } \\
\text { bei sieben Patienten } \\
(87,5 \%) \text {, als häufigste } \\
\text { NW zeigten sich eine } \\
\text { Hyperphosphatämie } \\
\text { und Diarrhöen. }\end{array}$ & $\begin{array}{l}\text { (Joerger et al. } \\
\text { 2017) } \\
\text { NCT01976741 }\end{array}$ \\
\hline $\begin{array}{l}\text { JNJ- } \\
42756493\end{array}$ & Pan-FGFR & $\begin{array}{l}\text { Therapierefraktäre } \\
\text { solide Tumore und } \\
\text { Lymphome }\end{array}$ & I & $\begin{array}{l}\text { Bei fünf von } 23 \text { Pati- } \\
\text { enten, deren Tumoren } \\
\text { FGFR- Alterationen } \\
\text { aufwiesen, konnte ein } \\
\text { Ansprechen beobach- } \\
\text { tet werden (darunter } \\
\text { Glioblastome, } \\
\text { Urothel- und Endo- } \\
\text { metriumkarzinome } \\
\text { mit FGFR2- oder } \\
\text { FGFR3- Translokati- } \\
\text { onen). 16 Patienten } \\
\text { zeigten eine stable } \\
\text { disease. Häufigste NW: } \\
\text { Hyperphosphatämie } \\
\text { und Asthenie. }\end{array}$ & $\begin{array}{l}\text { (Tabernero et } \\
\text { al. 2015) } \\
\text { NCT01703481 }\end{array}$ \\
\hline
\end{tabular}




\begin{tabular}{|c|c|c|c|c|c|}
\hline Wirkstoff & $\begin{array}{l}\text { Molekulares } \\
\text { Profil }\end{array}$ & Tumor-Typ & Phase & Ergebnis & Referenz \\
\hline AZD4547 & FGFR1-3 & $\begin{array}{l}\text { fortgeschrittene Ma- } \\
\text { gen-, Bronchial, } \\
\text { Mammakarzinome } \\
\text { mit einer FGFR1- } \\
\text { oder FGFR2- } \\
\text { Amplifikation }\end{array}$ & II & $\begin{array}{l}\text { Die Ansprechrate bei } \\
\text { FGFR1-amplifizierten } \\
\text { Mammakarzinomen } \\
\text { lag bei 12,5\% (1/8), } \\
\text { bei FGFR2- amplifi- } \\
\text { zierten gastroösopha- } \\
\text { gealen Karzinomen } \\
\text { lag sie bei 33\% (3/9). } \\
\text { Häufigste NW: Fati- } \\
\text { gue, Mukositis, Übel- } \\
\text { keit. }\end{array}$ & $\begin{array}{l}\text { (Smyth et al. } \\
\text { 2015) } \\
\text { NCT01795768 }\end{array}$ \\
\hline ARQ087 & Pan-FGFR & $\begin{array}{l}\text { Fortgeschrittene } \\
\text { solide Tumoren }\end{array}$ & I & $\begin{array}{l}\text { Von } 18 \text { Tumoren mit } \\
\text { genomischen FGFR- } \\
\text { Alterationen zeigten } \\
\text { drei Tumoren ein } \\
\text { partielles Ansprechen, } \\
\text { darunter zwei intrahe- } \\
\text { patische cholangiozel- } \\
\text { luläre Karzinome mit } \\
\text { FGFR2- Fusion und } \\
\text { ein Urothelkarzinom } \\
\text { mit FGF19- und } \\
\text { FGFR2-Amplifikation. } \\
\text { Bei zwei Tumoren } \\
\text { (cholangiozelluläres } \\
\text { Karzinom mit } \\
\text { FGFR2-Fusion, } \\
\text { FGFR1-amplifiziertes } \\
\text { Nebennierenrinden- } \\
\text { karzinom) konnte eine } \\
\text { stable disease sowie eine } \\
\text { Tumorverkleinerung } \\
\text { erzielt werden. Die } \\
\text { Phosphat- und } \\
\text { FGF19-Spiegel wer- } \\
\text { den als Indikatoren } \\
\text { für ein Ansprechen } \\
\text { genannt. Häufigste } \\
\text { NW: Fatigue und } \\
\text { Übelkeit. }\end{array}$ & $\begin{array}{l}\text { (Papadopoulos } \\
\text { et al. 2017) } \\
\text { NCT01752920 }\end{array}$ \\
\hline
\end{tabular}




\section{$7 \quad$ Literaturverzeichnis}

Al-Ahmadie HA, Iyer G, Janakiraman M, Lin O, Heguy A, Tickoo SK, Fine SW, Gopalan A, Chen YB, Balar A, et al. (2011): Somatic mutation of fibroblast growth factor receptor-3 (FGFR3) defines a distinct morphological subtype of high-grade urothelial carcinoma. J Pathol 224, 270-279

Amado RG, Wolf M, Peeters M, Van Cutsem E, Siena S, Freeman DJ, Juan T, Sikorski R, Suggs S, Radinsky R, et al. (2008): Wild-type KRAS is required for panitumumab efficacy in patients with metastatic colorectal cancer. J Clin Oncol 26, 1626-1634

Andre F, Bachelot T, Campone M, Dalenc F, Perez-Garcia JM, Hurvitz SA, Turner N, Rugo H, Smith JW, Deudon S, et al. (2013): Targeting FGFR with dovitinib (TKI258): preclinical and clinical data in breast cancer. Clin Cancer Res $\underline{19}$, 3693-3702

Beenken A, Mohammadi M (2009): The FGF family: biology, pathophysiology and therapy. Nat Rev Drug Discov $\underline{8}, 235-253$

Bertotti A, Migliardi G, Galimi F, Sassi F, Torti D, Isella C, Cora D, Di Nicolantonio F, Buscarino M, Petti C, et al. (2011): A molecularly annotated platform of patient-derived xenografts ("xenopatients") identifies HER2 as an effective therapeutic target in cetuximabresistant colorectal cancer. Cancer Discov 1, 508-523

http://www.biosb.com/wp-content/uploads/2016/07/ZytoLight-SPEC-FGFR3-BreakApart FGFR2 FGFR1-Quadruple-Color-Probe z-2186-ce-ivd.pdf; Zugriff am 23.09.2018

Buecher B, Cacheux W, Rouleau E, Dieumegard B, Mitry E, Lievre A (2013): Role of microsatellite instability in the management of colorectal cancers. Dig Liver Dis $\underline{45}, 441-449$

https://www.cancer.gov/publications/dictionaries/cancer-terms?cdrid=770481; Zugriff am 23.09.2018

CancerGenomeAtlas (2012): Comprehensive molecular characterization of human colon and rectal cancer. Nature $\underline{487}, 330-337$

Chae YK, Ranganath K, Hammerman PS, Vaklavas C, Mohindra N, Kalyan A, Matsangou M, Costa R, Carneiro B, Villaflor VM, et al. (2017): Inhibition of the fibroblast growth factor receptor (FGFR) pathway: the current landscape and barriers to clinical application. Oncotarget $\underline{8}, 16052-16074$

Chesi M, Nardini E, Brents LA, Schrock E, Ried T, Kuehl WM, Bergsagel PL (1997): Frequent translocation $\mathrm{t}(4 ; 14)(\mathrm{p} 16.3 ; \mathrm{q} 32.3)$ in multiple myeloma is associated with increased expression and activating mutations of fibroblast growth factor receptor 3. Nat Genet $\underline{16}, 260$ 264

https://www.clinicaltrials.gov/; Zugriff am 23.09.2018 
Courjal F, Cuny M, Simony-Lafontaine J, Louason G, Speiser P, Zeillinger R, Rodriguez C, Theillet C (1997): Mapping of DNA amplifications at 15 chromosomal localizations in 1875 breast tumors: definition of phenotypic groups. Cancer Res $\underline{57}$, 4360-4367

Desnoyers LR, Pai R, Ferrando RE, Hotzel K, Le T, Ross J, Carano R, D'Souza A, Qing J, Mohtashemi I, et al. (2008): Targeting FGF19 inhibits tumor growth in colon cancer xenograft and FGF19 transgenic hepatocellular carcinoma models. Oncogene 27, 85-97

Dieci MV, Arnedos M, Andre F, Soria JC (2013): Fibroblast growth factor receptor inhibitors as a cancer treatment: from a biologic rationale to medical perspectives. Cancer Discov $\underline{3}, 264-$ 279

Dienstmann R, Rodon J, Prat A, Perez-Garcia J, Adamo B, Felip E, Cortes J, Iafrate AJ, Nuciforo P, Tabernero J (2014): Genomic aberrations in the FGFR pathway: opportunities for targeted therapies in solid tumors. Ann Oncol 25, 552-563

Dietmaier W, Wallinger S, Bocker T, Kullmann F, Fishel R, Ruschoff J (1997): Diagnostic microsatellite instability: definition and correlation with mismatch repair protein expression. Cancer Res $\underline{57}$, 4749-4756

Escudier B, Grunwald V, Ravaud A, Ou YC, Castellano D, Lin CC, Gschwend JE, Harzstark A, Beall S, Pirotta N, et al. (2014): Phase II results of Dovitinib (TKI258) in patients with metastatic renal cell cancer. Clin Cancer Res 20, 3012-3022

Eswarakumar VP, Lax I, Schlessinger J (2005): Cellular signaling by fibroblast growth factor receptors. Cytokine Growth Factor Rev 16, 139-149

Finelli P, Fabris S, Zagano S, Baldini L, Intini D, Nobili L, Lombardi L, Maiolo AT, Neri A (1999): Detection of $\mathrm{t}(4 ; 14)(\mathrm{p} 16.3 ; \mathrm{q} 32)$ chromosomal translocation in multiple myeloma by double-color fluorescent in situ hybridization. Blood 94, 724-732

Fong Y, Fortner J, Sun RL, Brennan MF, Blumgart LH (1999): Clinical score for predicting recurrence after hepatic resection for metastatic colorectal cancer: analysis of 1001 consecutive cases. Ann Surg 230, 309-318; discussion 318-321

Fromme JE, Schildhaus HU (2018): [FGFR3 overexpression is a relevant alteration in colorectal cancer] Pathologe $\underline{39}, 189-192$

Fromme JE, Schmitz K, Wachter A, Grzelinski M, Zielinski D, Koppel C, Conradi LC, Homayounfar K, Hugo T, Hugo S, et al. (2018): FGFR3 mRNA overexpression defines a subset of oligometastatic colorectal cancers with worse prognosis. Oncotarget $\underline{9}$, 32204-32218

Galdemard C, Yamagata H, Brison O, Lavialle C (2000): Regulation of FGF-3 gene expression in tumorigenic and non-tumorigenic clones of a human colon carcinoma cell line. J Biol Chem $\underline{275}, 17364-17373$

https://www.genomics.agilent.com/productSearch.jsp?ProductID=AG-SFP-942; Zugriff am 23.09.2018

Giacchetti S, Itzhaki M, Gruia G, Adam R, Zidani R, Kunstlinger F, Brienza S, Alafaci E, Bertheault-Cvitkovic F, Jasmin C, et al. (1999): Long-term survival of patients with 
unresectable colorectal cancer liver metastases following infusional chemotherapy with 5fluorouracil, leucovorin, oxaliplatin and surgery. Ann Oncol 10, 663-669

Goke F, Goke A, von Massenhausen A, Franzen A, Sharma R, Kirsten R, Bohm D, Kristiansen G, Stenzinger A, Wynes M, et al. (2013): Fibroblast growth factor receptor 1 as a putative therapy target in colorectal cancer. Digestion $\underline{88}, 172-181$

Goke F, Franzen A, Hinz TK, Marek LA, Yoon P, Sharma R, Bode M, von Maessenhausen A, Lankat-Buttgereit B, Goke A, et al. (2015): FGFR1 Expression Levels Predict BGJ398 Sensitivity of FGFR1-Dependent Head and Neck Squamous Cell Cancers. Clin Cancer Res 21, 4356-4364

Grose R, Dickson C (2005): Fibroblast growth factor signaling in tumorigenesis. Cytokine Growth Factor Rev 16, 179-186

Guagnano V, Kauffmann A, Wohrle S, Stamm C, Ito M, Barys L, Pornon A, Yao Y, Li F, Zhang Y, et al. (2012): FGFR genetic alterations predict for sensitivity to NVP-BGJ398, a selective pan-FGFR inhibitor. Cancer Discov 2, 1118-1133

Guffanti F, Chila R, Bello E, Zucchetti M, Zangarini M, Ceriani L, Ferrari M, Lupi M, Jacquet-Bescond A, Burbridge MF, et al. (2016): In Vitro and In Vivo Activity of Lucitanib in FGFR1/2 Amplified or Mutated Cancer Models. Neoplasia 19, 35-42

Hong DS, Kurzrock R, Wheler JJ, Naing A, Falchook GS, Fu S, Kim KB, Davies MA, Nguyen LM, George GC, et al. (2015): Phase I Dose-Escalation Study of the Multikinase Inhibitor Lenvatinib in Patients with Advanced Solid Tumors and in an Expanded Cohort of Patients with Melanoma. Clin Cancer Res 21, 4801-4810

Jang JH (2005): Reciprocal relationship in gene expression between FGFR1 and FGFR3: implication for tumorigenesis. Oncogene $24,945-948$

Jenuwein T, Allis CD (2001): Translating the Histone Code. Science 293, 1074-1080

Jeske YW, Ali S, Byron SA, Gao F, Mannel RS, Ghebre RG, DiSilvestro PA, Lele SB, Pearl ML, Schmidt AP, et al. (2017): FGFR2 mutations are associated with poor outcomes in endometrioid endometrial cancer: An NRG Oncology/Gynecologic Oncology Group study. Gynecol Oncol 145, 366-373

Jo P, Konig A, Schirmer M, Kitz J, Conradi LC, Azizian A, Bernhardt M, Wolff HA, Grade M, Ghadimi M, et al. (2016): Heterogeneity of KRAS Mutation Status in Rectal Cancer. PLoS One $\underline{11}$, e0153278

Joerger M, Schuler MH, Cassier PA, Hildebrandt S, Behre S, Helmbrecht C, Kerpen S, Zielinski D, Ince S, Ocker M, et al. (2017): Patient selection using novel RNA-based approaches: Early experience from a phase I study with the pan-FGFR inhibitor BAY 1163877 in patients with urothelial bladder cancer. J Clin Oncol $\underline{35}, 386-386$

Jung EJ, Jung EJ, Min SY, Kim MA, Kim WH (2012): Fibroblast growth factor receptor 2 gene amplification status and its clinicopathologic significance in gastric carcinoma. Hum Pathol $\underline{43}$, 1559-1566 
Kaibori M, Sakai K, Ishizaki M, Matsushima H, De Velasco MA, Matsui K, Iida H, Kitade H, Kwon AH, Nagano H, et al. (2016): Increased FGF19 copy number is frequently detected in hepatocellular carcinoma with a complete response after sorafenib treatment. Oncotarget $\underline{7}$, 49091-49098

Kallioniemi OP, Wagner U, Kononen J, Sauter G (2001): Tissue microarray technology for high-throughput molecular profiling of cancer. Hum Mol Genet 10, 657-662

Kanas GP, Taylor A, Primrose JN, Langeberg WJ, Kelsh MA, Mowat FS, Alexander DD, Choti MA, Poston G (2012): Survival after liver resection in metastatic colorectal cancer: review and meta-analysis of prognostic factors. Clin Epidemiol $\underline{4}$, 283-301

Karapetis CS, Khambata-Ford S, Jonker DJ, O'Callaghan CJ, Tu D, Tebbutt NC, Simes RJ, Chalchal H, Shapiro JD, Robitaille S, et al. (2008): K-ras mutations and benefit from cetuximab in advanced colorectal cancer. $\mathrm{N}$ Engl J Med $\underline{359}, 1757-1765$

Karapetis CS, Jonker D, Daneshmand M, Hanson JE, O'Callaghan CJ, Marginean C, Zalcberg JR, Simes J, Moore MJ, Tebbutt NC, et al. (2014): PIK3CA, BRAF, and PTEN status and benefit from cetuximab in the treatment of advanced colorectal cancer--results from NCIC CTG/AGITG CO.17. Clin Cancer Res 20, 744-753

Karkera JD, Cardona GM, Bell K, Gaffney D, Portale JC, Santiago-Walker A, Moy CH, King P, Sharp M, Bahleda R, et al. (2017): Oncogenic Characterization and Pharmacologic Sensitivity of Activating Fibroblast Growth Factor Receptor (FGFR) Genetic Alterations to the Selective FGFR Inhibitor Erdafitinib. Mol Cancer Ther 16, 1717-1726

Kavuri SM, Jain N, Galimi F, Cottino F, Leto SM, Migliardi G, Searleman AC, Shen W, Monsey J, Trusolino L, et al. (2015): HER2 activating mutations are targets for colorectal cancer treatment. Cancer Discov $\underline{5}, 832-841$

Khattak MA, Martin HL, Beeke C, Price T, Carruthers S, Kim S, Padbury R, Karapetis CS (2012): Survival differences in patients with metastatic colorectal cancer and with single site metastatic disease at initial presentation: results from South Australian clinical registry for advanced colorectal cancer. Clin Colorectal Cancer 11, 247-254

Kononen J, Bubendorf L, Kallioniemi A, Barlund M, Schraml P, Leighton S, Torhorst J, Mihatsch MJ, Sauter G, Kallioniemi OP (1998): Tissue microarrays for high-throughput molecular profiling of tumor specimens. Nat Med $\underline{4}, 844-847$

Koole K, Brunen D, van Kempen PM, Noorlag R, de Bree R, Lieftink C, van Es RJ, Bernards R, Willems SM (2016): FGFR1 Is a Potential Prognostic Biomarker and Therapeutic Target in Head and Neck Squamous Cell Carcinoma. Clin Cancer Res 22, 3884-3893

https://www.krebsdaten.de/Krebs/DE/Content/Krebsarten/Darmkrebs/darmkrebs node. html;jsessionid=251B449C8F126302CEA148CC81E435D0.1 cid298; Zugriff am 02.09.2018, a

https://www.krebsdaten.de/Krebs/DE/Content/Methoden/Ueberlebensraten/ueberlebensr aten node.html; Zugriff am 03.10.2018, b 
Kurosu H, Ogawa Y, Miyoshi M, Yamamoto M, Nandi A, Rosenblatt KP, Baum MG, Schiavi S, Hu MC, Moe OW, et al. (2006): Regulation of fibroblast growth factor-23 signaling by klotho. J Biol Chem 281, 6120-6123

Kwak Y, Nam SK, Seo AN, Kim DW, Kang SB, Kim WH, Lee HS (2015): Fibroblast Growth Factor Receptor 1 Gene Copy Number and mRNA Expression in Primary Colorectal Cancer and Its Clinicopathologic Correlation. Pathobiology $\underline{82}, 76-83$

Langer-Safer PR, Levine M, Ward DC (1982): Immunological method for mapping genes on Drosophila polytene chromosomes. Proc Natl Acad Sci U S A $\underline{79}$, 4381-4385

Leitlinienprogramm-Onkologie: S3-Leitlinie kolorektales Karzinom. Hrsg. Deutsche Krebsgesellschaft, Deutsche Krebshilfe, AWMF. Langversion 2.0, 2017; http://www.leitlinienprogramm-onkologie.de/leitlinien/kolorektales-karzinom/, Zugriff am $02.09 .2018]$

Levsky JM, Singer RH (2003): Fluorescence in situ hybridization: past, present and future. J Cell Sci 116, 2833-2838

Lievre A, Bachet JB, Le Corre D, Boige V, Landi B, Emile JF, Cote JF, Tomasic G, Penna C, Ducreux M, et al. (2006): KRAS mutation status is predictive of response to cetuximab therapy in colorectal cancer. Cancer Res $\underline{66}, 3992-3995$

Mathur A, Ware C, Davis L, Gazdar A, Pan BS, Lutterbach B (2014): FGFR2 is amplified in the NCI-H716 colorectal cancer cell line and is required for growth and survival. PLoS One $\underline{9}$, e98515

Mekenkamp LJ, Koopman M, Teerenstra S, van Krieken JH, Mol L, Nagtegaal ID, Punt CJ (2010): Clinicopathological features and outcome in advanced colorectal cancer patients with synchronous vs metachronous metastases. Br J Cancer 103, 159-164

Misale S, Di Nicolantonio F, Sartore-Bianchi A, Siena S, Bardelli A (2014): Resistance to antiEGFR therapy in colorectal cancer: from heterogeneity to convergent evolution. Cancer Discov $\underline{4}, 1269-1280$

Mohammadi M, Olsen SK, Ibrahimi OA (2005): Structural basis for fibroblast growth factor receptor activation. Cytokine Growth Factor Rev 뜨, 107-137

Montenarh M: Transkription und posttranskriptionale Prozessierung der RNA. In: Löffler G, Petrides PE, Heinrich PC (Hrsg.): Biochemie und Pathobiochemie. 8. Auflage; Springer, Heidelberg 2007, 255-283

Ney JT, Froehner S, Roesler A, Buettner R, Merkelbach-Bruse S (2012): High-resolution melting analysis as a sensitive prescreening diagnostic tool to detect KRAS , BRAF , PIK3CA , and AKT1 mutations in formalin-fixed, paraffin-embedded tissues. Arch Pathol Lab Med 136, 983-992

Nogova L, Sequist LV, Perez Garcia JM, Andre F, Delord JP, Hidalgo M, Schellens JH, Cassier PA, Camidge DR, Schuler M, et al. (2017): Evaluation of BGJ398, a Fibroblast Growth Factor Receptor 1-3 Kinase Inhibitor, in Patients With Advanced Solid Tumors Harboring Genetic Alterations in Fibroblast Growth Factor Receptors: Results of a Global Phase I, Dose-Escalation and Dose-Expansion Study. J Clin Oncol 포, 157-165 
Ori A, Wilkinson MC, Fernig DG (2008): The heparanome and regulation of cell function: structures, functions and challenges. Front Biosci $\underline{13}$, 4309-4338

Ornitz DM, Itoh N (2001): Fibroblast growth factors. Genome Biol 2, REVIEWS3005

Orr-Urtreger A, Bedford MT, Burakova T, Arman E, Zimmer Y, Yayon A, Givol D, Lonai P (1993): Developmental localization of the splicing alternatives of fibroblast growth factor receptor-2 (FGFR2). Dev Biol 158, 475-486

Papadopoulos KP, El-Rayes BF, Tolcher AW, Patnaik A, Rasco DW, Harvey RD, LoRusso PM, Sachdev JC, Abbadessa G, Savage RE, et al. (2017): A Phase 1 study of ARQ 087, an oral pan-FGFR inhibitor in patients with advanced solid tumours. Br J Cancer 117, 1592

Parish A, Schwaederle M, Daniels G, Piccioni D, Fanta P, Schwab R, Shimabukuro K, Parker BA, Helsten T, Kurzrock R (2015): Fibroblast growth factor family aberrations in cancers: clinical and molecular characteristics. Cell Cycle 14, 2121-2128

Parker BC, Annala MJ, Cogdell DE, Granberg KJ, Sun Y, Ji P, Li X, Gumin J, Zheng H, Hu L, et al. (2013): The tumorigenic FGFR3-TACC3 gene fusion escapes miR-99a regulation in glioblastoma. J Clin Invest $\underline{123}, 855-865$

Reed GH, Kent JO, Wittwer CT (2007): High-resolution DNA melting analysis for simple and efficient molecular diagnostics. Pharmacogenomics $\underline{8}, 597-608$

Reis-Filho JS, Simpson PT, Turner NC, Lambros MB, Jones C, Mackay A, Grigoriadis A, Sarrio D, Savage K, Dexter T, et al. (2006): FGFR1 emerges as a potential therapeutic target for lobular breast carcinomas. Clin Cancer Res 12, 6652-6662

Ricol D, Cappellen D, El Marjou A, Gil-Diez-de-Medina S, Girault JM, Yoshida T, Ferry G, Tucker G, Poupon MF, Chopin D, et al. (1999): Tumour suppressive properties of fibroblast growth factor receptor 2-IIIb in human bladder cancer. Oncogene $\underline{18}, 7234-7243$

Robert Koch-Institut (2018a): Zentrum für Krebsregisterdaten, Darmkrebs.

Robert Koch-Institut (2018b): Zentrum für Krebsregisterdaten, Überlebensraten.

Rossi A, Latiano TP, Parente P, Chiarazzo C, Limosani F, Di Maggio G, Maiello E (2017): The potential role of nintedanib in treating colorectal cancer. Expert Opin Pharmacother $\underline{18}$, $1153-1162$

Sanger F, Coulson AR (1975): A rapid method for determining sequences in DNA by primed synthesis with DNA polymerase. J Mol Biol 또, 441-448

Sartore-Bianchi A, Trusolino L, Martino C, Bencardino K, Lonardi S, Bergamo F, Zagonel V, Leone F, Depetris I, Martinelli E, et al. (2016): Dual-targeted therapy with trastuzumab and lapatinib in treatment-refractory, KRAS codon 12/13 wild-type, HER2-positive metastatic colorectal cancer (HERACLES): a proof-of-concept, multicentre, open-label, phase 2 trial. Lancet Oncol 17, 738-746 
Sato T, Oshima T, Yoshihara K, Yamamoto N, Yamada R, Nagano Y, Fujii S, Kunisaki C, Shiozawa M, Akaike M, et al. (2009): Overexpression of the fibroblast growth factor receptor1 gene correlates with liver metastasis in colorectal cancer. Oncol Rep 21, 211-216

Schildhaus HU, Heukamp LC, Merkelbach-Bruse S, Riesner K, Schmitz K, Binot E, Paggen E, Albus K, Schulte W, Ko YD, et al. (2012): Definition of a fluorescence in-situ hybridization score identifies high- and low-level FGFR1 amplification types in squamous cell lung cancer. Mod Pathol 25, 1473-1480

Schildhaus HU, Nogova L, Wolf J, Buettner R (2013): FGFR1 amplifications in squamous cell carcinomas of the lung: diagnostic and therapeutic implications. Transl Lung Cancer Res $\underline{2}$, $92-100$

Schultheis AM, Bos M, Schmitz K, Wilsberg L, Binot E, Wolf J, Buttner R, Schildhaus HU (2014): Fibroblast growth factor receptor 1 (FGFR1) amplification is a potential therapeutic target in small-cell lung cancer. Mod Pathol $\underline{27}, 214-221$

\section{https://seer.cancer.gov/statfacts/html/colorect.html; Zugriff am 20.08.2018}

Seo AN, Jin Y, Lee HJ, Sun PL, Kim H, Jheon S, Kim K, Lee CT, Chung JH (2014): FGFR1 amplification is associated with poor prognosis and smoking in non-small-cell lung cancer. Virchows Arch $\underline{465}, 547-558$

Sequist LV, Cassier P, Varga A, Tabernero J, Schellens JH, Delord J-P, LoRusso P, Camidge DR, Medina MH, Schuler M, et al. (2014): Abstract CT326: Phase I study of BGJ398, a selective pan-FGFR inhibitor in genetically preselected advanced solid tumors. Cancer Res $\underline{74}$, CT326-CT326

Shi YJ, Tsang JY, Ni YB, Chan SK, Chan KF, Tse GM (2016): FGFR1 is an adverse outcome indicator for luminal A breast cancers. Oncotarget $\underline{7}, 5063-5073$

Singh D, Chan JM, Zoppoli P, Niola F, Sullivan R, Castano A, Liu EM, Reichel J, Porrati P, Pellegatta S, et al. (2012): Transforming fusions of FGFR and TACC genes in human glioblastoma. Science $\underline{337}, 1231-1235$

Smyth EC, Turner NC, Peckitt C, Pearson A, Brown G, Chua S, Gillbanks A, Johnston SRD, Tarazona N, Cutts R, et al. (2015): Phase II multicenter proof of concept study of AZD4547 in FGFR amplified tumours. J Clin Oncol $\underline{33}$, 2508-2508

Soria JC, DeBraud F, Bahleda R, Adamo B, Andre F, Dienstmann R, Delmonte A, Cereda R, Isaacson J, Litten J, et al. (2014): Phase I/IIa study evaluating the safety, efficacy, pharmacokinetics, and pharmacodynamics of lucitanib in advanced solid tumors. Ann Oncol $\underline{25}, 2244-2251$

Tabernero J, Bahleda R, Dienstmann R, Infante JR, Mita A, Italiano A, Calvo E, Moreno V, Adamo B, Gazzah A, et al. (2015): Phase I Dose-Escalation Study of JNJ-42756493, an Oral Pan-Fibroblast Growth Factor Receptor Inhibitor, in Patients With Advanced Solid Tumors. J Clin Oncol $\underline{33}, 3401-3408$

Taylor JGt, Cheuk AT, Tsang PS, Chung JY, Song YK, Desai K, Yu Y, Chen QR, Shah K, Youngblood V, et al. (2009): Identification of FGFR4-activating mutations in human 
rhabdomyosarcomas that promote metastasis in xenotransplanted models. J Clin Invest $\underline{119}$, 3395-3407

Therneau T (2015): A Package for Survival Analysis in S. version 2.38. https://CRAN.Rproject.org $/$ package $=$ survival

Tian S, Simon I, Moreno V, Roepman P, Tabernero J, Snel M, van't Veer L, Salazar R, Bernards R, Capella G (2013): A combined oncogenic pathway signature of BRAF, KRAS and PI3KCA mutation improves colorectal cancer classification and cetuximab treatment prediction. Gut $\underline{62}, 540-549$

Touat M, Ileana E, Postel-Vinay S, Andre F, Soria JC (2015): Targeting FGFR Signaling in Cancer. Clin Cancer Res 21, 2684-2694

Turkmen S, Binder A, Gerlach A, Niehage S, Theodora Melissari M, Inandiklioglu N, Dorken B, Burmeister T (2014): High prevalence of immunoglobulin light chain gene aberrations as revealed by FISH in multiple myeloma and MGUS. Genes Chromosomes Cancer $\underline{53}$, 650-656

Turner N, Grose R (2010): Fibroblast growth factor signalling: from development to cancer. Nat Rev Cancer 10, 116-129

Unal HU, Demiralay E, Tepeoglu M, Fidan C, Kilickap S (2013): Lack of relationships between FGF19 staining pattern, lymph node metastasis and locally invasive characteristics of the tumor in colorectal cancers. Asian Pac J Cancer Prev 14, 3151-3154

Van Cutsem E, Cervantes A, Nordlinger B, Arnold D, Group EGW (2014): Metastatic colorectal cancer: ESMO Clinical Practice Guidelines for diagnosis, treatment and follow-up. Ann Oncol 25 Suppl 3, iii1-9

Van Cutsem E, Cervantes A, Adam R, Sobrero A, Van Krieken JH, Aderka D, Aranda Aguilar E, Bardelli A, Benson A, Bodoky G, et al. (2016): ESMO consensus guidelines for the management of patients with metastatic colorectal cancer. Ann Oncol 27, 1386-1422

van der Pool AE, Lalmahomed ZS, Ozbay Y, de Wilt JH, Eggermont AM, Jzermans JN, Verhoef C (2010): 'Staged' liver resection in synchronous and metachronous colorectal hepatic metastases: differences in clinicopathological features and outcome. Colorectal Dis $\underline{12}$, e229235

Van Loon K, Venook AP (2014): Curable patient with metastatic colorectal cancer: balancing effective therapies and toxicities. J Clin Oncol $\underline{32}$, 991-996

Wang F, Flanagan J, Su N, Wang LC, Bui S, Nielson A, Wu X, Vo HT, Ma XJ, Luo Y (2012): RNAscope: a novel in situ RNA analysis platform for formalin-fixed, paraffin-embedded tissues. J Mol Diagn 14, 22-29

Weiser MR, Jarnagin WR, Saltz LB (2013): Colorectal cancer patients with oligometastatic liver disease: what is the optimal approach? Oncology (Williston Park) 27, 1074-1078

Weiss J, Sos ML, Seidel D, Peifer M, Zander T, Heuckmann JM, Ullrich RT, Menon R, Maier S, Soltermann A, et al. (2010): Frequent and focal FGFR1 amplification associates with therapeutically tractable FGFR1 dependency in squamous cell lung cancer. Sci Transl Med $\underline{2}$, $62 \mathrm{ra93}$ 
Wynes MW, Hinz TK, Gao D, Martini M, Marek LA, Ware KE, Edwards MG, Bohm D, Perner S, Helfrich BA, et al. (2014): FGFR1 mRNA and protein expression, not gene copy number, predict FGFR TKI sensitivity across all lung cancer histologies. Clin Cancer Res $\underline{20}$, 3299-3309

Yang C, Jin C, Li X, Wang F, McKeehan WL, Luo Y (2012): Differential specificity of endocrine FGF19 and FGF21 to FGFR1 and FGFR4 in complex with KLB. PLoS One 7 , e33870

Zhang X, Ibrahimi OA, Olsen SK, Umemori H, Mohammadi M, Ornitz DM (2006): Receptor specificity of the fibroblast growth factor family. The complete mammalian FGF family. J Biol Chem $\underline{281}, 15694-15700$

https://www.zytovision.com/products/zytolight/z-2168; Zugriff am 23.09.2018 


\section{Danksagung}

Mein besonderer Dank gilt Herrn Univ.-Prof. Dr. med. Hans-Ulrich Schildhaus für die Ermöglichung dieser Promotion und der Überlassung des Themas sowie die Bereitstellung der Ausstattung des Forschungslabors. Er hat mich mit viel Engagement bei dieser Arbeit stets unterstützt. Ihm verdanke ich meine Begeisterung für die molekulare Tumorpathologie und die daraus resultierenden therapeutischen Möglichkeiten, die ich nun im Rahmen meiner wissenschaftlichen Tätigkeit in der Dermato-Onkologie weiter erforschen möchte.

Besonders möchte ich mich auch bei Frau Dr. Katja Schmitz für die Hilfe bei der Auswertung der Fluoreszenz-in-situ-Hybridisierung und RNA-in-situ-Hybridisierung bedanken.

Des Weiteren bedanke ich mich bei Frau Tabea Hugo und Frau Dr. Kirsten Reuter-Jessen für die Durchführung der Mutationsanalysen und die Analyse der Mikrosatelliteninstabilität sowie bei Frau Laura Lukat und Frau Sara Hugo für die Anfertigungen der FISH-Präparate.

Zudem gilt mein Dank Frau Astrid Wachter und Frau Priv.-Doz. Dr. Annalen Bleckmann für die Hilfe bei der statistischen Auswertung der Daten.

Darüber hinaus danke ich Frau Mercedes Martin-Ortega und Frau Sina Eckstein für die Durchführung der Immunhistochemie für die Mikrosatelliteninstabilitäts-Analyse.

Zu guter Letzt möchte ich meinen Eltern und meinem Freund danken, die mich während der gesamten Dissertation liebevoll unterstützt haben. 


\section{Veröffentlichung und Preise}

Die aus meiner Arbeit am Dissertationsthema hervorgegangenen Daten wurden bereits publiziert:

Fromme JE, Schmitz K, Wachter A, Grzelinski M, Zielinski D, Koppel C, Conradi LC, Homayounfar K, Hugo T, Hugo S, et al. (2018): FGFR3 mRNA overexpression defines a subset of oligometastatic colorectal cancers with worse prognosis. Oncotarget $\underline{9}$, 32204-32218

Fromme JE, Schildhaus HU (2018): [FGFR3 overexpression is a relevant alteration in colorectal cancer] Pathologe $\underline{39}, 189-192$

Ferner wurden diese Daten auf dem Jahreskongress der Deutschen Gesellschaft für Pathologie (DGP) 2018 in Berlin vorgestellt und mit dem Promotionspreis der DGP ausgezeichnet. 